\title{
Perspectives and challenges for lead-free energy-storage multilayer ceramic capacitors
}

\author{
Peiyao $\mathrm{ZHAO}^{a}$, Ziming $\mathrm{CAI}^{b}$, Longwen $\mathrm{WU}^{c}$, \\ Chaoqiong $\mathrm{ZHU}^{a}$, Longtu $\mathrm{LI}^{a}$, Xiaohui $\mathrm{WANG}^{a}{ }^{*}$,
}

${ }^{a}$ State Key Laboratory of New Ceramics and Fine Processing, School of Materials Science and Engineering, Tsinghua University, Beijing 100084, China

${ }^{b}$ School of Material Science and Physics, China University of Mining and Technology, Xuzhou 221116, China

${ }^{c}$ College of Electrical Engineering, Sichuan University, Chengdu 610065, China

Received: July 1, 2021; Accepted: July 10, 2021

(c) The Author(s) 2021.

\begin{abstract}
The growing demand for high-power-density electric and electronic systems has encouraged the development of energy-storage capacitors with attributes such as high energy density, high capacitance density, high voltage and frequency, low weight, high-temperature operability, and environmental friendliness. Compared with their electrolytic and film counterparts, energy-storage multilayer ceramic capacitors (MLCCs) stand out for their extremely low equivalent series resistance and equivalent series inductance, high current handling capability, and high-temperature stability. These characteristics are important for applications including fast-switching third-generation wide-bandgap semiconductors in electric vehicles, $5 \mathrm{G}$ base stations, clean energy generation, and smart grids. There have been numerous reports on state-of-the-art MLCC energy-storage solutions. However, lead-free capacitors generally have a low-energy density, and high-energy density capacitors frequently contain lead, which is a key issue that hinders their broad application. In this review, we present perspectives and challenges for lead-free energy-storage MLCCs. Initially, the energy-storage mechanism and device characterization are introduced; then, dielectric ceramics for energy-storage applications with aspects of composition and structural optimization are summarized. Progress on state-of-the-art energy-storage MLCCs is discussed after elaboration of the fabrication process and structural design of the electrode. Emerging applications of energy-storage MLCCs are then discussed in terms of advanced pulsed power sources and high-density power converters from a theoretical and technological point of view. Finally, the challenges and future prospects for industrialization of lab-scale lead-free energy-storage MLCCs are discussed.
\end{abstract}

Keywords: multilayer ceramic capacitors (MLCCs); lead-free dielectric ceramics; energy storage; high power density

\footnotetext{
* Corresponding author.

E-mail:wxh@tsinghua.edu.cn
} 


\section{Introduction}

In recent decades, the consumption of energy and natural resources has increased alongside our growing population and social and technical advancements. However, there are significant challenges associated with the sustainability of using coal, oil, and natural gas as our primary sources of energy. First, the consumption of fossil fuels has caused increasingly serious environmental pollution and ecological destruction, and second, non-renewable fossil energy is a limited resource. Therefore, clean and renewable energy sources, such as solar and wind energy, have developed rapidly and become major contributors. Nevertheless, the supply of these energy sources is periodic and unstable because of natural environmental variations, and hence, energy-storage and conversion devices become a topic of intense research interest [1], these including lithium batteries, electrochemical capacitors, and dielectric capacitors. For practical applications, energy-storage and conversion devices are expected to have high energy density, high power density, high conversion efficiency, wide operating temperature range, environmental friendliness, and low cost.

The energy and power density requirements for common energy-storage devices are shown in Fig. 1 [2]. Compared with other energy-storage devices, dielectric capacitors have ultra-high power densities $>10 \mathrm{~kW} \cdot \mathrm{kg}^{-1}$, and hence, they have ultra-high charging and discharging speed, which can release stored energy in the microsecond or nanosecond time scale, enabling an extremely high pulse power. Additionally, they have positive attributes including ultra-long cycle life, safety, and reliability. Thus, dielectric capacitors play a very important role in high-power energy-storage and pulse- power systems, such as consumer electronics, advanced medical device, electric/hybrid energy vehicles, smart grids, and electromagnetic weapons [3,4]; these devices are also key to the application and development of third-generation semiconductor devices. However, currently used commercial polymer dielectric capacitors have a comparatively low energy density of $<0.1 \mathrm{Wh} \cdot \mathrm{kg}^{-1}$, which results in relatively large and heavy energy-storage and pulse-power systems. For example, the capacitors in high-voltage direct-current transmission converter valves occupy $\sim 50 \%$ of the device volume and $60 \%$ of its weight, and the weight of the capacitors under each carriage of a high-speed train exceeds $50 \mathrm{~kg}$. The large volume would also introduce a large equivalent series inductance (ESL), which may result in damage or even failure of semiconductor devices when quickly switched. This means that these capacitors cannot currently meet the requirements for application in electronic devices and systems that require compact and light integrated capacitors $[5,6]$. Here, the energy-storage properties of some commercial MLCCs are listed in Table 1.

At present, the dielectric material of the dielectric energy-storage capacitor, which is used in the main inverter of an electric vehicle, is biaxially-oriented polypropylene (BOPP). For this type of linear dielectric, its energy-storage density is $<0.2 \mathrm{~J} \cdot \mathrm{cm}^{-3}$, its maximum operating temperature is $<105{ }^{\circ} \mathrm{C}$, and the temperature of its long-term working environment should be $<70{ }^{\circ} \mathrm{C}$ [9]. The relatively low stable working temperature severely limits the application of polymer capacitors. Hence, inorganic dielectric films have gained significant research attention in recent years. Methods such as polymorphic nanodomain design [10] and strain engineering [11] have been demonstrated to effectively

Table 1 Energy-storage properties of some commercial MLCCs

\begin{tabular}{llcc}
\hline \multicolumn{1}{c}{ Commercial MLCCs } & Energy & $E_{\mathrm{b}}\left(\mathrm{MV} \cdot \mathrm{m}^{-1}\right)$ & $\eta(\%)$ \\
\hline PLZT-based (B58031I5105 M002) [7] & $93.0 \mathrm{~mJ} @ 500 \mathrm{~V}\left(0.69 \mathrm{~J} \cdot \mathrm{cm}^{-3}\right)$ & - & 89.5 \\
BT-based (C1812C334K CRACTU) [7] & $10.7 \mathrm{~mJ} @ 500 \mathrm{~V}\left(0.37 \mathrm{~J} \cdot \mathrm{cm}^{-3}\right)$ & 65 & 62.9 \\
C16 (C0G) [8] & $0.88 \mathrm{~J} @ 1 \mathrm{kV}$ & 13.2 & - \\
C11 (Z5U) [8] & $0.02 \mathrm{~J} @ 1 \mathrm{kV}$ & 10 & - \\
PMN-a (Z5U) [8] & $0.02 \mathrm{~J} @ 1 \mathrm{kV}$ & 11 & - \\
PMN-b (Z5U) [8] & $0.02 \mathrm{~J} @ 1 \mathrm{kV}$ & 16 & - \\
PLZT (X7T) [8] & $0.71 \mathrm{~J} @ 1 \mathrm{kV}$ & 30 & - \\
C08 (X7R) [8] & $1.40 \mathrm{~J} @ 1 \mathrm{kV}$ & 40 & - \\
C20 (X7R) [8] & $1.34 \mathrm{~J} @ 1 \mathrm{kV}$ & 90 \\
Exp (X7R) [8] & $4.82 \mathrm{~J} @ 1 \mathrm{kV}$ & -
\end{tabular}




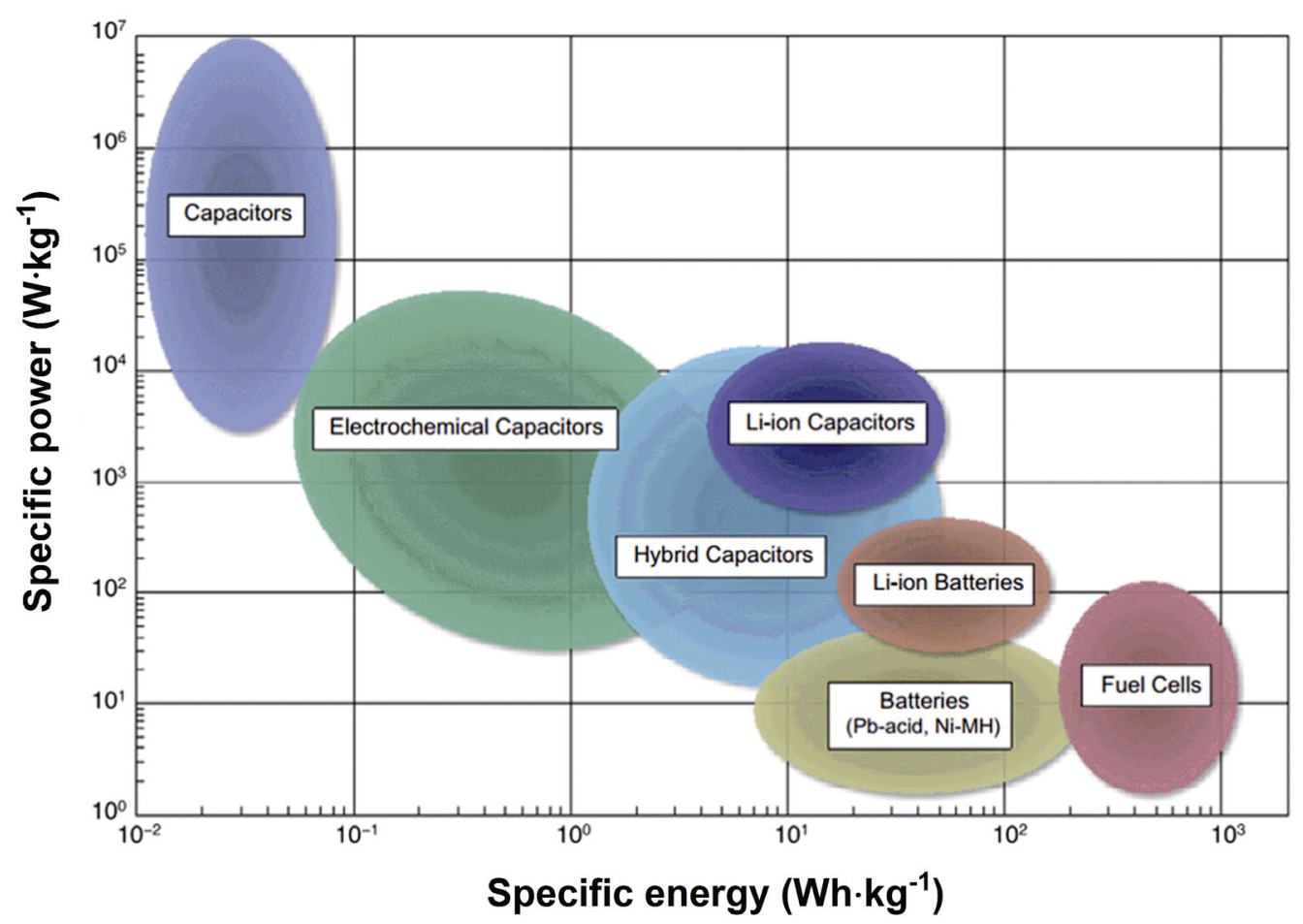

Fig. 1 Relationship between energy density and power density among common energy-storage devices. Reproduced with permission from Ref. [2], (C) Elsevier Ltd. 2015.

increase the energy-storage density of dielectric films. Pan et al. [10] introduced multi-morphic nano-domains in $\mathrm{BiFeO}_{3}$-system films, enabling an energy-storage density $>112 \mathrm{~J} \cdot \mathrm{cm}^{-3}$, which demonstrates the excellent potential of inorganic dielectric energy-storage materials. However, the low volume of the films leads to a low total energy storage, and hence, their application prospects are limited. Comparatively, thinner ceramic dielectric layers in multilayer ceramic capacitors (MLCCs) can realize larger electric capacitance and dielectric breakdown strength. The favorable structure endows the MLCC with an ultra-low equivalent series inductance. Additionally, the ceramic dielectric can withstand high temperatures, and therefore, the MLCC is considered as the most promising energy-storage dielectric capacitor.

With the goal of optimizing the composition of dielectric materials, the manufacturing process, and the structure of materials and devices, many researchers have made great effort to develop highly reliable MLCC devices with high energy densities, high energy conversion efficiencies, high power densities, high capacitances, and broad operational temperature ranges via simulations and experiments. The successful development of such MLCCs would ultimately broaden their application in the field of energy storage.

\section{Energy-storage mechanism and characterizations}

The storage of electric energy is the functional basis of capacitors in electronic devices. The energy-storage capability is called capacitance, which is determined by the physical geometry of the capacitor and the permittivity of the dielectric materials. When dielectric capacitors are used under an external voltage, charges with opposite sign and equal magnitude accumulate at the electrodes, referred to as the charging process (Fig. 2(a)). The charges form an internal electric field with a direction opposite to the external electric field. The internal electric field increases as the accumulated charge increases. The charging process will end when the internal electric field induced by the accumulated charges is equal to the external field. During the charging process, the charges drift under the externally applied electric field, and electrostatic energy is stored in the dielectric [12].

One of the most important parameters for evaluating the energy-storage properties of dielectric capacitors is the energy-storage density $(W)$. The $W$ of dielectric capacitors can be characterized in two ways. The most commonly used method is integrating the area between the polarization axis and the polarization 

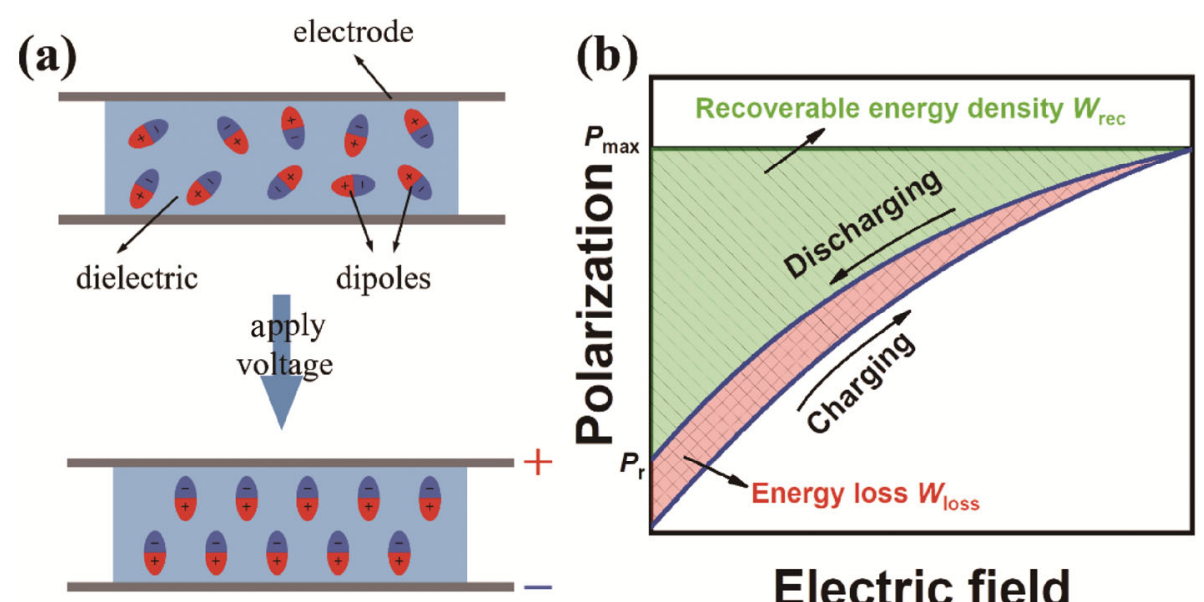

\section{Electric field}

Fig. 2 (a) Schematic of a dielectric between two electrodes before and after applying an external voltage. Reproduced with permission from Ref. [13], (C) Elsevier Ltd. 2021. (b) Calculation of the energy-storage performance of a dielectric.

versus electric field curves (also named $P-E$ loops), i.e., the blue curve shown in Fig. 2(b). The green shaded area is equal to the recoverable energy density $\left(W_{\text {rec }}\right)$, which means the released energy density during the discharging process. The red shaded area is equal to the energy loss $\left(W_{\text {loss }}\right)$ during the charge-discharge process. The total energy density $\left(W_{\text {total }}\right)$ stored in the charging process is equal to the sum of $W_{\text {rec }}$ and $W_{\text {loss }}$. Therefore, the parameters of the energy-storage properties can be calculated by the following equations:

$$
\begin{gathered}
W_{\text {total }}=\int_{0}^{P_{\max }} E \mathrm{~d} P \\
W_{\text {rec }}=\int_{P_{\mathrm{r}}}^{P_{\max }} E \mathrm{~d} P \\
\eta=\frac{W_{\text {rec }}}{W_{\text {total }}}=\frac{W_{\text {rec }}}{W_{\text {rec }}+W_{\text {loss }}}
\end{gathered}
$$

where $P_{\max }$ and $P_{\mathrm{r}}$ are the saturation and remnant polarizations under the applied electric field $(E)$, respectively, and $\eta$ is the energy efficiency. The above equations indicate that high saturation polarization, low remnant polarization, and high dielectric breakdown field $\left(E_{\mathrm{b}}\right)$ facilitate a higher energy density and energy efficiency in the dielectric materials. The dielectric material should have low dielectric loss, low leakage current, and high insulation to sustain the high applied electric field. Especially, the $E_{\mathrm{b}}$ depends on both internal factors (including the dielectric constant, band gap $\left(E_{\mathrm{g}}\right)$, density, defects, grain size, and grain boundary) and external factors (such as the sample area, sample thickness and electrode shape size, temperature, humidity, type of voltage, and test duration) [12]. The thickness of dielectrics has a significant effect on $E_{\mathrm{b}}$ because of the fewer defects in thinner dielectric layer. The $E_{\mathrm{b}}$ exponentially increases as the thickness $(t)$ of the single dielectric layer decreases [12,14-17], and it roughly follows this relationship: $E_{\mathrm{b}} \propto 1 / t^{0.5}$. Hence, there would be more stored energy in the MLCC with thinner dielectric and more layers.

The $W_{\text {rec }}$ can also be obtained via charge-discharge measurements using a discharge resistor and a capacitance load circuit, as shown in Fig. 3. The dielectric capacitor is charged by the external power source. Then, the stored energy is discharged to a load resistor $(R)$ in series with the capacitor. The current $(I)$ passing through the resistor is then recorded as $I(t)$, where $t$ is the time. The $W_{\text {rec }}$ can be calculated using the following equation:

$$
W_{\text {rec }}=\int I(t)^{2} R \mathrm{~d} t / V
$$

where $V$ is the volume of the dielectric capacitor. It is worth noting that $R$ should be much larger than the equivalent series resistor of the capacitor, so that most of the stored energy will be delivered to the load resistor and the measured energy density will be nearly the same as the stored energy density [12]. The $W_{\text {rec }}$ calculated from $P-E$ loops is usually higher than that calculated by the discharge current, which may be attributed to the different characterization mechanisms of the quasistatic $P-E$ loops (1-100 Hz, near second scale) and the dynamic charge-discharge method (near microsecond or submicrosecond scale) with different frequencies. 


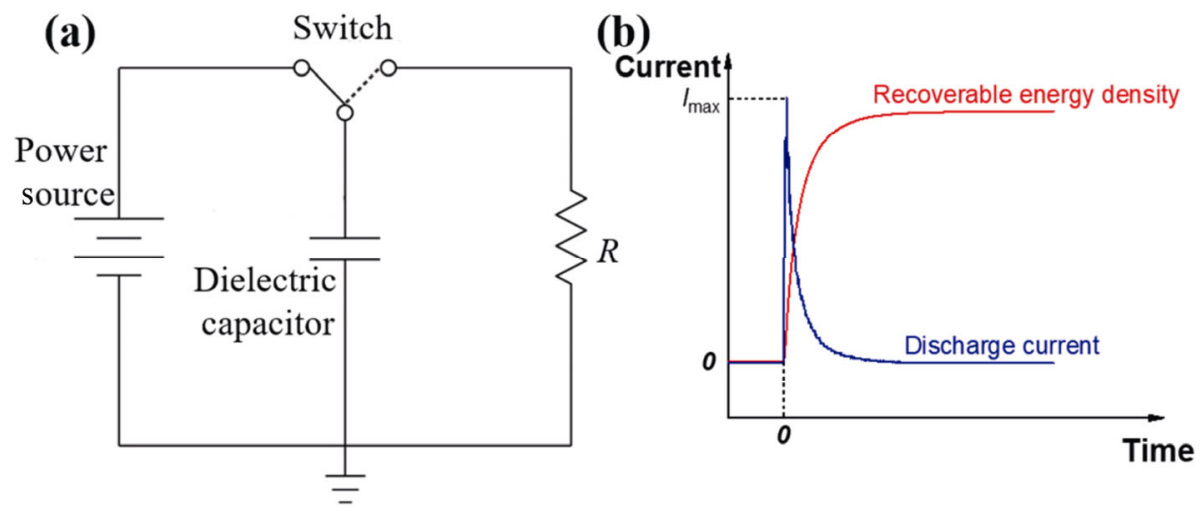

Fig. 3 (a) Schematic diagram of the charge-discharge circuit. (b) Discharge current and corresponding calculated $W_{\text {rec }}$. Reproduced with permission from Ref. [12], C Elsevier Ltd. 2018.

\section{Dielectric ceramics with excellent energy- storage properties}

To obtain dielectric ceramics with excellent energystorage properties, composition modification and structure optimization have been widely used in recent research to effectively increase the $P_{\max }$ and $E_{\mathrm{b}}$ and decrease the $P_{\mathrm{r}}$ of dielectrics, leading to high $W_{\text {rec }}$ and high $\eta$.

\section{1 Composition optimization}

Based on the different polarization responses to the applied electric field, energy-storage dielectric materials can be divided into linear dielectric, ferroelectric, relaxor ferroelectric, and antiferroelectric. The relationship between the polarization and electric field is shown in Fig. 4. Linear dielectric features in high breakdown strength but low dielectric permittivity. Simple oxides or nitrides and zirconates or hafniates, such as $\mathrm{Al}_{2} \mathrm{O}_{3}$, $\mathrm{Si}_{3} \mathrm{~N}_{4}, \mathrm{CaZrO}_{3}$, and $\mathrm{CaHfO}_{3}$, respectively, are always linear dielectrics. Ferroelectric ceramics possess a high dielectric permittivity because of their high spontaneous polarization, which are widely used as dielectrics in MLCCs. However, their high remnant polarization and low breakdown strength lead to a relatively low recoverable energy density, which is not suitable for energy-storage applications. A common approach for ferroelectric ceramic modification is to disturb the long-range order of the domains, resulting in the formation of polar nano regions (PNRs), which is referred to as relaxor ferroelectrics. The PNR is highly activated, resulting in "slim" hysteresis loops with a high recoverable energy density and a relatively low energy loss, and these characteristics are suitable for energy-storage applications. Antiferroelectric features in double hysteresis loops with low remnant polarization have recently drawn significant attention for energystorage applications. However, there are few lead-free antiferroelectric ceramic systems, and thus, further in depth studies on antiferroelectric ceramics are needed.

The lead-based ceramics usually exhibit excellent energy storage properties by constructing field-induced multiphase transitions and decreasing grain size. Wang et al. [18] studied the energy-storage properties of $\left(\mathrm{Pb}_{0.98} \mathrm{La}_{0.02}\right)\left(\mathrm{Zr}_{0.55} \mathrm{Sn}_{0.45}\right)_{0.995} \mathrm{O}_{3}$ (PLZS) antiferroelectric ceramics. An ultra-high $W_{\text {rec }}$ of $10.4 \mathrm{~J} \cdot \mathrm{cm}^{-3}$ and a high $\eta$ of $87 \%$ were achieved at $40 \mathrm{MV} \cdot \mathrm{m}^{-1}$. Similarly, Liu et al. [19] studied the $\left(\mathrm{Pb}_{0.98-x} \mathrm{La}_{0.02} \mathrm{Sr}_{x}\right)\left(\mathrm{Zr}_{0.9} \mathrm{Sn}_{0.1}\right)_{0.995} \mathrm{O}_{3}$ (PLSZS) antiferroelectric ceramics, which possessed an ultra-high $W_{\text {rec }}$ of $11.18 \mathrm{~J} \cdot \mathrm{cm}^{-3}$ and a high $\eta$ of $82.2 \%$ under $39.5 \mathrm{MV} \cdot \mathrm{m}^{-1}$. These lead-based materials could possess both ultrahigh $W_{\text {rec }}$ and high $\eta$, which was difficult to be achieved in other lead-free energy storage ceramics. However, the lead-based ceramic would cause serious environmental pollution due to toxicity of lead element. Hence, it is urgent to develop the lead-free dielectric materials. This section mainly introduces the compositional optimization of several common lead-free nonlinear dielectric ceramics, such as $\mathrm{BaTiO}_{3}$-based, $\mathrm{K}_{0.5} \mathrm{Na}_{0.5} \mathrm{NbO}_{3}$-based, $\mathrm{BiFeO}_{3}$-based, $\mathrm{Bi}_{0.5} \mathrm{Na}_{0.5} \mathrm{TiO}_{3}$-based, $\mathrm{AgNbO}_{3}$-based, and $\mathrm{NaNbO}_{3^{-}}$ based energy-storage ceramics, covering ferroelectric, relaxor ferroelectric, and antiferroelectric ceramics.

\subsection{1 $\mathrm{BaTiO}_{3}$-based}

Barium titanate, $\mathrm{BaTiO}_{3}$, is one of the most studied and widely used lead-free dielectric ceramics, and it exhibits a paraelectric cubic phase above the Currie temperature $\left(T_{\mathrm{C}}\right)$ of $125{ }^{\circ} \mathrm{C}$ and a ferroelectric tetragonal phase near room temperature. The macrodomains and typical ferroelectricity of $\mathrm{BaTiO}_{3}$ ceramics lead to a high $P_{\mathrm{r}}$ and very low $\eta$. Most studies on $\mathrm{BaTiO}_{3}$-based bulk 

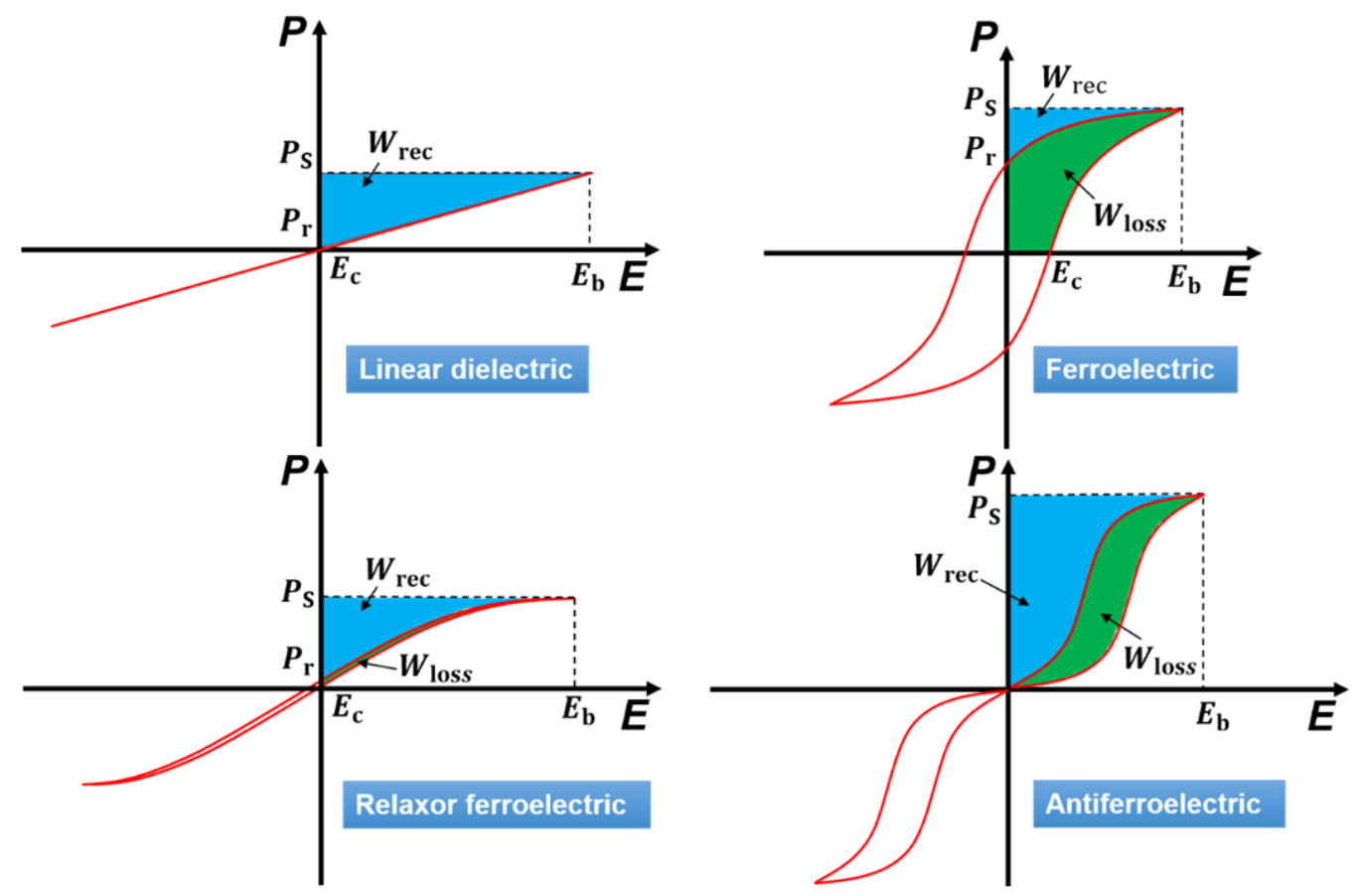

Fig. 4 Schematic diagram of the hysteresis loops (polarization as a function of electric field) for: (a) linear dielectrics, (b) ferroelectrics, (c) relaxor ferroelectrics, and (d) antiferroelectrics.

ceramics attempted to improve the $E_{\mathrm{b}}$ and decrease the $P_{\mathrm{r}}$ via reducing grain size, coating dielectrics with low permittivity and high insulation, or doping the A/B site ions in a perovskite lattice. Grain size reduction and grain core-shell structure construction will be introduced in detail in Section 3.2 "Structure optimization".

A/B-site ion doped $\mathrm{BaTiO}_{3}$ ceramics are usually obtained via the addition of $\mathrm{La}, \mathrm{Ca}, \mathrm{Zr}$, Sr, or $\mathrm{BiMeO}_{3}$ (Me symbolizes trivalent or average trivalent metallic ions). Generally, the compositions of $(\mathrm{Ba}, \mathrm{La}) \mathrm{TiO}_{3}$, $(\mathrm{Ba}, \mathrm{Ca}) \mathrm{TiO}_{3}, \mathrm{Ba}(\mathrm{Zr}, \mathrm{Ti}) \mathrm{O}_{3}$, and $(\mathrm{Ba}, \mathrm{Ca}, \mathrm{Sr})(\mathrm{Ti}, \mathrm{Zr}) \mathrm{O}_{3}$ cannot yield an appreciable $W_{\text {rec }}$ of $>1 \mathrm{~J} \cdot \mathrm{cm}^{-3}$ [20-24]. The addition of $\mathrm{BiMeO}_{3}$ could destroy the long-range ferroelectric order in $\mathrm{BaTiO}_{3}$ and form PNRs with short-range order in the solid solutions. Ogihara et al. $[25,26]$ studied the relaxor characteristics of the $\mathrm{BaTiO}_{3}-\mathrm{BiScO}_{3}$ (BT-BS) ceramics. The activation energy for relaxation for BT-BS ceramics is very high, and this type of relaxor ferroelectric is termed as a "weakly coupled relaxor". The PNRs in weakly coupled relaxor ferroelectrics are isolated and randomly located in the matrix, and the interactions between the PNRs are very weak. Therefore, the PNRs possess fast responses under the applied electric field, resulting in limited spontaneous polarization, lower $P_{\mathrm{r}}$, narrower hysteresis loops, and higher $\eta$. The $0.7 \mathrm{BT}-0.3 \mathrm{BS}$ ceramics had a $W_{\text {rec }}$ of $2.3 \mathrm{~J} \cdot \mathrm{cm}^{-3}$ at an $E_{\mathrm{b}}$ of $22.5 \mathrm{MV} \cdot \mathrm{m}^{-1}$. Shen et al. [27] studied $\mathrm{BaTiO}_{3}-\mathrm{BiYbO}_{3}$ ceramics, and they observed that with increasing $\mathrm{BiYbO}_{3}$ content, there was a gradual change from a normal ferroelectric behavior to highly diffusive and dispersive relaxor-like characteristics, and the nonlinearity of the $(1-x) \mathrm{BaTiO}_{3}-$ $x \mathrm{BiYbO}_{3}(\mathrm{BT}-\mathrm{BY})$ ceramics was markedly weakened. The 0.91BT-0.09BY ceramics exhibited a maximum $W_{\text {rec }}$ of $0.71 \mathrm{~J} \cdot \mathrm{cm}^{-3}$ with a $\eta$ of $82.6 \%$ under 9.3 $\mathrm{MV} \cdot \mathrm{m}^{-1}$.

Many other $\mathrm{BaTiO}_{3}-\mathrm{BiMeO}_{3}$ solid solutions are also weakly coupled relaxor ferroelectrics, where $\mathrm{Me}$ represents average trivalent $\mathrm{B}$-sites for two or more cations, such as $\mathrm{BaTiO}_{3}-\mathrm{Bi}\left(\mathrm{Zn}_{2 / 3} \mathrm{Nb}_{1 / 3}\right) \mathrm{O}_{3}$ (BT-BZN) [28-30], $\mathrm{BaTiO}_{3}-\mathrm{Bi}\left(\mathrm{Zn}_{0.5} \mathrm{Zr}_{0.5}\right) \mathrm{O}_{3} \quad$ (BT-BZZ) [31], $\mathrm{BaTiO}_{3}-\mathrm{Bi}\left(\mathrm{Mg}_{0.5} \mathrm{Zr}_{0.5}\right) \mathrm{O}_{3} \quad(\mathrm{BT}-\mathrm{BMZ}) \quad[32,33]$, $\mathrm{BaTiO}_{3}-\mathrm{Bi}\left(\mathrm{Mg}_{2 / 3} \mathrm{Nb}_{1 / 3}\right) \mathrm{O}_{3} \quad$ (BT-BMN) [34,35], $\mathrm{BaTiO}_{3}-\mathrm{Bi}\left(\mathrm{Zn}_{0.5} \mathrm{Sn}_{0.5}\right) \mathrm{O}_{3} \quad$ (BT-BZS) [36], $\mathrm{BaTiO}_{3}-\mathrm{Bi}\left(\mathrm{Zn}_{2 / 3}(\mathrm{Nb}, \mathrm{Ta})_{1 / 3}\right) \mathrm{O}_{3}$ (BT-BZNT) [37], and $\mathrm{BaTiO}_{3}-\mathrm{Bi}\left(\mathrm{Mg}_{0.5} \mathrm{Ti}_{0.5}\right) \mathrm{O}_{3}$ (BT-BMT) [38,39]. The energy-storage properties of $\mathrm{BaTiO}_{3}-\mathrm{Bi}\left(\mathrm{Zn}_{2 / 3} \mathrm{Nb}_{1 / 3}\right) \mathrm{O}_{3}$ (BT-BZN) ceramics were studied, and a maximum $W_{\text {rec }}$ of $0.79 \mathrm{~J} \cdot \mathrm{cm}^{-3}$ with a $\eta$ of $93.5 \%$ under 13.1 $\mathrm{MV} \cdot \mathrm{m}^{-1}$ was achieved for the $0.85 \mathrm{BT}-0.15 \mathrm{BZN}$ ceramic. The $\mathrm{BaTiO}_{3}-\mathrm{Bi}\left(\mathrm{Mg}_{0.5} \mathrm{Ti}_{0.5}\right) \mathrm{O}_{3}$ (BT-BMT) ceramics were prepared via nano-scale polarization mismatch and reconstruction [38], as shown in Fig. 5. With increasing BMT concentration, the displacement 
of $\mathrm{Bi}^{3+}$ cations could be sufficiently established and lead to an enhanced $P_{\max }$, which was because of the large polarizability of the $\mathrm{Bi}^{3+}$ ion caused by the $6 \mathrm{~s}$ lone-pair electrons [12]. Additionally, there are numerous Ti-rich and Bi-rich PNRs that coexist in the matrix, which can respond quickly to an electric field and yield a high $\eta$. This enabled the realization of an ultra-high $W_{\text {rec }}$ of $4.49 \mathrm{~J} \cdot \mathrm{cm}^{-3}$ with a $\eta$ of $93 \%$ under $34 \mathrm{MV} \cdot \mathrm{m}^{-1}$ for the $0.6 \mathrm{BT}-0.4 \mathrm{BMT}$ ceramic. However, the average ceramic grain size in this system was much larger at $>8 \mu \mathrm{m}$, which was unfavorable for miniaturization of the MLCCs.

Yuan et al. [33] studied $\mathrm{BaTiO}_{3}-\mathrm{Bi}\left(\mathrm{Mg}_{0.5} \mathrm{Zr}_{0.5}\right) \mathrm{O}_{3}$ (BT-BMZ) ceramics. They determined that the dynamic PNRs along with the decreased grain size, increased bulk density, and consequently enhanced $E_{\mathrm{b}}$ were responsible for the enhanced energy-storage properties of $0.85 \mathrm{BT}-0.15 \mathrm{BMZ}$ ceramic, leading to a high $W_{\text {rec }}$ of $2.9 \mathrm{~J} \cdot \mathrm{cm}^{-3}$ with a $\eta$ of $86.8 \%$ under $30.14 \mathrm{MV} \cdot \mathrm{m}^{-1}$.
Subsequently, bioinspired raspberry-like hierarchically structured nanocomposites have been prepared by enclosing microsized BT-BMZ relaxor ferroelectrics using core-shell BT-BMZ@ $\mathrm{SiO}_{2}$ nanoparticles [33], as shown in Fig. 6. The synergistic effects of the bioinspired hierarchical structure and the insulating $\mathrm{SiO}_{2}$ resulted in a significantly improved dielectric breakdown strength and a sustained large polarization, which could be corroborated via experimental characterizations and theoretical simulations. As a result, a high $W_{\text {rec }}$ of $3.41 \mathrm{~J} \cdot \mathrm{cm}^{-3}$ and a $\eta$ of $85.1 \%$ were achieved in 93wt\%BT-BMZ/7wt\%BT-BMZ@ $\mathrm{SiO}_{2}$ (BTBMZ-7BTBMZS) ceramic under $34.5 \mathrm{MV} \cdot \mathrm{m}^{-1}$, along with good thermal stability.

It is worth noting that to decrease the MLCC cost, $\mathrm{BaTiO}_{3}$-based dielectric ceramics must have antireduction properties, so that they can be co-fired with the $\mathrm{Ni}$ internal electrodes in a reducing atmosphere. To sinter in a reducing atmosphere, the $\mathrm{BaTiO}_{3}$ powders
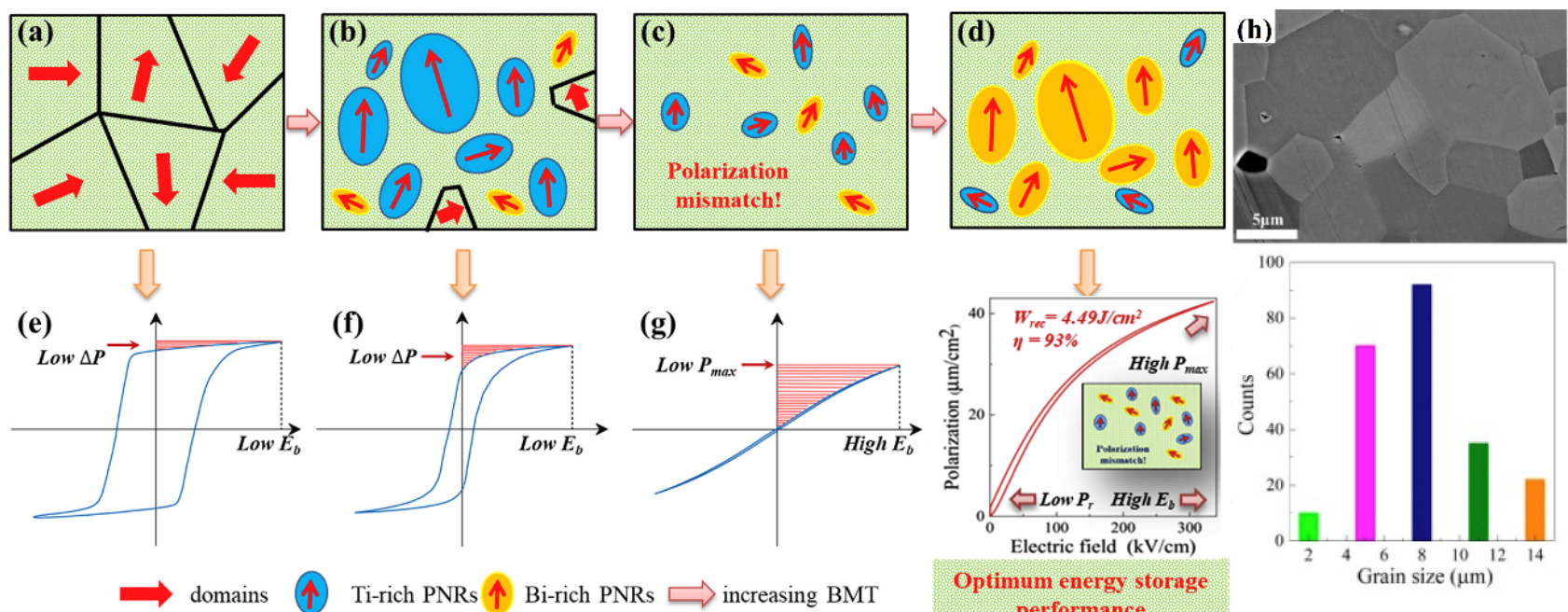

Ti-rich PNRs $\uparrow$ Bi-rich PNRs $\Longrightarrow$ increasing BMT
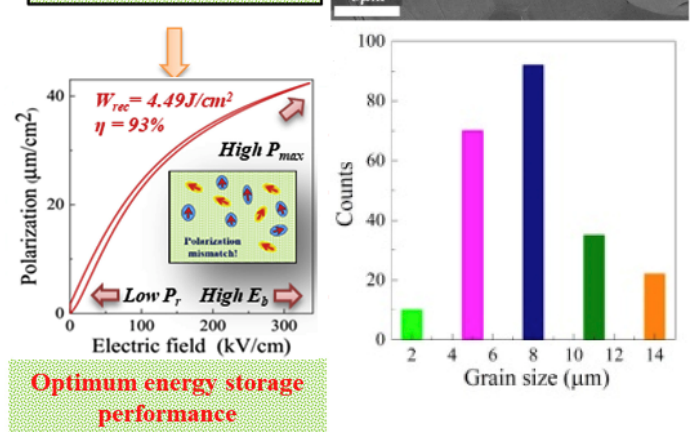

Fig. 5 (a-g) Schematic diagram of the nano-scale polarization mismatch and reconstruction strategy. (h) SEM image for 0.6BT-0.4BMT ceramic and the grain size distribution. Reproduced with permission from Ref. [38], (C) Elsevier Ltd. 2019.
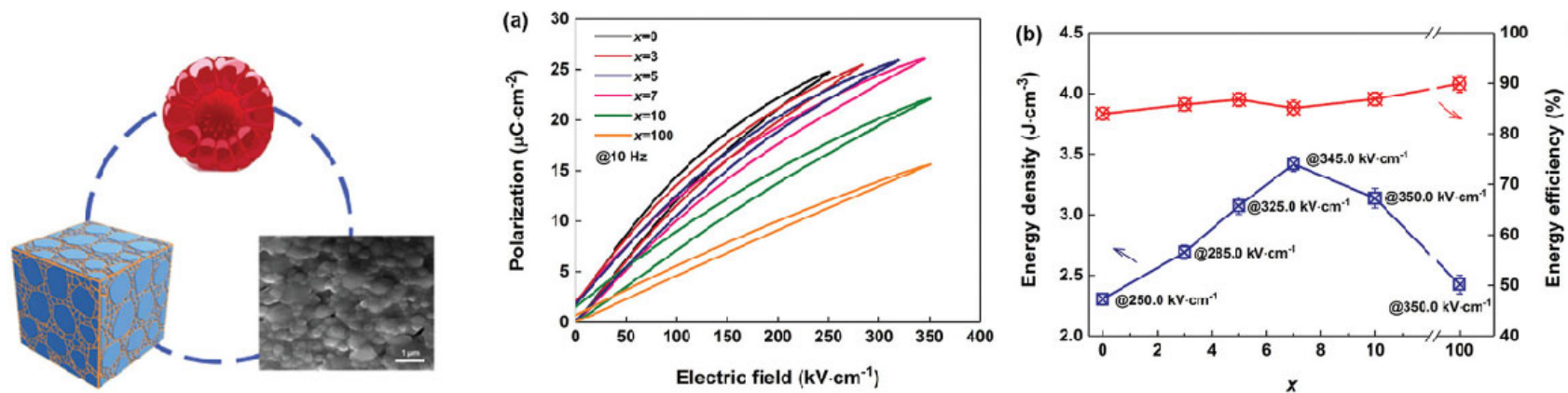

Fig. 6 Schematic of BT-BMZ-based raspberry-like hierarchically structured ceramics. (a) $P-E$ loops and (b) energy-storage properties at room temperature for ceramics with various BT-BMZ@ $\mathrm{SiO}_{2}$ contents. Reproduced with permission from Ref. [33], (C) WILEY-VCH Verlag GmbH \& Co. KGaA, Weinheim 2020. 
are usually doped with $\mathrm{MgO}, \mathrm{MnO}_{2}$, or rare earth oxides. Zhao et al. [40] studied the influence of $\mathrm{Al}_{2} \mathrm{O}_{3}$ on the energy-storage properties of anti-reduction $\mathrm{BaTiO}_{3}$-based ceramics prepared via a uniform chemical coating method. Coating with $\mathrm{Al}_{2} \mathrm{O}_{3}$ achieved not only a smaller grain size $(140 \mathrm{~nm})$ and a narrower distribution but also higher $E_{\mathrm{b}}, W_{\text {rec }}$, and $\eta$ at ambient temperature, as shown in Fig. 7. The $\mathrm{BaTiO}_{3}$-based ceramics coated with $1.2 \mathrm{~mol} \% \mathrm{Al}_{2} \mathrm{O}_{3}$ had an enhanced $W_{\text {rec }}$ of $0.51 \mathrm{~J} \cdot \mathrm{cm}^{-3}$ and a $\eta$ of $79.6 \%$ under $9.1 \mathrm{MV} \cdot \mathrm{m}^{-1}$. Although the $W_{\text {rec }}$ value was relatively low, the anti-reduction properties allow this $\mathrm{BaTiO}_{3}$-based ceramic to have practical significance for future application in energy-storage Ni-electrode MLCCs.

In summary, $\mathrm{BaTiO}_{3}$-based ceramics can synergistically achieve both a high $W_{\text {rec }}$ and a high $\eta$, which are promising for energy-storage capacitors. Of particular significance is that the $\mathrm{BaTiO}_{3}-\mathrm{Bi} M e \mathrm{O}_{3}$ dielectric ceramics exhibit relatively high permittivity and energy density over the temperature range from -50 to $150{ }^{\circ} \mathrm{C}$ with good temperature stability because of the diffuse phase transition around the dielectric maxima. Specifically,
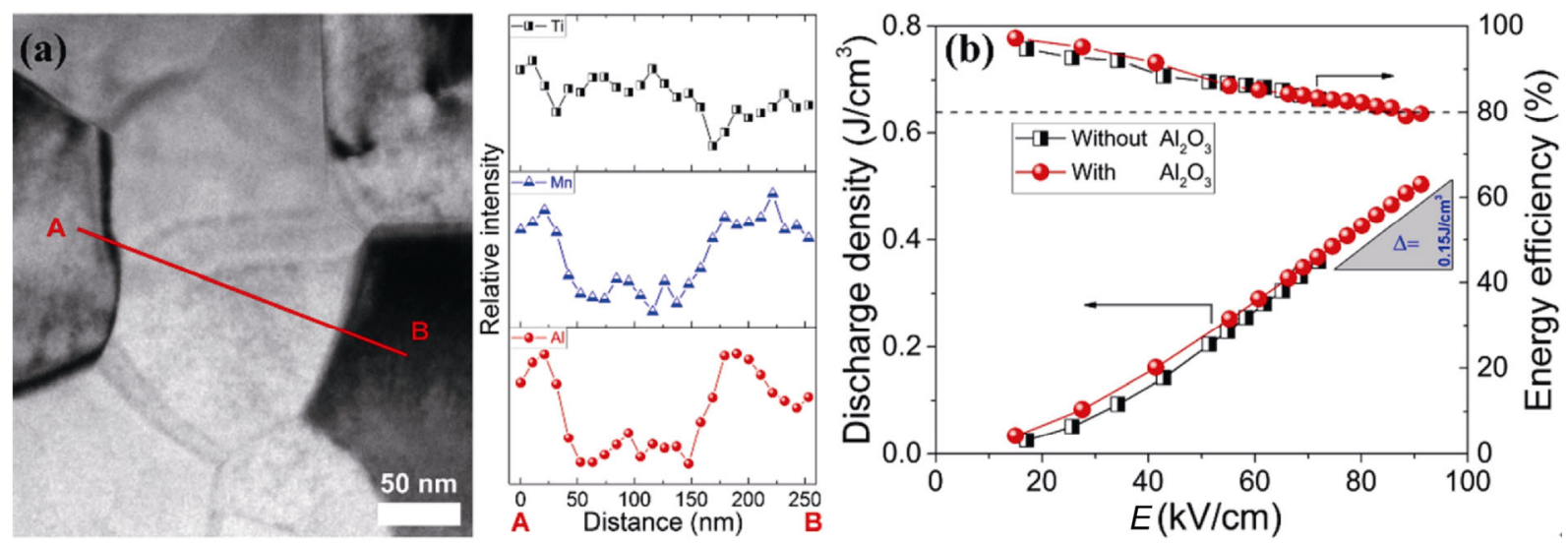

Fig. 7 (a) $\mathrm{Al}, \mathrm{Mn}$, and Ti element distribution in the $\mathrm{BaTiO}_{3}$-based ceramics with $\mathrm{Al}_{2} \mathrm{O}_{3}$ coating. (b) Energy-storage properties of the $\mathrm{BaTiO}_{3}$-based ceramics without and with an $\mathrm{Al}_{2} \mathrm{O}_{3}$ coating. Reproduced with permission from Ref. [40], (C) The American Ceramic Society 2017.

Table 2 Energy-storage properties of BT-based bulk ceramics

\begin{tabular}{|c|c|c|c|}
\hline Dielectric ceramic & $W_{\text {rec }}\left(\mathrm{J} \cdot \mathrm{cm}^{-3}\right)$ & $E_{\mathrm{b}}\left(\mathrm{MV} \cdot \mathrm{m}^{-1}\right)$ & $\eta(\%)$ \\
\hline $0.7 \mathrm{BT}-0.3 \mathrm{BS}[25]$ & 2.3 & 22.5 & - \\
\hline $0.91 \mathrm{BT}-0.09 \mathrm{BY}[27]$ & 0.71 & 9.3 & 82.6 \\
\hline $0.85 \mathrm{BT}-0.15 \mathrm{BZN}[28]$ & 0.79 & 13.1 & 93.5 \\
\hline $0.87 \mathrm{BT}-0.13 \mathrm{BZNT}[37]$ & 1.44 & 21.8 & 92.5 \\
\hline $0.85 \mathrm{BT}-0.15 \mathrm{BMZ}[32]$ & 2.9 & 30.14 & 86.8 \\
\hline BTBMZ-7 wt\% BTBMZ@ $\mathrm{SiO}_{2}[33]$ & 3.41 & 34.5 & 85.1 \\
\hline $0.9 \mathrm{BT}-0.1 \mathrm{BMN}[35]$ & 1.13 & 14.35 & 95.8 \\
\hline $0.88 \mathrm{BT}-0.12 \mathrm{Bi}(\mathrm{Ni}, \mathrm{Nb}) \mathrm{O}_{3}[41]$ & 2.09 & 20 & 95.9 \\
\hline $0.9 \mathrm{BT}-0.1 \mathrm{Bi}(\mathrm{Zn}, \mathrm{Zr}) \mathrm{O}_{3}[31]$ & 2.46 & 26.4 & 86.8 \\
\hline $0.9 \mathrm{BT}-0.1 \mathrm{Bi}(\mathrm{Mg}, \mathrm{Nb}) \mathrm{O}_{3}[42]$ & 1.7 & 21 & 90 \\
\hline $0.85 \mathrm{BT}-0.15 \mathrm{Bi}(\mathrm{Zn}, \mathrm{Sn}) \mathrm{O}_{3}[36]$ & 2.41 & 23 & 91.6 \\
\hline $0.9 \mathrm{BT}-0.1 \mathrm{BiInO}_{3}[43]$ & 0.753 & $\sim 14$ & 89.4 \\
\hline $0.6 \mathrm{BT}-0.4 \mathrm{BMT}[38]$ & 4.49 & 34 & 93 \\
\hline $0.88 \mathrm{BT}-0.12 \mathrm{BMT}[39]$ & 1.81 & 22.4 & $\sim 88$ \\
\hline $0.88 \mathrm{BT}-0.12 \mathrm{Bi}(\mathrm{Li}, \mathrm{Nb}) \mathrm{O}_{3}[44]$ & 2.032 & 27 & 88 \\
\hline $0.9 \mathrm{BT}-0.1 \mathrm{Bi}(\mathrm{Li}, \mathrm{Ta}) \mathrm{O}_{3}[45]$ & 2.2 & 28 & 88.1 \\
\hline $0.86 \mathrm{BT}-0.14 \mathrm{Bi}(\mathrm{Zn}, \mathrm{Ti}) \mathrm{O}_{3}[46]$ & 0.81 & 12 & 94 \\
\hline BT-based@ $\mathrm{Al}_{2} \mathrm{O}_{3}[40]$ & 0.51 & 9.1 & 79.6 \\
\hline
\end{tabular}


$\mathrm{BaTiO}_{3}$-based dielectric ceramics with anti-reduction properties can co-fire with base metal internal electrodes $(\mathrm{Ni}, \mathrm{Cu})$, which would significantly reduce the cost of multilayer ceramic capacitors and be suitable for practical power electronics and pulsed power technology applications.

\subsection{2 $\mathrm{K}_{0.5} \mathrm{Na}_{0.5} \mathrm{NbO}_{3}$-based}

Potassium-sodium niobate, $\mathrm{K}_{0.5} \mathrm{Na}_{0.5} \mathrm{NbO}_{3}(\mathrm{KNN})$, is a solid solution formed between ferroelectric $\mathrm{KNbO}_{3}$ and antiferroelectric $\mathrm{NaNbO}_{3}$. With increasing temperature, $\mathrm{KNN}$ ceramics show several phase transitions, i.e., the rhombohedral phase $\left(\mathrm{R},<-190{ }^{\circ} \mathrm{C}\right)$, the orthorhombic phase $\left(\mathrm{O},-190-220{ }^{\circ} \mathrm{C}\right)$, the tetragonal phase $(\mathrm{T}$, $\left.220-420{ }^{\circ} \mathrm{C}\right)$, and the cubic phase $\left(\mathrm{C},>420{ }^{\circ} \mathrm{C}\right)$ [47]. $\mathrm{KNN}$-based ceramics usually have a large ferroelectricity with good piezoelectric properties, which are not suitable for energy-storage applications. The addition of $\mathrm{SrMO}_{3}$ ( $M$ is tetravalent or average tetravalent metallic ions, such as $\mathrm{Ti}$ or $\mathrm{Sc}_{0.5} \mathrm{Nb}_{0.5}$ ) or $\mathrm{BiMeO}_{3}$ into $\mathrm{KNN}$ would form a KNN-based solid solution [48-53]. With increasing content of the second component, there are a shift of $T_{\mathrm{C}}$ towards low temperature and a broadening of the dielectric permittivity peak, which indicate that the relaxor behavior of $\mathrm{KNN}$-based solid solutions is strengthened. Through compositional modification and grain size engineering, the breakdown strength $\left(E_{\mathrm{b}}\right)$ and the response relationship between the polarization $(P)$ and external electric field $(E)$ of
KNN-based relaxor ferroelectrics would be improved, which leads to better energy-storage properties.

The addition of $\mathrm{Sr}\left(\mathrm{Zn}_{1 / 3} \mathrm{Nb}_{2 / 3}\right) \mathrm{O}_{3}(\mathrm{SZN})$ into $\mathrm{KNN}$ leads to diffuse phase transitions and a typical relaxor-like behavior [52]. A uniform grain size $<200 \mathrm{~nm}$ and a dense microstructure were prepared via a conventional sintering method. The $0.94 \mathrm{KNN}-0.06 \mathrm{SZN}$ possesses a $W_{\text {rec }}$ of $1.5 \mathrm{~J} \cdot \mathrm{cm}^{-3}$ with a $\eta$ of $50 \%$ under $18 \mathrm{MV} \cdot \mathrm{m}^{-1}$, and a high optical transparency. Similarly, a high $W_{\text {rec }}$ of $2.02 \mathrm{~J} \cdot \mathrm{cm}^{-3}$ with a $\eta$ of $81.4 \%$ under $29.5 \mathrm{MV} \cdot \mathrm{m}^{-1}$, and a high optical transparency were achieved for the $0.8 \mathrm{KNN}-0.2 \mathrm{Sr}\left(\mathrm{Sc}_{0.5} \mathrm{Nb}_{0.5}\right) \mathrm{O}_{3}(0.8 \mathrm{KNN}-$ $0.2 \mathrm{SSN}$ ) ceramic with a uniform grain size of $\sim 500 \mathrm{~nm}$ [49]. Introducing $\mathrm{ZnO}$ into the $0.8 \mathrm{KNN}-0.2 \mathrm{SSN}$ ceramic could form a liquid phase to promote densification, which reduced the sintering temperature by $\sim 100$ $200{ }^{\circ} \mathrm{C}$ and led to lower porosity and a higher $E_{\mathrm{b}}$ [54]. An enhanced $W_{\text {rec }}$ of $2.6 \mathrm{~J} \cdot \mathrm{cm}^{-3}$ with a $\eta$ of $73.2 \%$ and $E_{\mathrm{b}}$ of $40 \mathrm{MV} \cdot \mathrm{m}^{-1}$ was achieved in $0.8 \mathrm{KNN}-$ $0.2 \mathrm{SSN}-0.5 \mathrm{~mol} \% \mathrm{ZnO}$ ceramic, as shown in Figs. $8(\mathrm{a})-8(\mathrm{c})$. The $(1-x) \mathrm{KNN}-x \mathrm{SrTiO}_{3}(\mathrm{KNN}-\mathrm{ST})$ ceramics were prepared via a strategy where the composition drives the grain size to the submicrometer scale [55]. With increasing ST content, the average grain size decreased from $2.26 \mu \mathrm{m}$ for pure $\mathrm{KNN}$ to $0.35 \mu \mathrm{m}$ for $0.85 \mathrm{KNN}-0.15 \mathrm{ST}$ and $0.28 \mu \mathrm{m}$ for $0.8 \mathrm{KNN}-0.2 \mathrm{ST}$, and the ferroelectric properties of the $(1-x) \mathrm{KNN}-x \mathrm{ST}$ ceramics were also dramatically reduced. The fine nanograin led to a markedly large $E_{\mathrm{b}}$ of $40 \mathrm{MV} \cdot \mathrm{m}^{-1}$.

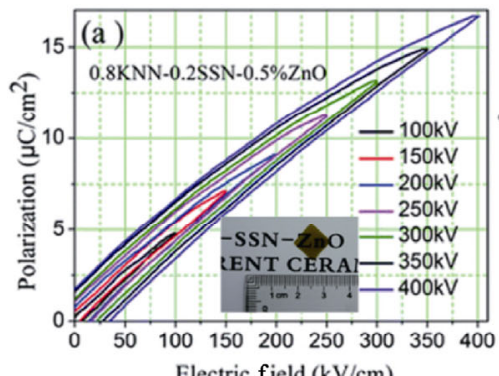
Electric field $(\mathrm{kV} / \mathrm{cm})$

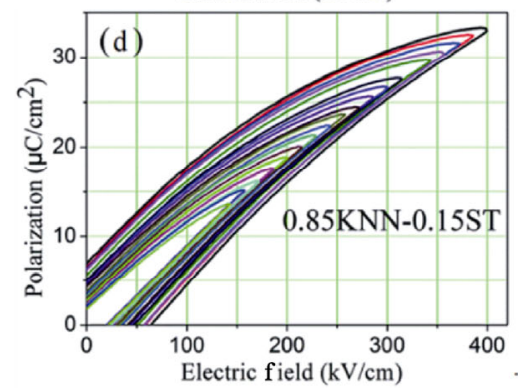

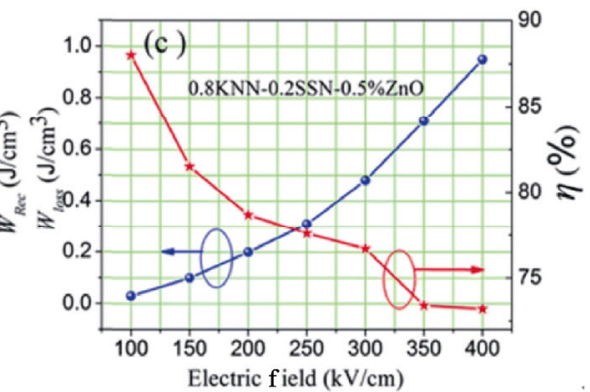
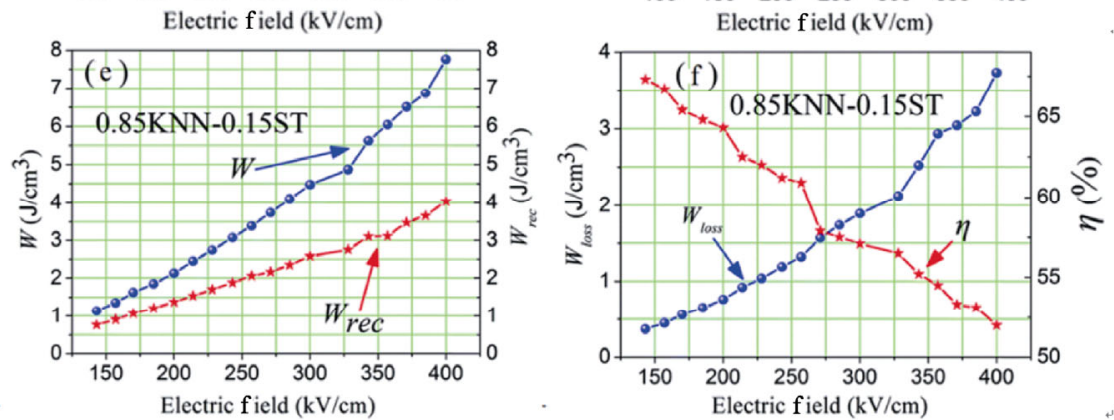

Fig. $8 P-E$ loops and energy-storage properties at room temperature of (a-c) $0.8 \mathrm{KNN}-0.2 \mathrm{SSN}-0.5 \% \mathrm{ZnO}$ and $(\mathrm{d}-\mathrm{f}) 0.85 \mathrm{KNN}-$ 0.15ST. Reproduced with permission from Refs. [54,55], (C) The Royal Society of Chemistry 2016. 
A large $W_{\text {rec }}$ of $4.03 \mathrm{~J} \cdot \mathrm{cm}^{-3}$ with a $\eta$ of $52 \%$ was obtained for $0.85 \mathrm{KNN}-0.15 \mathrm{ST}$ (Figs. 8 (d) $-8(\mathrm{f})$ ), and a large $W_{\text {rec }}$ of $3.67 \mathrm{~J} \cdot \mathrm{cm}^{-3}$ with a high $\eta$ of $72.1 \%$ was obtained for $0.8 \mathrm{KNN}-0.2 \mathrm{ST}$.

The addition of $\mathrm{BiFeO}_{3}(\mathrm{BF})$ into $\mathrm{KNN}$ also reduced the grain size and enhanced the relaxation behavior [48]. The $0.9 \mathrm{KNN}-0.1 \mathrm{BF}$ ceramic with an average grain size of $150 \mathrm{~nm}$ possesses a $W_{\text {rec }}$ of $2.0 \mathrm{~J} \cdot \mathrm{cm}^{-3}$ with a $\eta$ of $61 \%$ under $E_{\mathrm{b}}$ of $20.6 \mathrm{MV} \cdot \mathrm{m}^{-1}$. Moreover, the addition of $\mathrm{BF}$ also enhanced the bending strength, elastic modulus, and compression strength of $0.9 \mathrm{KNN}-$ $0.1 \mathrm{BF}$ ceramic by $\sim 200 \%$ compared with the pure KNN ceramics, which benefit the lifetime and reliability of the capacitors. The addition of $\mathrm{Bi}\left(\mathrm{Mg}_{2 / 3} \mathrm{Nb}_{1 / 3}\right) \mathrm{O}_{3}$ (BMN) into KNN ceramics was also studied [51]. Through grain size engineering and hybridization between the $\mathrm{Bi} 6 \mathrm{~s}$ and $\mathrm{O} 2 \mathrm{p}$ orbitals, the $E_{\mathrm{b}}$ and saturation polarization $\left(P_{\mathrm{s}}\right)$ of the $\mathrm{KNN}-\mathrm{BMN}$ ceramics were enhanced. A large $P_{\mathrm{s}}$ of $41 \mu \mathrm{C} \cdot \mathrm{cm}^{-2}$ and $E_{\mathrm{b}}$ of $30 \mathrm{MV} \cdot \mathrm{m}^{-1}$ were obtained in the $0.9 \mathrm{KNN}-$ $0.1 \mathrm{BMN}$ ceramic, leading to a large $W_{\text {rec }}$ of $4.08 \mathrm{~J} \cdot \mathrm{cm}^{-3}$ with a $\eta$ of $62.7 \%$. Similarly, $\mathrm{CuO}$ was used as a sintering aid in the $0.9 \mathrm{KNN}-0.1 \mathrm{BMN}$ ceramic to assist in densification through the liquid phase during sintering [50], which could reduce the sintering temperature from 1150 to $940{ }^{\circ} \mathrm{C}$. A large $W_{\text {rec }}$ of $4.02 \mathrm{~J} \cdot \mathrm{cm}^{-3}$ and a $\eta$ of $57.3 \%$ under an $E_{\mathrm{b}}$ of $40 \mathrm{MV} \cdot \mathrm{m}^{-1}$ were obtained in the $0.9 \mathrm{KNN}-0.1$ $\mathrm{BMN}-1 \mathrm{~mol} \% \mathrm{CuO}$ ceramic.

The two-step sintering reported by Chen and Wang [56] is widely used to control the grain size and prepare nanosized ceramics. In this work, by optimizing the grain size and grain boundary morphology via the twostep sintering method (Figs. 9(a)-9(e)), excellent
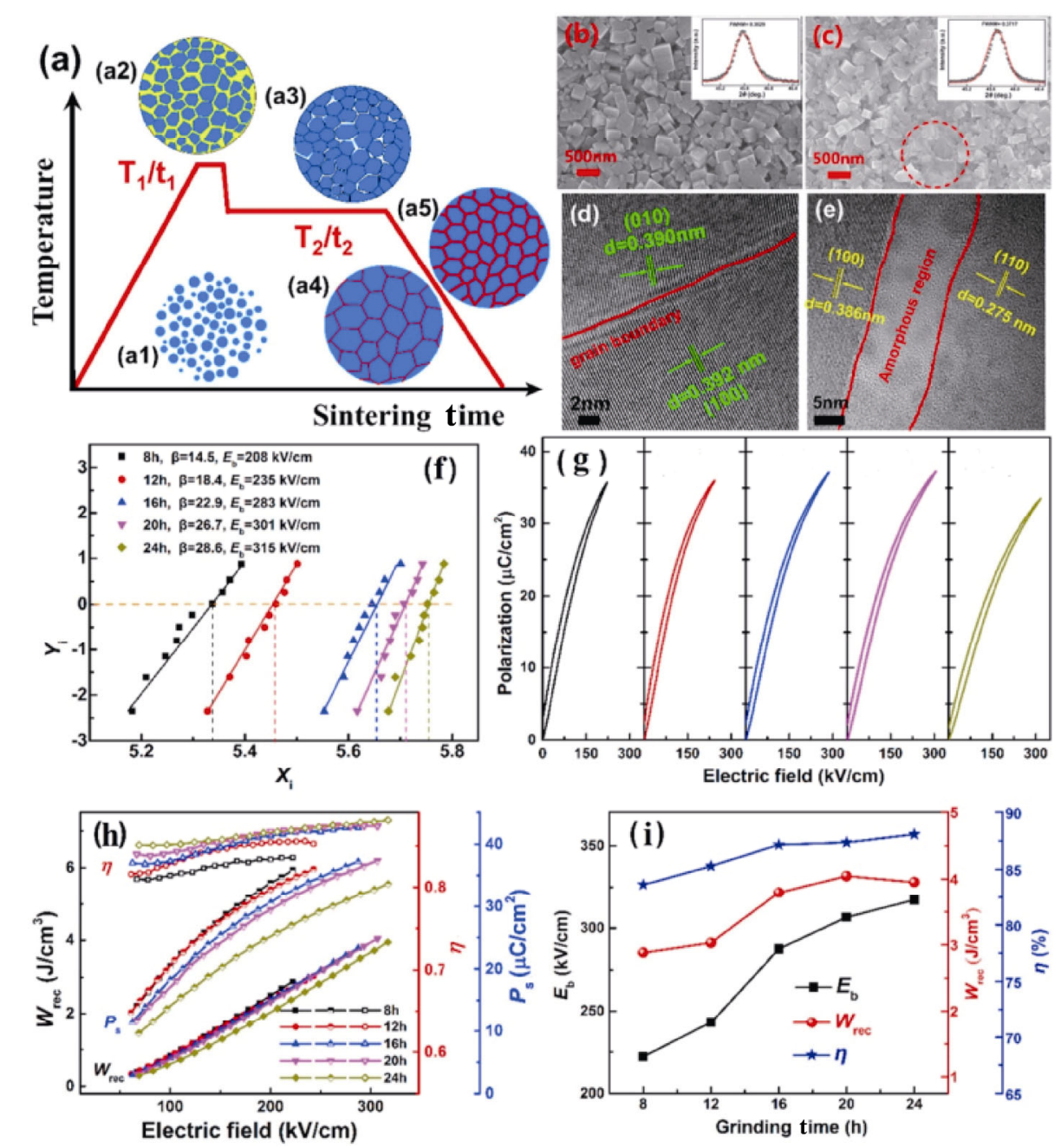

Fig. 9 (a) Schematic diagram of the two-step sintering method and corresponding ceramic morphologies. SEM and highresolution TEM images of the ceramics after grinding for (b, d) $8 \mathrm{~h}$ and (c, e) $20 \mathrm{~h}$. (f) Weibull distribution, (g) $P-E$ loops, and (h, i) energy-storage properties at room temperature for the $0.975 \mathrm{KNN}-0.075 \mathrm{BZTN}$ ceramic with various grinding durations. Reproduced with permission from Ref. [53], C The Chinese Ceramic Society 2020. 
energy-storage properties with both a large $W_{\text {rec }}$ of $4.02 \mathrm{~J} \cdot \mathrm{cm}^{-3}$ and a high $\eta$ of $87.4 \%$ under an $E_{\mathrm{b}}$ of $30.7 \mathrm{MV} \cdot \mathrm{m}^{-1}$ were obtained for the $0.925 \mathrm{KNN}-$ $0.075 \mathrm{Bi}\left(\mathrm{Zn}_{2 / 3}\left(\mathrm{Ta}_{0.5} \mathrm{Nb}_{0.5}\right)_{1 / 3}\right) \mathrm{O}_{3}(0.975 \mathrm{KNN}-0.075 \mathrm{BZTN})$ ceramic with an average grain size of $250 \mathrm{~nm}$ [53] (Figs. 9(h) and 9(i)).

In summary, most KNN-based relaxor ferroelectrics usually possess a relatively high $E_{\mathrm{b}}\left(>30 \mathrm{MV} \cdot \mathrm{m}^{-1}\right)$ and large $W_{\text {rec }}\left(2-4 \mathrm{~J} \cdot \mathrm{cm}^{-3}\right)$. However, the strong ferroelectricity and high remnant polarization $\left(P_{\mathrm{r}}\right)$ of most KNN-based ceramics lead to their low $\eta \quad(<75 \%)$, which is not suitable for energy-storage capacitors. Reducing the $P_{\mathrm{r}}$ and simultaneously achieving high energy-storage density and high energy efficiency in $\mathrm{KNN}$-based relaxor ferroelectric ceramics are key challenges for practical capacitor applications.

\subsection{3 $\mathrm{BiFeO}_{3}$-based}

$\mathrm{BiFeO}_{3}$-based $(\mathrm{BF})$ ceramics with a giant $P_{\mathrm{s}} \approx$ $100 \mu \mathrm{C} \cdot \mathrm{cm}^{-2}$, high Curie temperature, relative low sintering temperature, and a similar electron configuration for $\mathrm{Bi}^{3+}$ and $\mathrm{Pb}^{2+}$ are considered to be desirable candidates for energy-storage applications. However, there are still several drawbacks that BF-based ceramics need to overcome, such as large remnant polarization $\left(P_{\mathrm{r}}\right)$, undesirable breakdown strength $\left(E_{\mathrm{b}}\right)$, relatively large dielectric loss, and high conductivity that derives from the volatilization of $\mathrm{Bi}$ and the reduction of $\mathrm{Fe}^{3+}$ during the sintering process. To address these issues, numerous strategies for optimizing the energy-storage properties have been investigated, and they mainly focused on introducing multivalent elements to promote polar nanoregions and reducing defects to obtain an improved $E_{\mathrm{b}}$, and most of the modified BF-based

Table 3 Energy-storage properties of KNN-based bulk ceramics

\begin{tabular}{lccl}
\hline \multicolumn{1}{c}{ Dielectric ceramic } & $\begin{array}{c}W_{\text {rec }} \\
\left(\mathrm{J} \cdot \mathrm{cm}^{-3}\right)\end{array}$ & $\begin{array}{c}E_{\mathrm{b}} \\
\left(\mathrm{MV} \cdot \mathrm{m}^{-1}\right)\end{array}$ & $\begin{array}{c}\eta \\
(\%)\end{array}$ \\
\hline 0.94KNN-0.06SZN [52] & 1.5 & 18 & 50 \\
0.8KNN-0.2SSN [49] & 2.02 & 29.5 & 81.4 \\
0.8KNN-0.2SSN-0.5 mol\% ZnO [54] & 2.6 & 40 & 73.2 \\
0.85KNN-0.15ST [55] & 4.03 & 40 & 52 \\
0.8KNN-0.2ST [55] & 3.67 & 40 & 72.1 \\
0.9KNN-0.1BF [48] & 2.0 & 20.6 & 61 \\
0.9KNN-0.1BMN [51] & 4.08 & 30 & 62.7 \\
0.9KNN-0.1BMN-1 mol\% CuO [50] & 4.02 & 40 & 57.3 \\
0.975KNN-0.075BZTN [53] & 4.02 & 30.7 & 87.4 \\
\hline
\end{tabular}

ceramics are presented in the form of BF-BT-based ceramics.

Enhanced energy-storage properties have been achieved in modified BF-based relaxor ferroelectric ceramics. Qi et al. [57] proposed a nanodomainengineering strategy to integrate a high-spontaneouspolarization gene, a wide band gap, and a heterogeneous nanodomain structure. Excellent comprehensive properties that include a giant $W_{\text {rec }}$ of $8.12 \mathrm{~J} \cdot \mathrm{cm}^{-3}$ with a high $\eta$ of $90 \%$ at $36 \mathrm{MV} \cdot \mathrm{m}^{-1}$, along with an excellent thermal stability $\left( \pm 10 \%,-50-250{ }^{\circ} \mathrm{C}\right)$ were achieved in $\quad 0.57 \mathrm{BiFeO}_{3}-0.33 \mathrm{BaTiO}_{3}-0.1 \mathrm{NaNbO}_{3} \quad(0.57 \mathrm{BF}-$ $0.33 \mathrm{BT}-0.1 \mathrm{NN})$. The energy-storage properties and nanodomain characterizations are shown in Fig. 10. Similarly, Yan et al. [58] designed a $(1-x)\left(0.67 \mathrm{BiFeO}_{3}-\right.$ $\left.0.33 \mathrm{BaTiO}_{3}\right)-x \mathrm{Na} 0 .{ }_{73} \mathrm{Bi}_{0.09} \mathrm{NbO}_{3} \quad((1-x) \mathrm{BFBT}-x \mathrm{NBN})$ ceramic system, taking the advantage of the large band gap of $\mathrm{NN}$ to improve the $E_{\mathrm{b}}$ and disturbed the long-range ferroelectric order via substitution with low valence ions at the A-sites and high valence ions at the B-site to optimize the $\Delta P\left(P_{\max }-P_{\mathrm{r}}\right)$. They delivered a large $W_{\text {rec }}\left(>5 \mathrm{~J} \cdot \mathrm{cm}^{-3}\right)$ and a considerable $\eta$ of $\sim 80 \%$ with a high $E_{\mathrm{b}}\left(\geqslant 38 \mathrm{MV} \cdot \mathrm{m}^{-1}\right)$ for the $(1-x)$ BFBT $-x$ NBN ceramics with a broad composition range of $x=0.10-0.14$.

For some applications under a low electric field $\left(<20 \mathrm{MV} \cdot \mathrm{m}^{-1}\right)$, BF-based ceramics are ideal candidates because of their giant polarization. Ji et al. [59] introduced $\mathrm{BT}-\mathrm{BiMeO} \mathrm{O}_{3}$ perovskites to frustrate the long-range ferroelectric order and improve the poor electrical insulation of BF. Consequently, optimal energystorage properties with a high $W_{\text {rec }}$ of $3.06 \mathrm{~J} \cdot \mathrm{cm}^{-3}$ and an excellent $\eta$ of $92 \%$ were obtained at a relatively low electric field of $18.5 \mathrm{MV} \cdot \mathrm{m}^{-1}$ in $0.35 \mathrm{BiFeO}_{3}-$ $0.65\left(0.85 \mathrm{BaTiO}_{3}-0.15 \mathrm{Bi}\left(\mathrm{Sn}_{0.5} \mathrm{Zn}_{0.5}\right) \mathrm{O}_{3}\right)$. The details of various $\mathrm{BF}-$ based relaxor ferroelectric energy-storage ceramics are listed in Table 4. These results indicate that BF-based relaxor ceramics have excellent potential for high-energy-storage applications serving both low and high electric fields.

\subsection{4 $\mathrm{Bi}_{0.5} \mathrm{Na}_{0.5} \mathrm{TiO}_{3}$-based}

$\mathrm{Bi}_{0.5} \mathrm{Na}_{0.5} \mathrm{TiO}_{3}$ (BNT) is a conventional perovskite ceramic system that has been extensively studied since its discovery in the 1960s. Early research mainly focused on its piezoelectric properties; in recent years, it has also demonstrated excellent potential for dielectric energy-storage applications and attracted significant research attention. BNT ceramics have a relatively high 

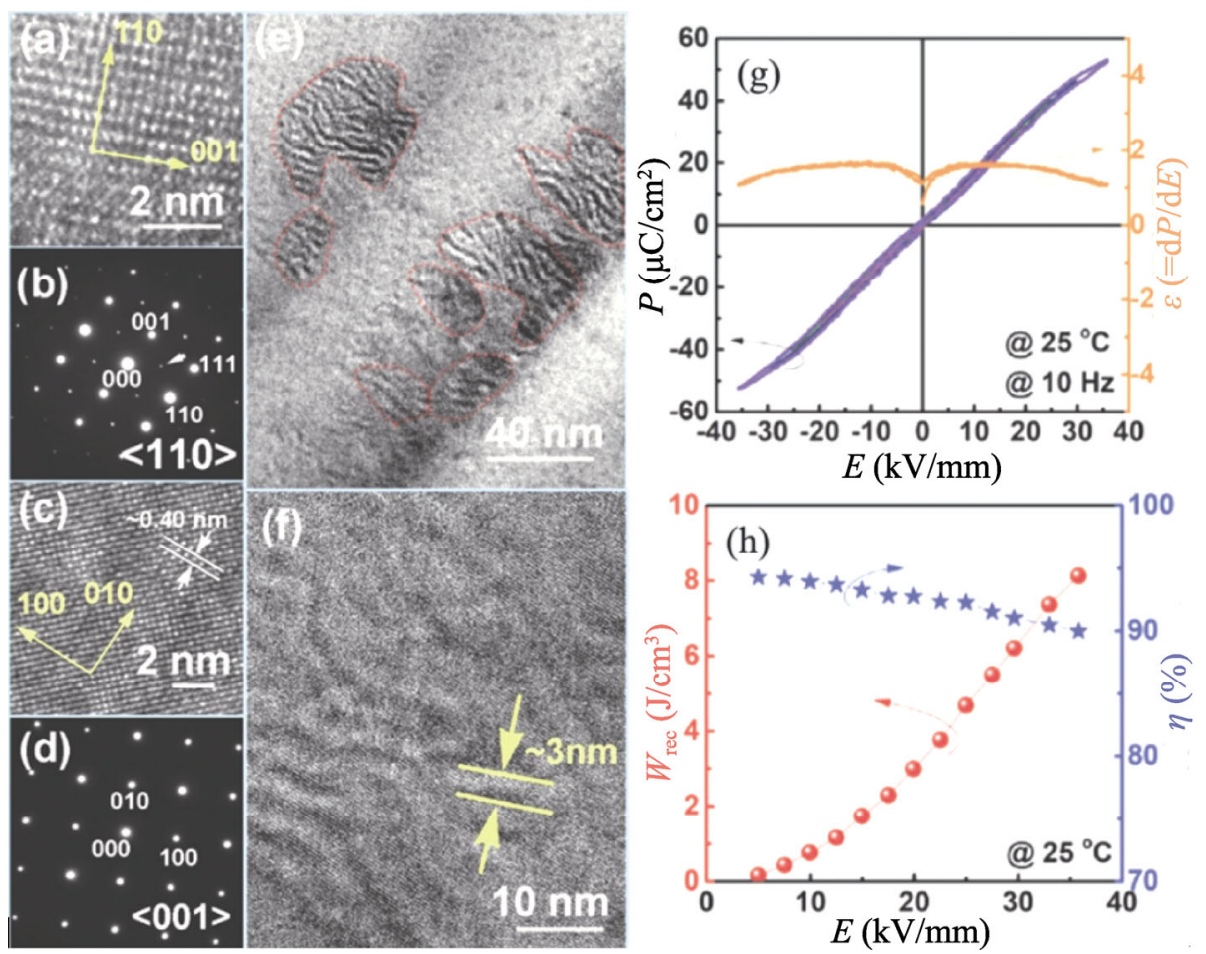

Fig. 10 (a-f) Nanodomain structures of $0.57 \mathrm{BF}-0.33 \mathrm{BT}-0.1 \mathrm{NN}$ ceramic. (g) $P-E$ loops and $\mathrm{d} P / \mathrm{d} E-E$ loops at $10 \mathrm{~Hz}$. (h) Recoverable energy density and efficiency as functions of the applied electric field. Reproduced with permission from Ref. [57], (C) WILEY-VCH Verlag GmbH \& Co. KGaA, Weinheim 2019.

Table 4 Energy-storage properties of BF-based relaxor ferroelectric bulk ceramics

\begin{tabular}{lccc}
\hline \multicolumn{1}{c}{ Dielectric ceramic } & $\begin{array}{c}W_{\text {rec }} \\
\left(\mathrm{J} \cdot \mathrm{cm}^{-3}\right)\end{array}$ & $\begin{array}{c}E_{\mathrm{b}} \\
\left(\mathrm{MV} \cdot \mathrm{m}^{-1}\right)\end{array}$ & $\begin{array}{c}\eta \\
(\%)\end{array}$ \\
\hline 0.88BFBT-0.12NBN [58] & 5.57 & 41 & 80 \\
0.35BF-0.65BTBSZ [59] & 3.06 & 18.5 & 92 \\
0.57BF-0.33BT-0.1NN [57] & 8.12 & 36 & 90 \\
0.56BF-0.3BT-0.14AN [60] & 2.11 & 19.5 & 84 \\
BF-SBT [61] & 2.01 & 18 & 75 \\
BLF-BT-Mn [62] & 1.08 & 13 & 49 \\
0.75BNF-0.25BT [63] & 1.82 & 18 & 45 \\
BF-BZT [64] & 2.56 & 16 & 75 \\
BBFTO-SAN [65] & 1.75 & 15.5 & 81 \\
BF-BT-0.12SBT [66] & 1.74 & 15 & 74 \\
BF-BST-LMN [67] & 3.38 & 23 & 59 \\
\hline
\end{tabular}

Note: $\quad 0.75 \mathrm{BNF}-0.25 \mathrm{BT}: \quad 0.75\left(\mathrm{Bi}_{1-x} \mathrm{Nd}_{x}\right) \mathrm{FeO}_{3}-0.25 \mathrm{BaTiO}_{3} ; \quad$ BZT: $\mathrm{Ba}\left(\mathrm{Zn}_{1 / 2} \mathrm{Ta}_{2 / 3}\right) \mathrm{O}_{3}$.

Curie temperature $\left(320{ }^{\circ} \mathrm{C}\right)$ and they are ferroelectric materials with a rhombic symmetry at room temperature. More importantly, the similar lone pair electronic $6 \mathrm{~s}^{2}$ configuration of the $\mathrm{Bi}^{3+}$ ion and the distorted perovskite structure is beneficial for simultaneously delivering a large polarization along with macroscopic relaxor characteristics. However, the low $E_{\mathrm{b}}$ and large $P_{\mathrm{r}}$ of the pure BNT ceramics make it difficult to obtain high $W_{\text {rec }}$ and $\eta$. To solve these issues, numerous studies have focused on constructing a morphotropic phase boundary (MPB) or doping with other elements, and various ceramic systems have been developed, such as the BNT-Sr(Ti/Zr) $\mathrm{O}_{3}$-based (BNT-ST/Z), BNT$\mathrm{NaNbO}_{3}$-based (BNT-NN), and $\mathrm{BNT}-\mathrm{BaTiO}_{3}$-based (BNT-BT) systems.

It is well known that BNT has a relaxor feature between $200{ }^{\circ} \mathrm{C}\left(T_{\mathrm{s}}\right)$ and $320{ }^{\circ} \mathrm{C}$ (Curie temperature, $T_{\mathrm{m}}$ ). Therefore, by decreasing the $T_{\mathrm{s}}$ of BNT below room temperature, its $P_{\mathrm{r}}$ can be reduced and $W_{\text {rec }}$ can be improved. Qiao et al. [68] introduced $\mathrm{La}^{3+}$ into the $\mathrm{Sr}^{2+}$ site of the BNT-ST ceramics: this is because $\mathrm{La}^{3+}$ doping plays a role in decreasing the grain size and delaying saturation of the polarization electric field in BNT-based ceramics, as shown in Fig. 11(a). With increasing $\mathrm{Sr}_{0.7} \mathrm{La}_{0.2} \mathrm{TiO}_{3}$ (SLT) content, the crystal structure transforms from a rhombohedral phase to a weakly polarized pseudo-cubic phase, and the $T_{\mathrm{s}}$ shifts from $200{ }^{\circ} \mathrm{C}$ to approximately room temperature, with enhanced relaxation behavior and improved $E_{\mathrm{b}}$. The sample with $x=0.45$ had a large $W_{\text {rec }}$ of $4.14 \mathrm{~J} \cdot \mathrm{cm}^{-3}$, a high $\eta$ of $92.2 \%$, excellent frequency stability, and excellent fatigue resistance. 


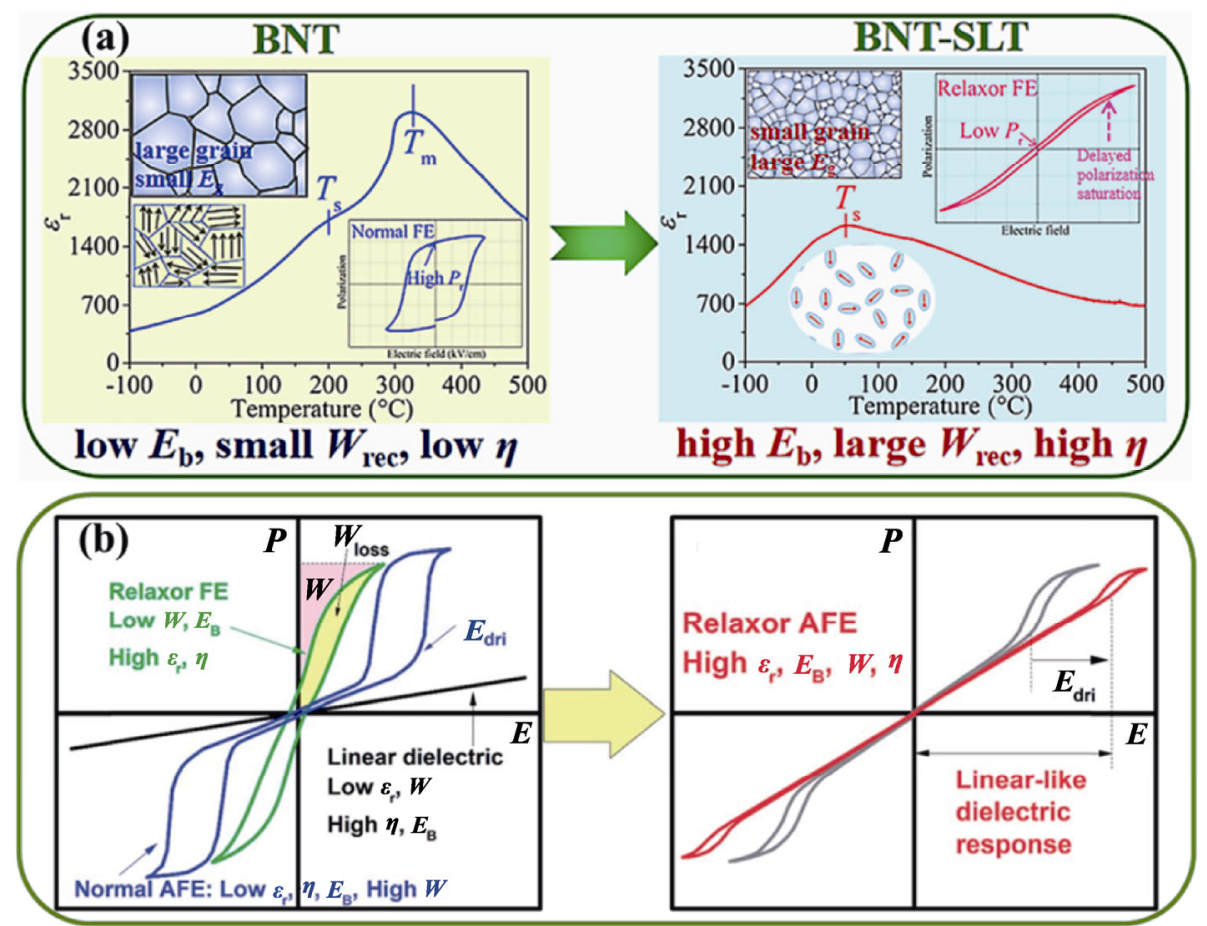

Fig. 11 (a) Schematic diagram for simultaneously achieving large $W_{\text {rec }}$ and high $\eta$ : the $E_{\mathrm{b}}$ increased via decreasing grain size and increasing band gap; the relaxation behavior was enhanced by driving $T_{\mathrm{s}}$ to room temperature; and the electric field of polarization saturation was delayed by reducing the tolerance factor. Reproduced with permission from Ref. [68], (C) Elsevier B.V. 2020. (b) Schematic diagram of the energy-storage properties for various types of dielectric ceramics: from the $P-E$ loops for purely linear nonpolar dielectric, relaxor ferroelectric, and normal antiferroelectric ceramics (left), to the $P-E$ loops expected for a relaxor antiferroelectric ceramic (right). Reproduced with permission from Ref. [69], (C) The Royal Society of Chemistry 2019.

Additionally, defect control is another effective approach to improve the comprehensive energy-storage properties. Yan et al. [70] adopted a strategy via A-site defect engineering with Bi-excess and Na-deficiency to reduce the generation of oxygen vacancies, designing a ceramic with a composition of $0.75 \mathrm{Bi}_{(0.5+x)} \mathrm{Na}_{(0.5-x)} \mathrm{TiO}_{3}-$ $0.25 \mathrm{SrTiO}_{3}$ (BNST- $x$ ). Bi plays a major role in the volatilized component, with the volatilization temperature of $\mathrm{Bi}_{2} \mathrm{O}_{3}\left(\sim 825{ }^{\circ} \mathrm{C}\right)$ during the sintering process being much lower than that of $\mathrm{Na}_{2} \mathrm{O}\left(\sim 1132{ }^{\circ} \mathrm{C}\right)$ in BNTbased ceramics. Defect control via moderating the $\mathrm{Bi} / \mathrm{Na}$ ratio is beneficial for inhibiting grain growth and improving $E_{\mathrm{b}}$. An ultra-high $W_{\text {rec }}$ of $5.63 \mathrm{~J} \cdot \mathrm{cm}^{-3}$ and an outstanding $\eta$ of $94 \%$ were simultaneously achieved at a relatively high electric field of 53.5 $\mathrm{MV} \cdot \mathrm{m}^{-1}$ in the BNST- 0.08 ceramic.

Furthermore, temperature stability is crucial for reliable operation of dielectric capacitors in complex environments. Notably, the BNT-based relaxor ceramics are considered to be promising for thermally-stable dielectric capacitor applications because of their diffuse phase transition behavior. Zhou et al. [71] developed an ergodic relaxor ferroelectric composed of
$0.8 \mathrm{Bi}_{0.5} \mathrm{Na}_{0.5} \mathrm{TiO}_{3}-0.2 \mathrm{NaTaO}_{3}(0.8 \mathrm{BNT}-0.2 \mathrm{NT})$, exhibiting the superior temperature stability of $W_{\text {rec }}$ with a variation of $<10 \%$ over an ultrawide temperature range from -50 to $300{ }^{\circ} \mathrm{C}$. Zhu et al. [72] chose $\mathrm{NN}$ to modify $0.95 \mathrm{BNT}-0.05 \mathrm{SZ}$ and realized coexistence of the rhombohedral $(\mathrm{R})$ and tetragonal $(\mathrm{T})$ phases. The diffuse phase transition from the $R$ phase to the $T$ phase was responsible for the superior temperature stability of both the energy-storage and dielectric properties. A large $W_{\text {rec }}$ of $3.14 \mathrm{~J} \cdot \mathrm{cm}^{-3}$ was obtained in the $0.85 \mathrm{BNTSZ}-0.15 \mathrm{NN}$ ceramic at a high temperature of $120{ }^{\circ} \mathrm{C}$ under $23 \mathrm{MV} \cdot \mathrm{m}^{-1}$, with a variation in the $W_{\text {rec }}$ of $< \pm 4 \%$ in the temperature range from 25 to $180{ }^{\circ} \mathrm{C}$ under $12 \mathrm{MV} \cdot \mathrm{m}^{-1}$. Additionally, variation of the dielectric permittivity of the $0.8 \mathrm{BNTSZ}-0.2 \mathrm{NN}$ ceramic was $< \pm 15 \%$ over the temperature range from -55 to $545{ }^{\circ} \mathrm{C}$, which is a record-high upper operating temperature, with a high room-temperature dielectric permittivity of 1170 .

Recently, BNT-based relaxor antiferroelectrics have drawn significant attention because of their large spontaneous polarization, small hysteresis, and high breakdown strength. Qi and Zuo [69] introduced $\mathrm{NaNbO}_{3}$ 
$(\mathrm{NN})$, which is in the antiferroelectric orthorhombic phase at room temperature, into BNT to stabilize the high-temperature antiferroelectric phase, forming relaxor antiferroelectric BNT-based ceramics, as seen in Fig. 11(b). As a result, a high $W_{\text {rec }}$ of $7.02 \mathrm{~J} \cdot \mathrm{cm}^{-3}$ and a desirable energy efficiency of $85 \%$ were obtained under an applied field of $39 \mathrm{MV} \cdot \mathrm{m}^{-1}$, which is superior to most BNT-based ceramics. Table 5 summarizes the energy-storage properties of recently reported BNTbased ceramics.

In summary, the main constraint on the energystorage properties in existing BNT-based ceramics can be attributed to their low breakdown strength. Modifying BNT-based ceramics to an antiferroelectric relaxor is one of the most promising approaches to simultaneously achieve high energy-storage density and good energy efficiency owing to the resulting large spontaneous polarization, small hysteresis, and high breakdown strength.

\subsection{5 $\mathrm{AgNbO}_{3}$-based}

Recently, $\mathrm{AgNbO}_{3}$ (AN) ceramics have received widespread attention as lead-free antiferroelectric materials for energy-storage applications. Through doping $\mathrm{Bi}$ or rare-earth elements at $\mathrm{A}$-site, doping $\mathrm{Ta}$ and $\mathrm{W}$ at $\mathrm{B}$-site, and adding $\mathrm{MnO}_{2}$ as sintering aid could improve the energy storage properties of $\mathrm{AN}$ ceramics.

Table 5 Energy-storage properties of BNT-based relaxor ferroelectric bulk ceramics

\begin{tabular}{lccc}
\hline \multicolumn{1}{c}{ Dielectric ceramic } & $\begin{array}{c}W_{\mathrm{rec}} \\
\left(\mathrm{J} \cdot \mathrm{cm}^{-3}\right)\end{array}$ & $\begin{array}{c}E_{\mathrm{b}} \\
\left(\mathrm{MV} \cdot \mathrm{m}^{-1}\right)\end{array}$ & $\begin{array}{c}\eta \\
(\%)\end{array}$ \\
\hline 0.9NBT-0.1LT [73] & 3.1 & 20 & 74.2 \\
NBT-BH [74] & 2.1 & 17.5 & 68.1 \\
BNT-BT-BZN [75] & 2.83 & 18 & 67 \\
BNST-0.08 [70] & 5.63 & 53.5 & 94 \\
BNT-SLT [68] & 4.14 & 31.5 & 92.2 \\
0.6BNT-0.4SST [76] & 3.52 & 26 & 84.2 \\
0.65(NBT-BKT)-0.35SBT [77] & 4.06 & 35 & 87.3 \\
BNT-SBT-4NN [78] & 3.08 & 22 & 81.4 \\
0.94(BNT-BST)-0.06KNN [79] & 2.65 & 18 & 84.6 \\
BNTSZNN [72] & 2.93 & 23 & 72 \\
BNT-NT [71] & 4.21 & 38 & 77.8 \\
BNT-0.4ST-0.02FN [80] & 3.36 & 17 & 81 \\
BNTST-CuO [81] & 2.2 & 23 & 73.4 \\
BLNKTANZ [82] & 3.24 & 20 & 82 \\
BNT-NN [69] & 7.02 & 39 & 85 \\
\hline
\end{tabular}

Zhao et al. [83] studied the $\mathrm{Ag}\left(\mathrm{Nb}_{1-x} \mathrm{Ta}_{x}\right) \mathrm{O}_{3}$ (ANT) solid solutions, and the Ta addition would effectively decrease the grain size and enhance the antiferroelectricity in ANT materials. As a result, a high $W_{\text {rec }}$ of $4.2 \mathrm{~J} \cdot \mathrm{cm}^{-3}$ and a $\eta$ of $69 \%$ were obtained under an applied field of $23 \mathrm{MV} \cdot \mathrm{m}^{-1}$ in ANT15 ceramics, which was $260 \%$ enhancement over the pure AN ceramics (Figs. 12(a) and 12(b)). Gao et al. [84] also studied the La-doped AN ceramics. The antiferroelectric phase stability would be enhanced by the La doping, and the average grain size decreased from 5.2 to $3.3 \mu \mathrm{m}$ with increasing $\mathrm{La}^{3+}$ content, leading to a higher $E_{\mathrm{b}}$. The $2 \mathrm{~mol} \%$ La-doped AN (ANL2) ceramics possessed the optimal energy storage properties with a high $W_{\text {rec }}$ of $4.4 \mathrm{~J} \cdot \mathrm{cm}^{-3}$ and a $\eta$ of $73 \%$ under an applied field of $27.3 \mathrm{MV} \cdot \mathrm{m}^{-1}$ (Figs. 12(c) and 12(d)).

$\mathrm{AgO}$ is sensitive to light and heat, and it needs to be stored in a dark environment. Because $\mathrm{AgO}$ will decompose into $\mathrm{Ag}$ and $\mathrm{O}_{2}$ at high temperature, the $\mathrm{AN}$ should be calcined and sintered in an $\mathrm{O}_{2}$ atmosphere. These features of AN ceramics make that the AN MLCCs can only use precious metals as inner electrodes, which will greatly increase the cost of the MLCCs. Moreover, the energy efficiency of AN ceramic is usually less than $75 \%$.

\subsection{6 $\mathrm{NaNbO}_{3}$-based}

The discovery of promising relaxor or antiferroelectric properties in some derivate solid solutions, such as $\mathrm{NaNbO}_{3}-\mathrm{SrTiO}_{3}, \mathrm{NaNbO}_{3}-\mathrm{BiMeO}_{3}$, and $\mathrm{NaNbO}_{3}-$ $\mathrm{Bi}_{0.5} \mathrm{Na}_{0.5} \mathrm{TiO}_{3}$ has resulted in $\mathrm{NaNbO}_{3}$-based ceramics emerging as an important functional dielectric material for energy storage [89-93].

Zhou et al. [89] introduced $\mathrm{Bi}_{2} \mathrm{O}_{3}$ into $\mathrm{NaNbO}_{3}$ ceramics to increase the $E_{\mathrm{b}}, P_{\max }$ and decrease the $P_{\mathrm{r}}$. The novel $\mathrm{Na}_{0.7} \mathrm{Bi}_{0.1} \mathrm{NbO}_{3}(\mathrm{NBN})$ ceramics displayed a relaxor-like frequency dispersion near room temperature, simultaneously exhibiting a high $W_{\text {rec }}$ of $4.03 \mathrm{~J} \cdot \mathrm{cm}^{-3}$ with a $\eta$ of $85.4 \%$ at an $E_{\mathrm{b}}$ of $25 \mathrm{MV} \cdot \mathrm{m}^{-1}$ (Figs. 13(a) and 13(b)). Zhou et al. [91] studied the $0.8 \mathrm{NaNbO}_{3}-$ $0.2 \mathrm{SrTiO}_{3}(0.8 \mathrm{NN}-0.2 \mathrm{ST})$ ceramic. Because of its small grain size and dense microstructure, $0.8 \mathrm{NN}-$ $0.2 \mathrm{ST}$ ceramic exhibited a $W_{\text {rec }}$ of $3.02 \mathrm{~J} \cdot \mathrm{cm}^{-3}$ with a $\eta$ of $80.7 \%$ at an $E_{\mathrm{b}}$ of $32.3 \mathrm{MV} \cdot \mathrm{m}^{-1}$, and it had excellent energy-storage properties related to its frequency, temperature, and fatigue resistance. Similarly, $\mathrm{BaZrO}_{3}$ and $\mathrm{CaZrO}_{3}$ doped $\mathrm{NaNbO}_{3}$-based antiferroelectric ceramics were also obtained [94]. The 

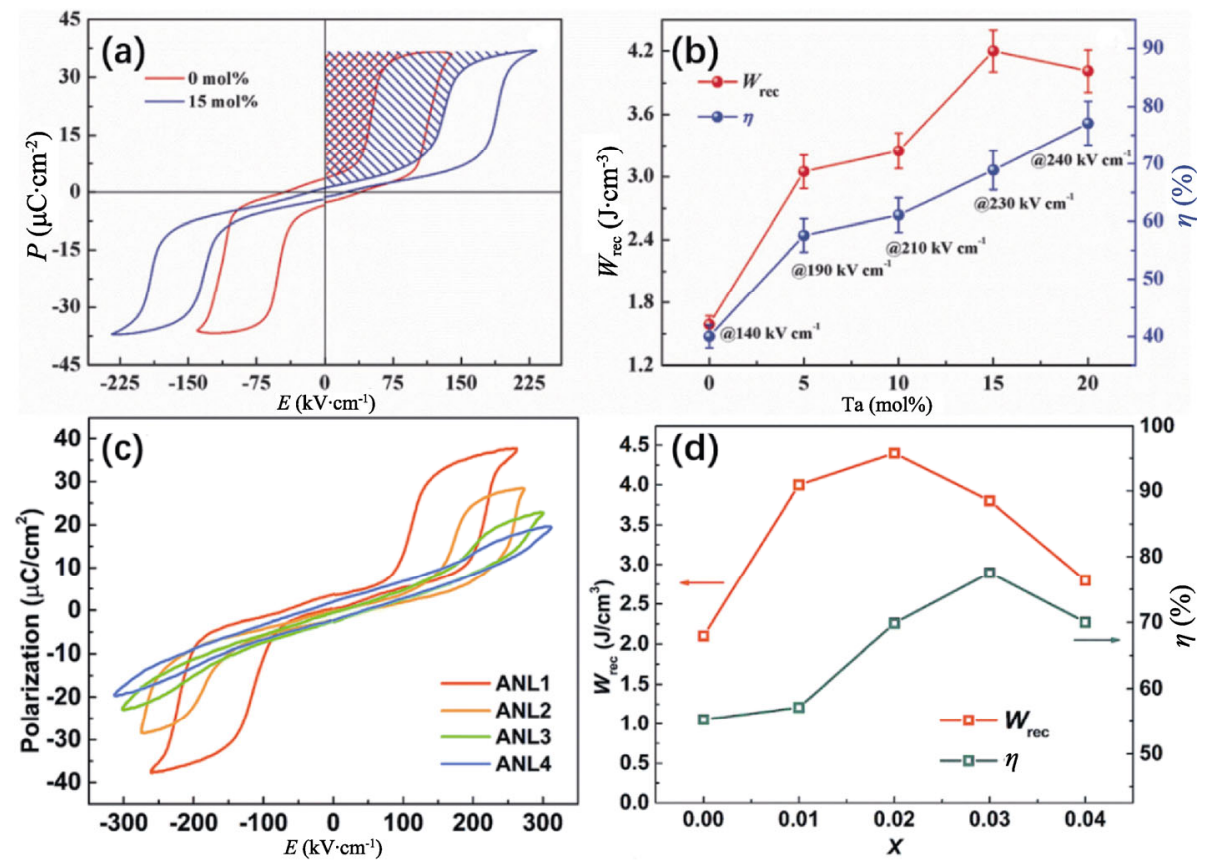

Fig. $12 P-E$ loops and energy-storage properties at room temperature of (a, b) ANT [83] and (c, d) ANL [84] ceramics. Reproduced with permission from Ref. [83], (C) WILEY-VCH Verlag GmbH \& Co. KGaA, Weinheim 2017; Ref. [84], C The Royal Society of Chemistry 2019.

Table 6 Energy-storage properties for AN-based bulk ceramics

\begin{tabular}{lccc}
\hline \multicolumn{1}{c}{ Dielectric ceramic } & $\begin{array}{c}W_{\text {rec }} \\
\left(\mathrm{J} \cdot \mathrm{cm}^{-3}\right)\end{array}$ & $\begin{array}{c}E_{\mathrm{b}} \\
\left(\mathrm{MV} \cdot \mathrm{m}^{-1}\right)\end{array}$ & $\begin{array}{c}\eta \\
(\%)\end{array}$ \\
\hline $\mathrm{AN}[83]$ & 2.1 & 14 & 40 \\
$\mathrm{ANT15}[83]$ & 4.2 & 23 & 69 \\
$\mathrm{ANL} 2[84]$ & 4.4 & 27.3 & 73 \\
$\mathrm{Ag}_{0.91} \mathrm{Sm}_{0.01} \mathrm{NbO}_{3}[85]$ & 5.2 & 29 & 68 \\
$\mathrm{AN}-0.1 \mathrm{wt} \% \mathrm{WO}_{3}[86]$ & 3.3 & 20 & 50 \\
$\mathrm{Ag}_{0.97} \mathrm{Bi}_{0.01} \mathrm{NbO}_{3}[87]$ & 2.6 & 17.5 & 55 \\
$\mathrm{Ag}_{0.88} \mathrm{Gd}_{0.04} \mathrm{NbO}_{3}[88]$ & 4.5 & 29 & 64 \\
\hline
\end{tabular}

$0.9 \mathrm{NaNbO}_{3}-0.06 \mathrm{BaZrO}_{3}-0.04 \mathrm{CaZrO}_{3} \quad(0.9 \mathrm{NN}-0.06 \mathrm{BZ}-$ $0.04 \mathrm{CZ}$ ) ceramic possessed a $W_{\text {rec }}$ of $1.59 \mathrm{~J} \cdot \mathrm{cm}^{-3}$ at an $E_{\mathrm{b}}$ of $23 \mathrm{MV} \cdot \mathrm{m}^{-1}$, but the $\eta$ was only $\sim 30 \%$. Wei et al. [95] chose the relaxor ferroelectric $\mathrm{Sr}_{0.7} \mathrm{Bi}_{0.2} \mathrm{TiO}_{3}$ (SBT) to partially replace the $\mathrm{NaNbO}_{3}$ ceramics, which introduced nanodomains and hindered the generation of field-induced ferroelectric phases, allowing the material to combine a large $P_{\max }$ with a near-zero $P_{\mathrm{r}}$. This led to the realization of a large $W_{\text {rec }}$ of $4.5 \mathrm{~J} \cdot \mathrm{cm}^{-3}$ and an ultra-high $\eta$ of $90.3 \%$ in the $0.8 \mathrm{NN}-0.2 \mathrm{SBT}$ ceramic at an $E_{\mathrm{b}}$ of $28.8 \mathrm{MV} \cdot \mathrm{m}^{-1}$, as shown in Figs. 13(c) and 13(d).

The $\mathrm{NaNbO}_{3}-\mathrm{BiMeO}_{3}$ ceramics have also been extensively studied, including $\mathrm{NaNbO}_{3}-\mathrm{Bi}\left(\mathrm{Mg}_{2 / 3} \mathrm{Ta}_{1 / 3}\right) \mathrm{O}_{3}$ (NN-BMT) [92], $\mathrm{NaNbO}_{3}-\mathrm{Bi}\left(\mathrm{Zn}_{0.5} \mathrm{Ti}_{0.5}\right) \mathrm{O}_{3}$ (NN-BZT) [96,97], $\mathrm{NaNbO}_{3}-\mathrm{Bi}\left(\mathrm{Mg}_{0.5} \mathrm{Zr}_{0.5}\right) \mathrm{O}_{3}$ (NN-BMZ) [98],
$\mathrm{NaNbO}_{3}-\mathrm{Bi}\left(\mathrm{Mg}_{2 / 3} \mathrm{Nb}_{1 / 3}\right) \mathrm{O}_{3} \quad(\mathrm{NN}-\mathrm{BMN}) \quad[99,100]$, $\mathrm{NaNbO}_{3}-\mathrm{Bi}\left(\mathrm{Ni}_{0.5} \mathrm{Zr}_{0.5}\right) \mathrm{O}_{3}$ (NN-BNZ) [101], $\mathrm{NaNbO}_{3}-$ $\mathrm{Bi}\left(\mathrm{Ni}_{0.67} \mathrm{Ta}_{0.33}\right) \mathrm{O}_{3}$ (NN-BNT) [102], and $\mathrm{NaNbO}_{3}-$ $\mathrm{Bi}\left(\mathrm{Ni}_{2 / 3} \mathrm{Nb}_{1 / 3}\right) \mathrm{O}_{3}(\mathrm{NN}-\mathrm{BNN})$ [103]. With the addition of $\mathrm{BiMeO}_{3}$, the long-range order in the $\mathrm{NaNbO}_{3}-$ $\mathrm{BiMeO} \mathrm{O}_{3}$ ceramic was destroyed, leading to a random local field, polar nanoregions (PNRs), and decreased $P_{\mathrm{r}}$. Hence, a high $E_{\mathrm{b}}$ and high energy-storage characteristics could be simultaneously obtained. The $0.85 \mathrm{NN}-0.15 \mathrm{BNT}$ ceramic [102] had a very high $W_{\text {rec }}$ of $5.53 \mathrm{~J} \cdot \mathrm{cm}^{-3}$ and $\eta$ of $82 \%$ at $57.5 \mathrm{MV} \cdot \mathrm{m}^{-1}$, and the $0.78 \mathrm{NN}-0.22 \mathrm{BMT}$ [92] ceramic had a high $W_{\text {rec }}$ of $5.01 \mathrm{~J} \cdot \mathrm{cm}^{-3}$ and $\eta$ of $86.1 \%$ at $62.7 \mathrm{MV} \cdot \mathrm{m}^{-1}$, as shown in Figs. 14(a) and 14(b).

Qi et al. [90] studied $0.76 \mathrm{NaNbO}_{3}-0.24 \mathrm{Bi}_{0.5} \mathrm{Na}_{0.5} \mathrm{O}_{3}$ $(0.76 \mathrm{NN}-0.24 \mathrm{BNT})$ ceramic. The introduction of BNT disrupted the long-range ordered antiferroelectric domains, which not only enhanced the driving electric field for the antiferroelectric to ferroelectric phase transition, but also decreased the polarization hysteresis between the loading and unloading. Additionally, smaller phase switching currents would also improve the $E_{\mathrm{b}}$. The orthorhombic Pnma symmetry antiferroelectric phase and relaxor characteristics of the $0.76 \mathrm{NN}-$ $0.24 \mathrm{BNT}$ ceramic contributed to the record $W_{\text {rec }}$ of $12.2 \mathrm{~J} \cdot \mathrm{cm}^{-3}$ with an acceptable $\eta$ of $69 \%$ at $68 \mathrm{MV} \cdot \mathrm{m}^{-1}$ (Figs. 14(c) and 14(d)), as well as the good thermal 
stability of the $W_{\text {rec }}\left(>7.4 \mathrm{~J} \cdot \mathrm{cm}^{-3}\right)$ and $\eta(>73 \%)$ values at $45 \mathrm{MV} \cdot \mathrm{m}^{-1}$ up to a temperature of $200{ }^{\circ} \mathrm{C}$.

Overall, the energy-storage properties of some recently reported $\mathrm{NaNbO}_{3}$-based ceramics are listed in Table 7 .
Introducing the appropriate relaxor end member into the $\mathrm{NaNbO}_{3}$ ceramics could lead to the formation of relaxor ferroelectrics or antiferroelectrics with an ultrahigh $E_{\mathrm{b}}, W_{\text {rec }}$, and acceptable $\eta$.
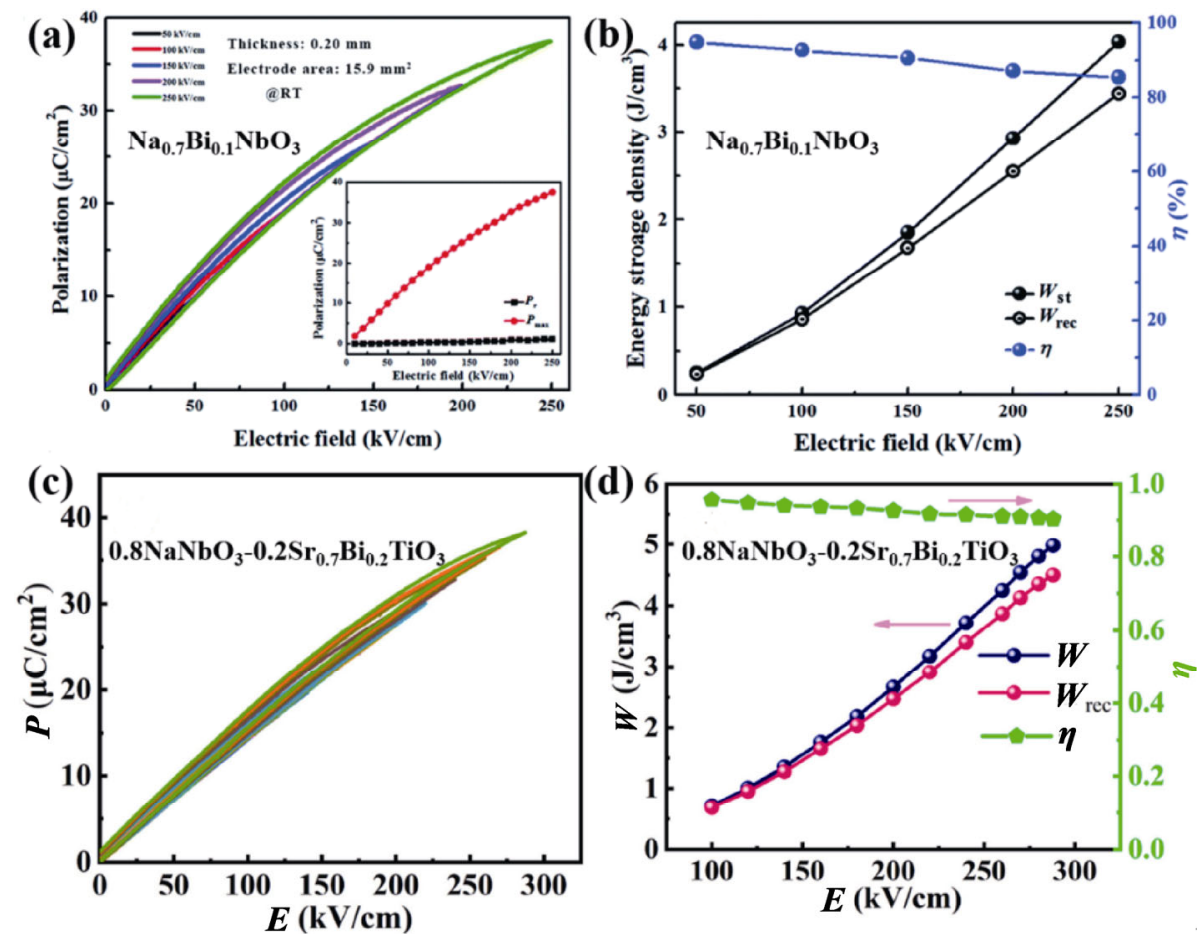

Fig. 13 (a) $P-E$ loops and (b) energy-storage properties of NBN ceramic at room temperature. Reproduced with permission from Ref. [89], (C) The Royal Society of Chemistry 2018. (c) $P-E$ loops and (d) energy-storage properties of 0.8 NN-0.2SBT ceramic at room temperature. Reproduced with permission from Ref. [95], C Elsevier Ltd and Techna Group S.r.l. 2020.
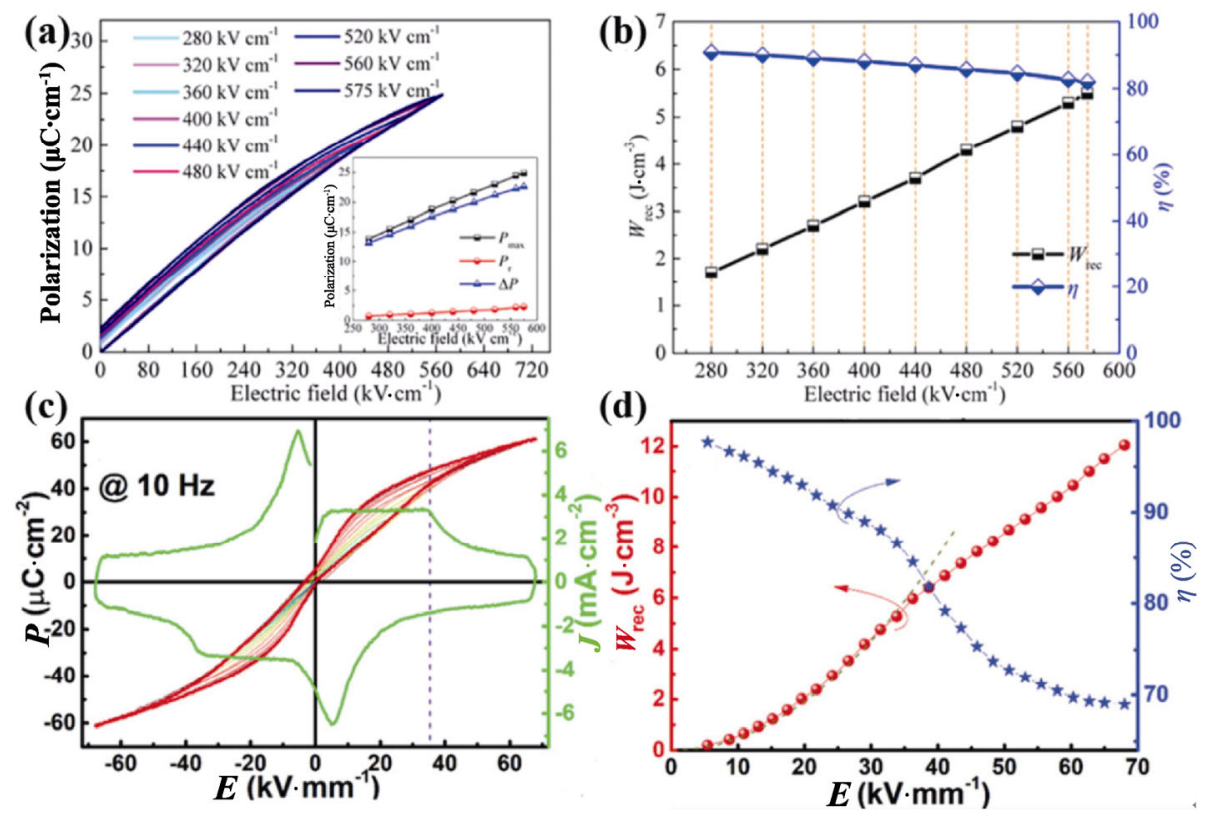

Fig. 14 (a) $P-E$ loops and (b) energy-storage properties of $0.85 \mathrm{NN}-0.15 \mathrm{BNT}$ ceramic at room temperature. Reproduced with permission from Ref. [102], (C) American Chemical Society 2020. (c) $P-E$ loops, current-electric field curve under $68 \mathrm{MV} \cdot \mathrm{m}^{-1}$, and (d) energy-storage properties of $0.85 \mathrm{NN}-0.15 \mathrm{BNT}$ ceramic at room temperature. Reproduced with permission from Ref. [90], (C) WILEY-VCH Verlag GmbH \& Co. KGaA, Weinheim 2019. 
The energy-storage properties of $\mathrm{BaTiO}_{3}$-based, $\mathrm{K}_{0.5} \mathrm{Na}_{0.5} \mathrm{NbO}_{3}$-based, $\mathrm{BiFeO}_{3}$-based, $\mathrm{Bi}_{0.5} \mathrm{Na}_{0.5} \mathrm{TiO}_{3^{-}}$ based, and $\mathrm{NaNbO}_{3}$-based ceramics are shown in Fig. 15. Overall, the $\mathrm{BaTiO}_{3}$-based ceramics, especially $\mathrm{BaTiO}_{3}-\mathrm{BiMeO}_{3}$ solid solutions, usually possess a very high $\eta$ with acceptable $W_{\text {rec }}$. The $\mathrm{K}_{0.5} \mathrm{Na}_{0.5} \mathrm{NbO}_{3}$ based ceramics possess a high $W_{\text {rec }}$, but the $\eta$ was relatively low. $\mathrm{BiFeO}_{3}$-based and $\mathrm{Bi}_{0.5} \mathrm{Na}_{0.5} \mathrm{TiO}_{3}$-based ceramics show a very high $W_{\text {rec }}$, which can be attributed to the very high polarization caused by the high content of $\mathrm{Bi}^{3+}$. $\mathrm{NaNbO}_{3}$-based ceramics usually possess an ultra-high $W_{\text {rec }}$. Introducing a relaxor member into $\mathrm{Bi}_{0.5} \mathrm{Na}_{0.5} \mathrm{TiO}_{3}$-based and $\mathrm{NaNbO}_{3}$-based ceramics could lead to the formation of relaxor antiferroelectric solid solutions, which also possess a relatively high $\eta$.

Table 7 Energy-storage properties of $\mathrm{NaNbO}_{3}$-based bulk ceramics

\begin{tabular}{|c|c|c|c|}
\hline Dielectric ceramic & $\begin{array}{c}W_{\text {rec }} \\
\left(\mathrm{J} \cdot \mathrm{cm}^{-3}\right)\end{array}$ & $\begin{array}{c}E_{\mathrm{b}} \\
\left(\mathrm{MV} \cdot \mathrm{m}^{-1}\right)\end{array}$ & $\begin{array}{c}\eta \\
(\%)\end{array}$ \\
\hline $\mathrm{Na}_{0.7} \mathrm{Bi}_{0.1} \mathrm{NbO}_{3}(\mathrm{NBN})$ [89] & 4.03 & 25 & 85.4 \\
\hline $0.8 \mathrm{NN}-0.2 \mathrm{ST}[91]$ & 3.02 & 32.3 & 80.7 \\
\hline $0.9 \mathrm{NN}-0.06 \mathrm{BZ}-0.04 \mathrm{CZ}$ [94] & 1.59 & 23 & 30 \\
\hline $0.8 \mathrm{NN}-0.2 \mathrm{SBT}[95]$ & 4.5 & 28.8 & 90.3 \\
\hline $0.93 \mathrm{NN}-0.07 \mathrm{BMZ}[98]$ & 2.31 & 25.5 & 80.2 \\
\hline $0.91 \mathrm{NN}-0.09 \mathrm{BZT}[96]$ & 2.2 & 25 & 62.7 \\
\hline $0.9 \mathrm{NN}-0.1 \mathrm{BMN}$ [99] & 2.8 & 30 & 82 \\
\hline $0.88 \mathrm{NN}-0.12 \mathrm{BNZ}[101]$ & 4.9 & 50 & $\sim 73$ \\
\hline $0.91 \mathrm{NN}-0.09 \mathrm{BZT}$ [97] & 2.1 & 20 & 76 \\
\hline $0.85 \mathrm{NN}-0.15 \mathrm{BNN}$ [103] & 3.31 & 44 & 80.9 \\
\hline $0.78 \mathrm{NN}-0.22 \mathrm{BMN}[100]$ & 3.51 & 51 & 87 \\
\hline $0.85 \mathrm{NN}-0.15 \mathrm{BNT}$ [102] & 5.53 & 57.5 & 82 \\
\hline $0.78 \mathrm{NN}-0.22 \mathrm{BMT}[92]$ & 5.01 & 62.7 & 86.1 \\
\hline $0.76 \mathrm{NN}-0.24 \mathrm{BNT}[90]$ & 12.2 & 68 & 69 \\
\hline
\end{tabular}

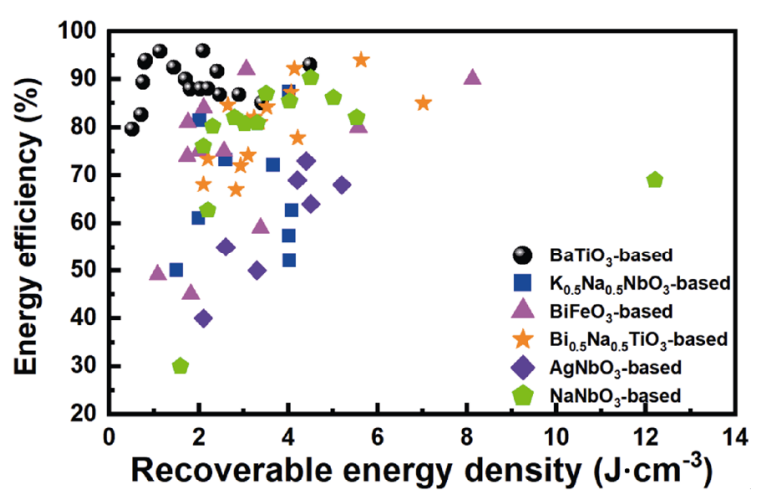

Fig. 15 Comparison of the energy-storage properties at room temperature between various lead-free non-linear dielectric ceramics $[25,27,28,31-33,35-39,40-46,48-55$, 57-92,94-103].

\section{2 Structure optimization}

Apart from composition modification, structural optimization is also an important and effective approach for enhancing the energy-storage properties of ceramic dielectrics, especially for increasing the $E_{\mathrm{b}}$. In this section, common approaches to structure optimization, such grain size engineering, core-shell structure construction, and layer-by-layer engineering, are reviewed to guide the structural design of new ceramic material systems.

\subsubsection{Grain size engineering}

The main obstacle that limits the energy-storage properties of ceramic dielectrics is the low $E_{\mathrm{b}}$. Generally, the $E_{\mathrm{b}}$ of a ceramic dielectric is highly related to the grain size $(G)$, and it is considered to fit the inverse power law $\left(E_{\mathrm{b}} \propto G^{-1 / 2}\right)[48,104]$. Significant effort has been made toward realizing finer grains and thus enhancing the $E_{\mathrm{b}}$ of dielectric ceramics.

Preparing nanosized raw ceramic materials is one effective approach to obtain dielectric ceramics with fine grains. In our previous study, BT particles with an average size of $30-80 \mathrm{~nm}$ were fabricated via sand milling [105]. After chemical coating, dense sintered ceramics with various grain size range from $49 \pm 17 \mathrm{~nm}$ (BT50) to $105 \pm 44 \mathrm{~nm}$ (BT100) were obtained, as shown in Fig. 16. Owing to the decreasing grain size, the $E_{\mathrm{b}}$ of BT50 reached $18.5 \mathrm{MV} \cdot \mathrm{m}^{-1}$, which is $42 \%$ higher than that of BT100.

The grain size effect on the $E_{\mathrm{b}}$ of dielectric ceramics is modeled using a phase-field model as well [106]. Four nanostructured ferroelectric ceramic samples with different grain sizes from 50 to $125 \mathrm{~nm}$ were constructed via Voronoi tessellations. The final patterns of the breakdown path are presented in Fig. 17. The nominal breakdown strength of a ferroelectric ceramic with a grain size of $50 \mathrm{~nm}$ is almost $50 \%$ higher than for a grain size of $125 \mathrm{~nm}$, and these results are in good agreement with the experimental work. As the grain size reduced, the volume fraction of the grain boundaries gradually increased. The grain boundary is the "strong" part of a ceramic under an applied electric field, and it is difficult to damage because of its higher breakdown energy. Similarly, the ceramic grain is the "weak" part and can easily be broken down compared with the grain boundary. Therefore, the enhanced $E_{\mathrm{b}}$ of the ferroelectric ceramic with smaller grains is aided by the larger number of grain boundaries. 

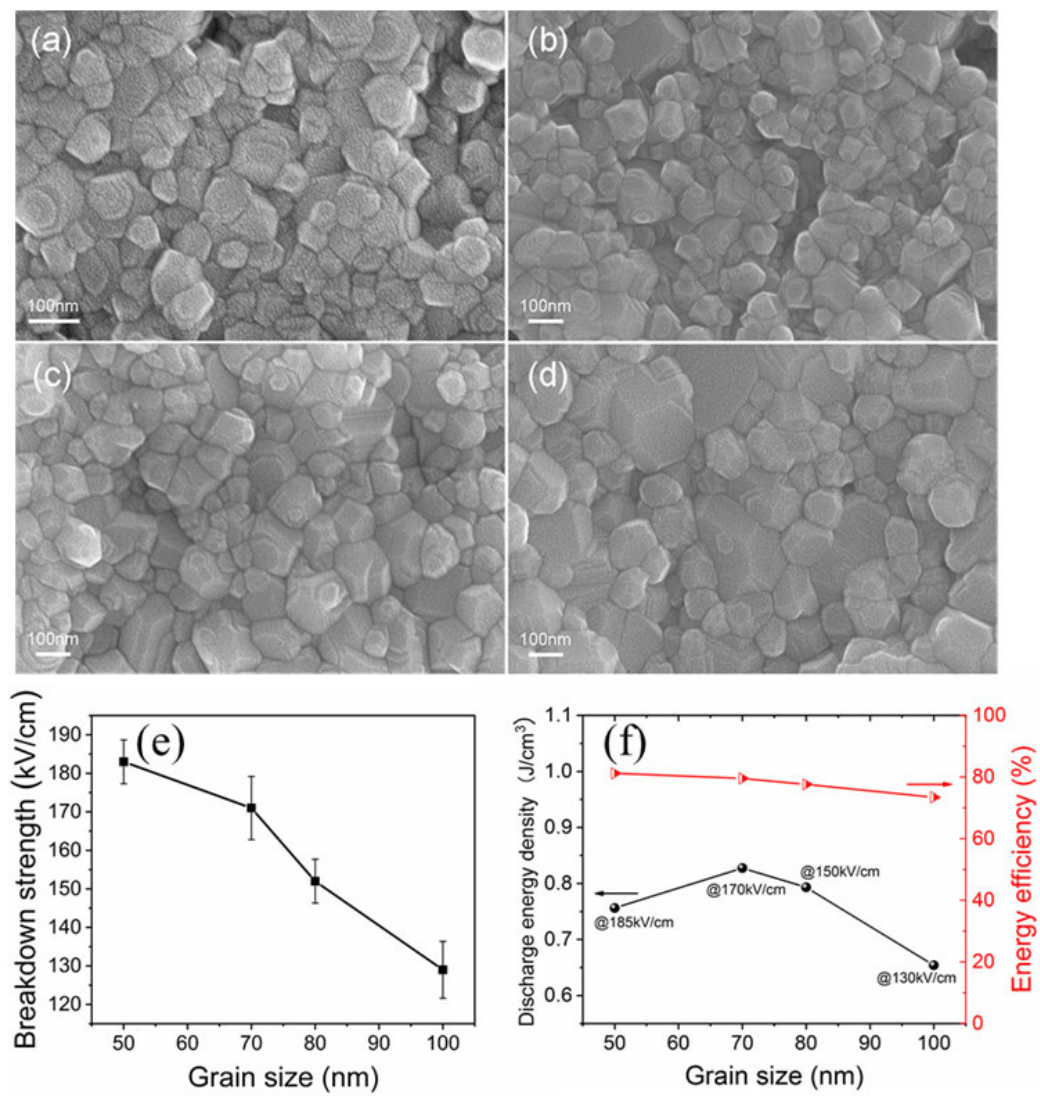

Fig. 16 Microstructure of $\mathrm{BaTiO}_{3}$-based ceramics with various grain sizes: (a) $49 \pm 17 \mathrm{~nm}$, (b) $67 \pm 28 \mathrm{~nm}$, (c) $77 \pm 34 \mathrm{~nm}$, and (d) $105 \pm 44 \mathrm{~nm}$. (e) Dielectric breakdown strength as a function of the grain size with the standard deviations. (f) Maximum recoverable energy density and the corresponding efficiency of the $\mathrm{BaTiO}_{3}$-based ceramics as a function of grain size. Reproduced with permission from Ref. [105], (c) The American Ceramic Society 2020.
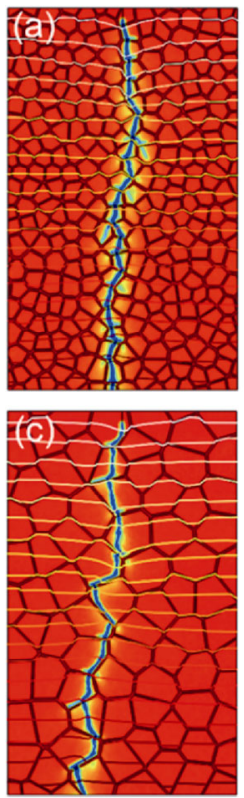
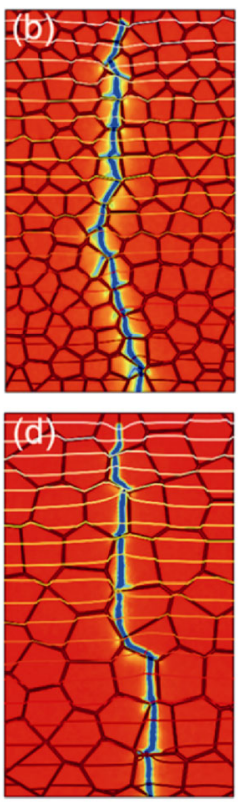

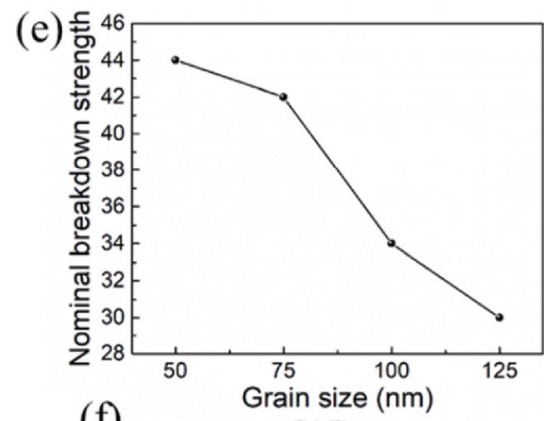

(f)
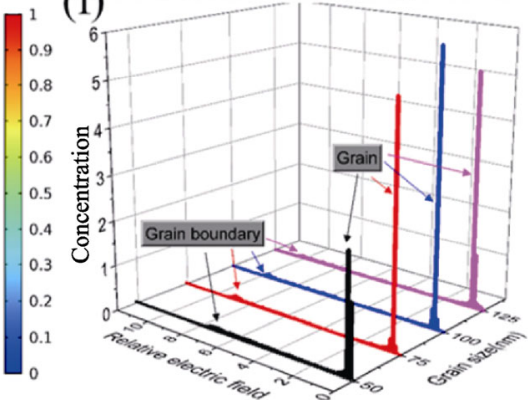

Fig. 17 Breakdown path featured for different grain sizes: (a) $50 \mathrm{~nm}$, (b) $75 \mathrm{~nm}$, (c) $100 \mathrm{~nm}$, and (d) $125 \mathrm{~nm}$. The contour lines are the equipotential lines of the then-current electric field. (e) Relation of the nominal breakdown strength against grain size. (f) Relative local electric field distribution of these ferroelectric ceramics at various grain sizes under a given applied electric field of $30 \mathrm{MV} \cdot \mathrm{m}^{-1}$. Reproduced with permission from Ref. [106], (c) The American Ceramic Society 2018. 
Element doping is another effective approach to prevent the diffusion of the grain boundary, and thus, inhibit grain growth. By introducing $\mathrm{BiFeO}_{3}$ to $\mathrm{K}_{0.5} \mathrm{Na}_{0.5} \mathrm{NbO}_{3}$ ceramics, Yang et al. [48] found that the grain size was significantly reduced from 5.4 to $0.15 \mu \mathrm{m}$. Finally, a large recoverable energy density of $2 \mathrm{~J} \cdot \mathrm{cm}^{-3}$ was obtained in the $0.9 \mathrm{~K}_{0.5} \mathrm{Na}_{0.5} \mathrm{NbO}_{3}-0.1 \mathrm{BiFeO}_{3}$ ceramic at $20.6 \mathrm{MV} \cdot \mathrm{m}^{-1}$. Similarly, Ren et al. [107] introduced $\mathrm{SrZrO}_{3}$ into the $\mathrm{K}_{0.5} \mathrm{Na}_{0.5} \mathrm{NbO}_{3}$ ceramic to engineer a fine grain size. The grain size could be sharply reduced from 4.88 to $190 \mathrm{~nm}$, as shown in Fig. 18. Interestingly, the obtained submicron grains not only improved the transparency of the ceramics, but also increased the $E_{\mathrm{b}}$, and thus the recoverable energy density.

Apart from the grain size, the distribution of the grain size, or rather the grain size uniformity, can have a strong influence on the dielectric breakdown strength of the dielectric ceramics, because breakdown often occurs at the weakest point with the largest breakdown probability. The grain size distribution effect of the $E_{\mathrm{b}}$ has been studied based on the phase-field breakdown model [108]. Figures 19(a)-19(d) show four typical samples with $\alpha=0.1,0.3,0.5$, and 0.7 ( $\alpha$ is a parameter used to quantify the regularity of the 2D Voronoi tessellation) and the corresponding standard deviations (SD, representing the non-uniformity degree) of $83.7,81.9,80.1$, and 78.7 , respectively. We can see that with increasing $\alpha$, the grain distribution becomes more uniform. This conclusion can further be drawn by the distribution fittings shown in Fig. 19(e), which shows that an increase of $\alpha$ results in a narrower distribution of the grain size. The nominal breakdown strength of these four ceramic samples as a function of the SD is plotted in Fig. 19(f). It is clear that as the SD decreases, the distribution of the grain size becomes more uniform and the breakdown strength is distinctly enhanced. Specifically, the dielectric breakdown strength of the ceramic with an $\mathrm{SD}=78.7$ is nearly $35 \%$ higher than that of the sample with an $\mathrm{SD}=83.7$.

\subsubsection{Core-shell structure}

Due to the high breakdown energy, $\mathrm{SiO}_{2}, \mathrm{Al}_{2} \mathrm{O}_{3}$, and other materials are often used for microstructure modification of ferroelectric ceramics to build a "coreshell" structure in the ferroelectric ceramics. The shell layer can effectively improve the $E_{\mathrm{b}}$ of dielectric ceramics. Chemical coating is a quite effective and simple method to modify the surface of ceramic particles and to form the core-shell structures [109,110]. First, ceramic particles are dispersed in aqueous or organic solutions to form uniform slurries. Then, the ceramic particles are coated by adding the doping elements into the uniform slurry in the form of inorganic solutions or organic solutions under an appropriate $\mathrm{pH}$ value

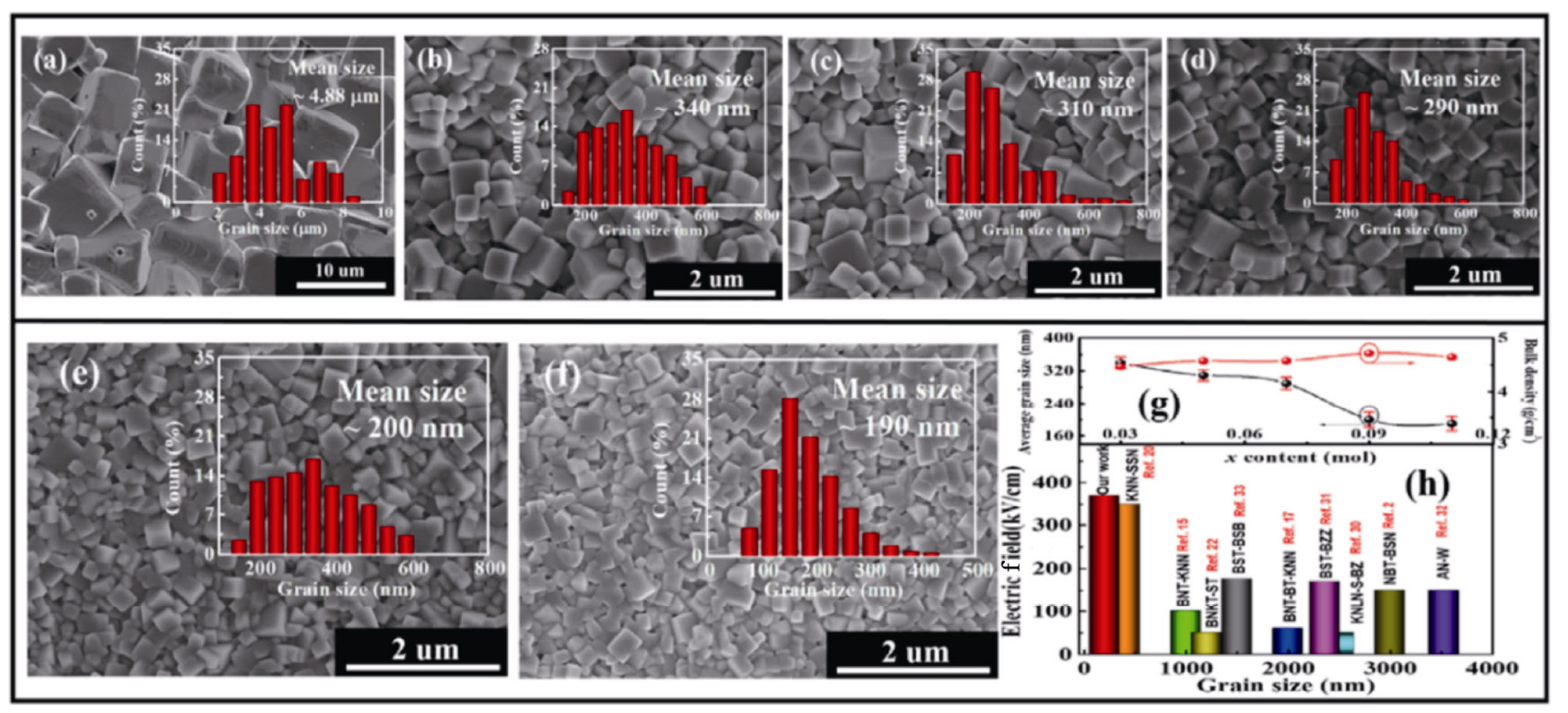

Fig. 18 SEM images and grain size distribution of the $(1-x) \mathrm{K}_{0.5} \mathrm{Na}_{0.5} \mathrm{NbO}_{3}-x \mathrm{SrZrO}_{3}$ ceramics: (a) $x=0$, (b) $x=0.03$, (c) $x=$ 0.05 , (d) $x=0.07$, (e) $x=0.09$, and (f) $x=0.11$. (g) Dependence of the mean grain size and bulk density on the composition. (h) Comparison of $E_{\mathrm{b}}$ and grain size between $0.91 \mathrm{~K}_{0.5} \mathrm{Na}_{0.5} \mathrm{NbO}_{3}-0.09 \mathrm{SrZrO}_{3}$ and other typical lead-free ceramics. Reproduced with permission from Ref. [107], (C) Elsevier B.V. 2020. 

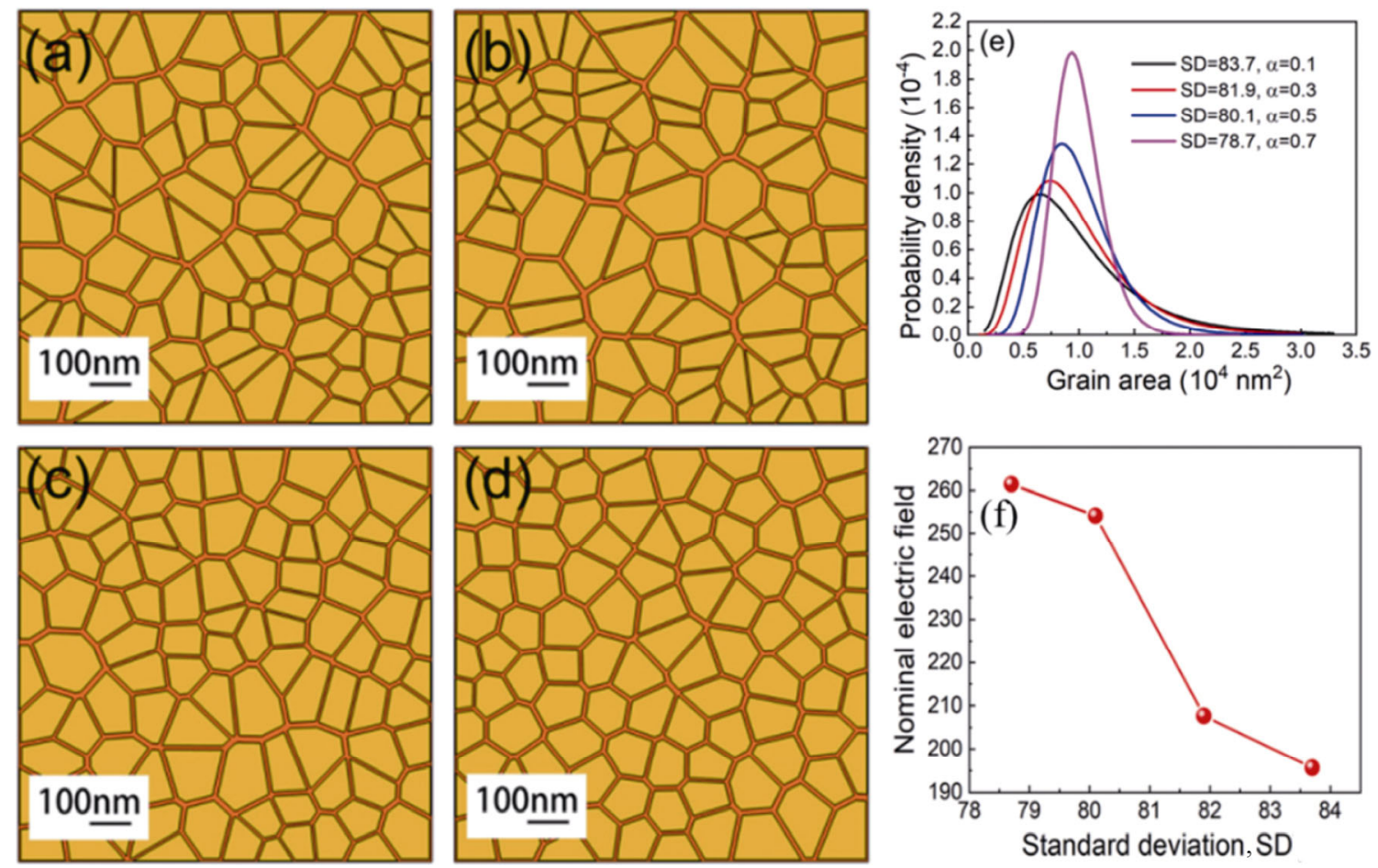

Fig. 19 Simulated samples generated with different $\alpha$ : (a) $\alpha=0.1$, (b) $\alpha=0.3$, (c) $\alpha=0.5$, and (d) $\alpha=0.7$. (e) Lognormal distribution fittings for the samples with various $\alpha$. (f) Nominal electric field as a function of the standard deviation. Reproduced with permission from Ref. [108], (C) Author(s) 2020.

through chemical coprecipitation. After drying and calcining at a certain temperature, the ceramic powders with core-shell structure will be obtained. The key issue of chemical coating is the uniformity of the coating layer, which will influence element diffusion and local distribution of the electric field. The twostep sintering method is quite effective for controlling the grain size and grain uniformity, and this enhances the breakdown strength and reliability of the core-shell structured ceramics [111].

Zhao et al. [40] coated the grain surface of $\mathrm{BaTiO}_{3}-$ based ceramics with a $2 \mathrm{~nm}$-thick layer of $\mathrm{Al}_{2} \mathrm{O}_{3}$, which allowed the $E_{\mathrm{b}}$ of the $\mathrm{BaTiO}_{3}$-based ceramics to increase from 7.88 to $10.85 \mathrm{MV} \cdot \mathrm{m}^{-1}$, and the corresponding recoverable energy density was increased by $42 \%$. Ma et al. [112] coated $\mathrm{SiO}_{2}$ on $\mathrm{BaTiO}_{3} @ \mathrm{La}_{2} \mathrm{O}_{3}$, and the breakdown field strength was increased by 62\%. Wang et al. [113] co-coated $\mathrm{SiO}_{2}$ and $\mathrm{Al}_{2} \mathrm{O}_{3}$ on $\mathrm{Ba}_{0.4} \mathrm{Sr}_{0.6} \mathrm{TiO}_{3}$ ceramics, and the breakdown field strength was increased from 8.6 to $49.3 \mathrm{MV} \cdot \mathrm{m}^{-1}$.

\subsubsection{Layer-by-layer engineering}

Layer-by-layer engineering is a flexible modification approach for dielectric ceramics, which can combine the advantages of two different layers and enable the realization of comprehensive energy-storage properties. For example, in our previous study, a layer-by-layer structured ceramic was developed by combining the advantages of composition modification and structure modification of ferroelectric ceramics, and it enabled the attainment of a superimposed effect [114].

Next, a cross-section scanning electron microscopy (SEM) image of the layer-by-layer ceramic is presented (Fig. 21(c)), in which the $0.87 \mathrm{BaTiO}_{3}-0.13 \mathrm{Bi}$ $\left(\mathrm{Zn}_{2 / 3}\left(\mathrm{Nb}_{0.85} \mathrm{Ta}_{0.15}\right)_{1 / 3}\right) \mathrm{O}_{3}$ (BTBZNT) layers, BaTiO 33 $\mathrm{wt} \% \mathrm{Al}_{2} \mathrm{O}_{3}, 1 \mathrm{wt} \% \mathrm{SiO}_{2}$ (BTAS) layers, and the interfaces can be clearly identified. The layers can also be confirmed via line scanning of the $\mathrm{Al}$ and $\mathrm{Si}$ elements in Fig. 21(b). Notably, the interface regions exhibit less porosity compared with the BTAS and BTBNZT layers, which may be caused by interdiffusion of multiple elements. The phase structure and morphology of the two surfaces are shown in Figs. 21(a), 21(d), and 21(e), respectively. The top BTBZNT layer shows a pure perovskite phase, while a second phase of $\mathrm{BaAl}_{2} \mathrm{O}_{4}$ can be observed in the bottom BTAS layer, which is in agreement with previous work [115]. The surface SEM images of the top and the bottom layers indicate the high density of sample S2, and the grain size of BTBZNT layer $(\sim 500 \mathrm{~nm})$ is larger than that of the 

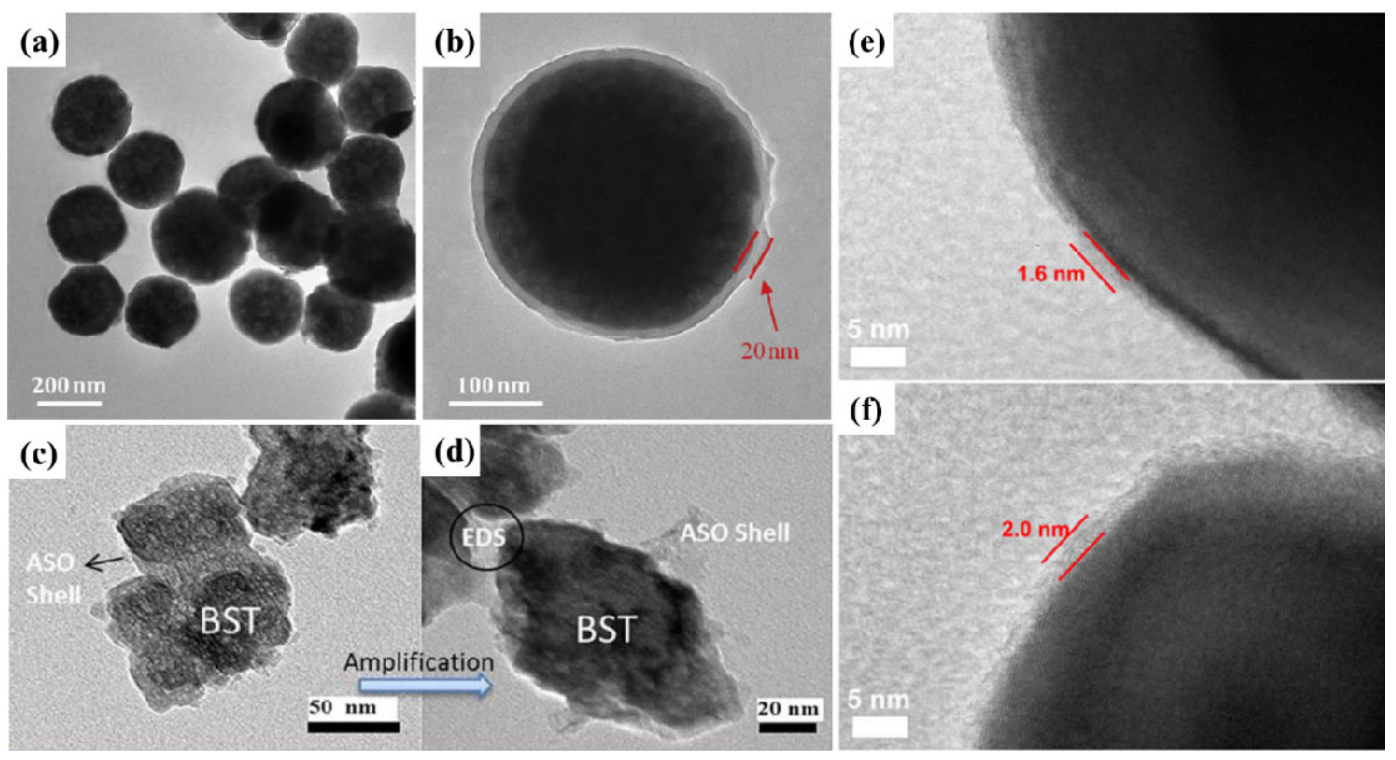

Fig. 20 FE-TEM images of $(\mathrm{a}, \mathrm{b}) \mathrm{BaTiO}_{3} @ \mathrm{La}_{2} \mathrm{O}_{3} @ \mathrm{SiO}_{2}$ particles [112], (c, d) BST-2A1S particles [113], and (e, f) BaTiO particles without and with $\mathrm{Al}_{2} \mathrm{O}_{3}$ [40]. Reproduced with permission from Ref. [112], (C) Elsevier B.V. 2016; Ref. [113], (C) Springer Science+Business Media New York 2013; Ref. [40], (C) The American Ceramic Society 2017.
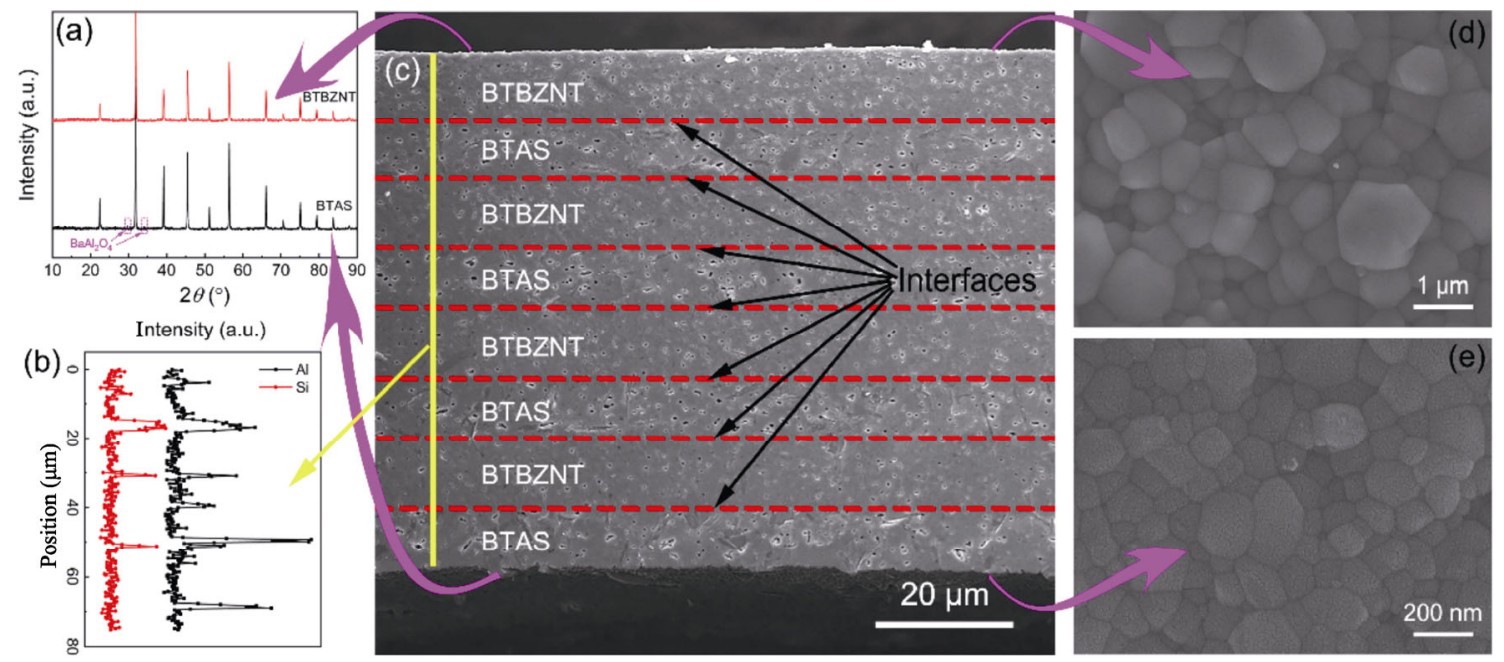

Fig. 21 Microstructure characterization of the layer-by-layer ceramics with four BTBZNT layers and four BTAS layers alternately arranged in parallel. The cross-section SEM image is shown in the middle (c), in which the BTBZNT layers, BTAS layers, and the interfaces can be clearly identified. The results can be further confirmed via line scanning of the Al and $\mathrm{Si}$ elements in (b). The XRD patterns and surface SEM images of each end of the BTBZNT and BTAS layers are presented in (a), (d), and (e), respectively. Reproduced with permission from Ref. [114], (C) The Royal Society of Chemistry 2019.

\section{BTAS layer $(\sim 100 \mathrm{~nm})$.}

By combining the complementary advantages of the two different layers and the interface effects, a recordhigh dielectric breakdown strength of $79 \mathrm{MV} \cdot \mathrm{m}^{-1}$ was obtained in layer-by-layer structured bulk ceramic when four BTBZNT layers and four BTAS layers arrange alternatingly in parallel. The corresponding recoverable energy density was $5.04 \mathrm{~J} \cdot \mathrm{cm}^{-3}$, which was clearly much higher than that of the $\mathrm{BaTiO}_{3}$-based ceramics $\left(\sim 1-2 \mathrm{~J} \cdot \mathrm{cm}^{-3}\right)$.
Recently, Yan et al. [116] proposed layer-by-layer engineering that combined high-polarization ferroelectric ceramics with a large grain size and the high breakdown strength of linear-like ceramics with a small grain size (Fig. 22). Based on this strategy, Yan et al. took advantage of the tape casting technique to design and fabricate layer-by-layer structured ceramics, and they investigated the relationship between the structure and properties in detail. The $E_{\mathrm{b}}$ could be gradually enhanced by increasing the thickness of the linear-like 


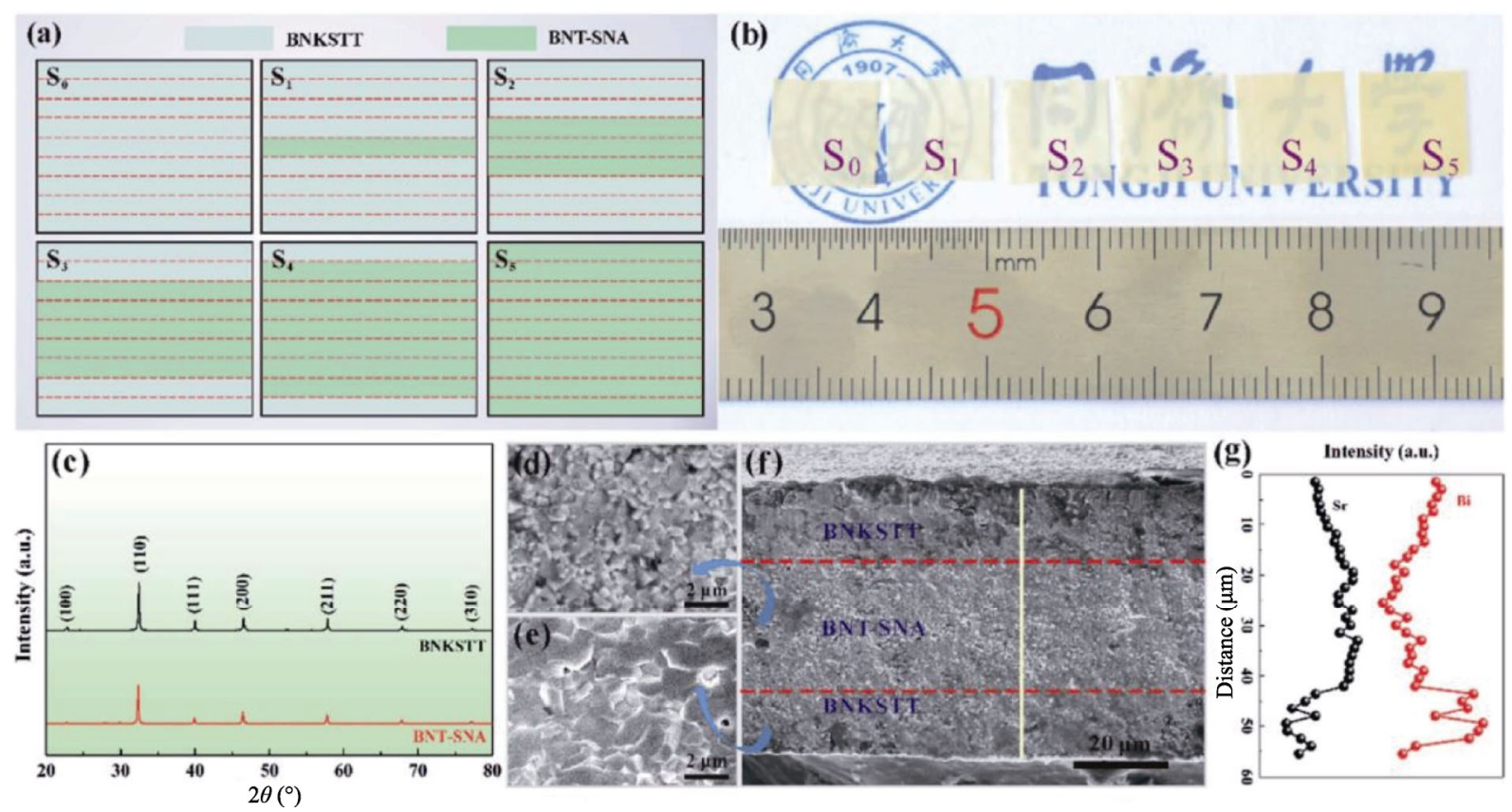

Fig. 22 (a) Schematic diagram of the prepared lead-free ceramics with sandwich structures; (b) photograph of the prepared ceramic samples; (c) XRD patterns for the samples BNKSTT (S0) and BNT-SNA (S5); cross-section images of the BNKSTT layer, the BNT-SNA layer, and S3 are presented in (d), (e), and (f), respectively; and (g) line scanning of the Bi and Sr elements for S3 in (f). Reproduced with permission from Ref. [116], (C) The Royal Society of Chemistry 2020.

ceramic layer. Interestingly, the designed layer-by-layer ceramic reached an ultra-high recoverable energy density of $6.78 \mathrm{~J} \cdot \mathrm{cm}^{-3}$ and a very high efficiency of $89.7 \%$ at a high electric field of $57.2 \mathrm{MV} \cdot \mathrm{m}^{-1}$.

Layer-by-layer engineering is one of the most effective approaches for the design of energy-storage ceramics because of flexible choice of the two different layers. Thus, one can combine the high-polarization layer and the high-breakdown-resistance layer together to achieve comprehensive energy-storage properties. However, the co-sintering of different layers is a major challenge and two-step sintering may be the optimal solution.

\section{Energy-storage MLCCs}

In this section, we introduce the preparation process and design of the inner electrode structure for energystorage MLCCs, together with the state-of-the-art lead-free energy-storage MLCCs.

\section{1 Preparation process}

The detailed structure and fabrication process for the MLCCs are shown in Fig. 23 [117]. The MLCCs consist of many ceramic dielectric layers and internal electrodes, which are alternately stacked in parallel, as shown in the center of Fig. 23. After co-sintering, metal with a low melting point was coated on both ends as external electrodes. The MLCCs were generally fabricated via the following process flow, which includes preparation of the ceramic powders, preparation of the ceramic slurry, the tape-casting process, screen printing of the internal electrodes, stacking and lamination, cutting, binder burnout and sintering, and dipping with external electrodes.

A ceramic slurry with good fluidity was prepared via ball-milling of the ceramic powders with solvent, dispersant, binder, and plasticizer in the appropriate proportion. The quality of the organic compound added into the ceramic slurry was related to the micro morphology, specific surface area, particle size distribution, and surface potential of the ceramic powders. The solvent, dispersant, and binder benefit distribution of the ceramic powders, and the binder would aid in the realization of ceramic tapes with a uniform thickness. Increasing the content of the ceramic powder and plasticizer would benefit the strength of the ceramic tapes. Ceramic powders with a narrow particle size distribution would enable the formation of flat and smooth ceramic tapes.

The ceramic slurry was coated on the polyethylene 


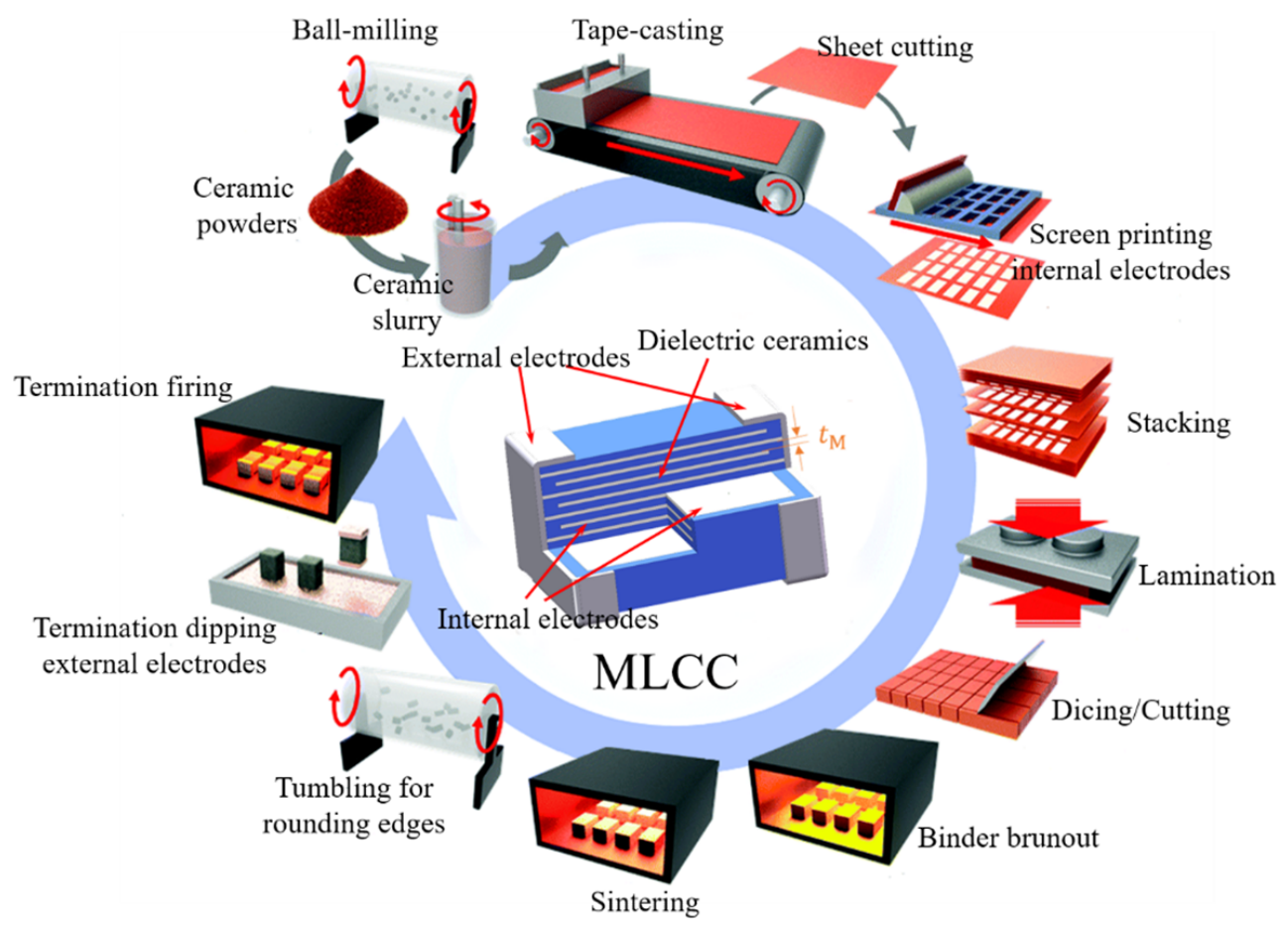

Fig. 23 Schematic diagram of MLCCs and their fabrication process. Reproduced with permission from Ref. [117], (C) The Royal Society of Chemistry 2019.

terephthalate tape via a doctor blade or a casting head to form the ceramic tapes. Good ceramic tapes must be flat and have a smooth surface, a uniform distribution, a high areal density of the ceramic powder, and no macroscopic pore defects, which can increase the adaptability of the subsequent preparation process flow and ensure MLCCs with good performance.

The internal electrodes are screen printed on one side of the ceramic tapes. Common internal electrode materials can be divided into two categories, including the base metals $\mathrm{Ni}$ and $\mathrm{Cu}$, and precious metals $\mathrm{Pd}, \mathrm{Pt}$, and $\mathrm{Ag} / \mathrm{Pd}$ alloy. For practical applications, the internal electrodes need to be selected according to the ceramic sintering process and the cost. It is worth noting that the $\mathrm{Ni}$ and $\mathrm{Cu}$ internal electrodes need to be sintered in a reducing atmosphere, and the corresponding dielectric ceramics must have anti-reduction properties. The thickness of the screen-printed internal electrode layer should be adjusted according to the thickness of the ceramic tapes. This ensures that the internal electrodes in the MLCCs are complete and continuous after sintering. Additionally, the shrinkage of the dielectric ceramics and the electrodes must be matched, which would decrease internal stress in the MLCCs and improve their mechanical strength and reliability.

After lamination and warm isostatic pressing, the stacked tapes will be cut into individual MLCC green bodies. To ensure the integrity of the MLCCs, a burnout process is required to remove the binder and prevent delamination and cracking of the MLCCs caused by rapid volatilization of the organic compounds at a high temperature. Then, the MLCC green bodies are co-fired at the ceramic sintering temperature. The heating rate, temperature, and duration of the burnout and sintering process have an important influence on the energystorage performance of the MLCCs. After sintering and tumbling to expose the internal electrodes, an external electrode paste will be used to terminate the opposite ends of the MLCCs for electrical measurements and applications.

\section{2 Electrode structure design}

The energy-storage density of the ceramic dielectrics mentioned above is limited by their low $E_{\mathrm{b}}$. The utilization of MLCCs for energy-storage applications has drawn increasing attention because the thickness of the dielectric layer is much smaller than that of bulk ceramics, which would significantly enhance the $E_{\mathrm{b}}$ of the MLCCs, and therefore, improve the energy-storage performance.

Marked efforts have been made to improve the energy-storage properties of ceramic dielectrics, while 
the structure of the internal electrodes has generally been ignored, which may strongly affect the $E_{\mathrm{b}}$ of the MLCCs. Notably, the $E_{\mathrm{b}}$ plays a dominant role in the energy-storage performance.

MLCCs are fabricated with tens of thin dielectric layers arranged in parallel between internal electrodes. When an electric field is applied, the local electric field is concentrated around the tip of the internal electrodes, which favors the initiation and propagation of breakdown path inside the MLCCs and finally greatly reduces the $E_{\mathrm{b}}$. The internal electrode structure, i.e., the margin length, would affect the distribution of the local electric field in the MLCCs. Different margin lengths would lead to different degrees of local field concentration around the electrode tips. Therefore, the design of the margin length is crucial for the MLCCs to achieve a high dielectric breakdown strength and a high energy density.

A finite element method (FEM) is widely used to model and design the microstructure of materials and devices at the macroscale. Wang et al. [118] calculated the distribution of the electric field via two-dimensional FEM by varying some geometric parameters of the MLCCs. The optimal geometric parameters were suggested after analysis of the concentration of the local electric field. Additionally, we calculated the distribution of the electric field inside the MLCCs based on a thermal-mechanical-electrical coupled FEM for more precise simulation results [119].

At the mesoscopic scale, a phase-field electromechanical breakdown model was developed in our previous work to simulate the dielectric breakdown behavior in MLCCs [120-122]. The final patterns of the breakdown path inside MLCCs with various margin lengths are shown in Figs. 24(a)-24(c). Generally, the breakdown path all display similar branch-like tree patterns. The breakdown path initiates at the end of the internal electrode tip and the entire breakdown occurs when the electrodes are bridged by the breakdown pathway. Figures 24(d) and 24(e) present the nominal field-charge-density relation and the nominal breakdown strength as a function of the margin length, respectively. It is clear that as the margin length increases, the nominal breakdown strength of the MLCCs would be significantly enhanced.

The advantages of this model are that the evolution of polarization vectors and the breakdown path can be visualized and the nominal breakdown strength can be calculated as well. Further, the phase-field electromechanical breakdown model can be used to analyze the thickness-dependent, stress-dependent, and defect-dependent breakdown behavior in the MLCCs.
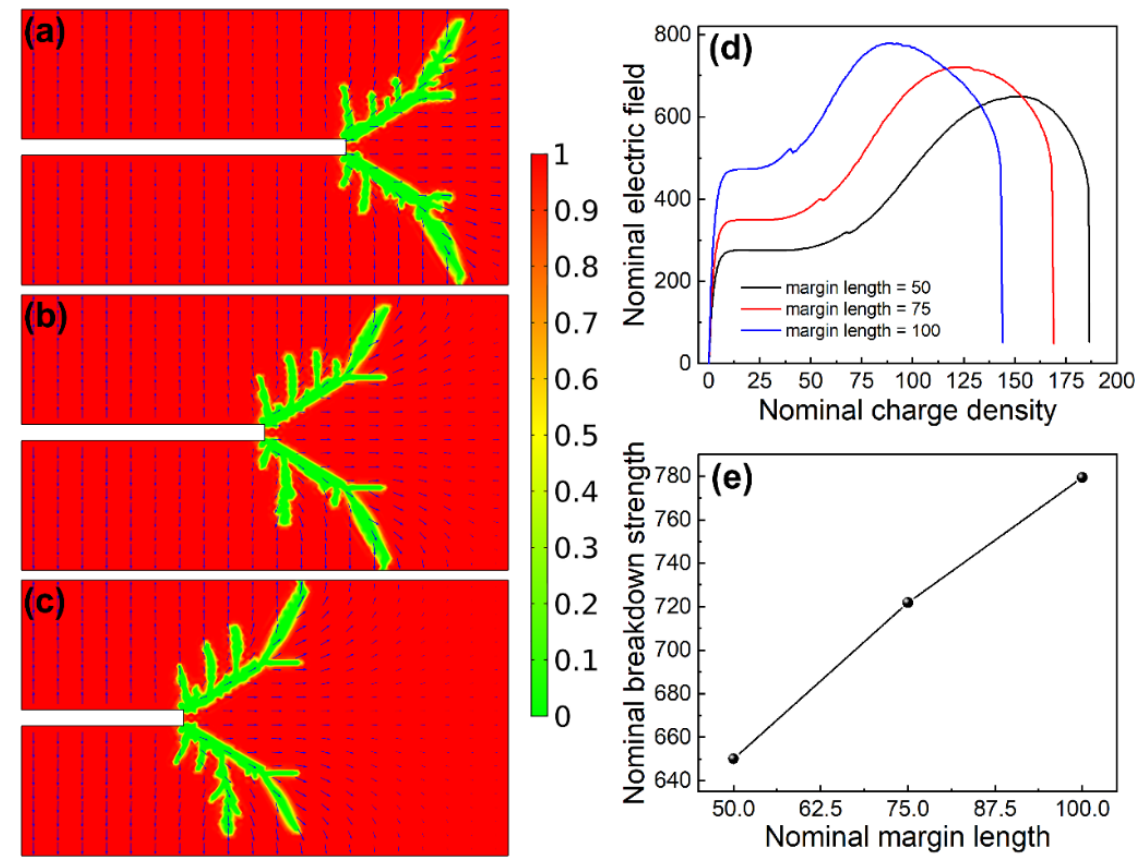

Fig. 24 Final patterns of the breakdown path for the selected region of MLCCs with various nominal margin lengths of (a) 50, (b) 75, and (c) 100. The shading represents the damage variable $s$ and the arrows indicate the polarization vectors $P$. (d) Nominal field-charge-density relation of MLCCs with various margin lengths. (e) Nominal breakdown strength as a function of the MLCC margin length. Reproduced with permission from Ref. [121], C Author(s) 2019. 
Apart from simulation of the electrical properties, Jiang et al. [123], Park et al. [124], Chen et al. [125], Huang et al. [126], and Franken et al. [127] independently calculated the distribution of stress in MLCCs with different internal electrode structures, obtained via various processes, including sintering, soldering, and the board flex test. In addition to leading to mechanical failure of the MLCCs, these stresses are related to the non-uniformity of electric field in the MLCCs.

The margin length dependent energy-storage performance was confirmed experimentally [121]. The 1210-type MLCC with internal 60Ag/40Pd electrodes were fabricated via the tape-casting technique. Various margin lengths of 100,200 , and $400 \mu \mathrm{m}$ were adopted. From Figs. 25(a) and 25(b), it is clear that the hysteresis loops for these MLCCs under the same applied field were almost the same because the dielectric layer materials were totally identical. However, because of the difference in the breakdown strength, the maximum polarization measured was quite different. As the margin length increased from 100 to $400 \mu \mathrm{m}$, the $E_{\mathrm{b}}$ was enhanced from 78.3 to $89.5 \mathrm{MV} \cdot \mathrm{m}^{-1}$ as seen in Fig. 25(c). The calculated recoverable energy density and
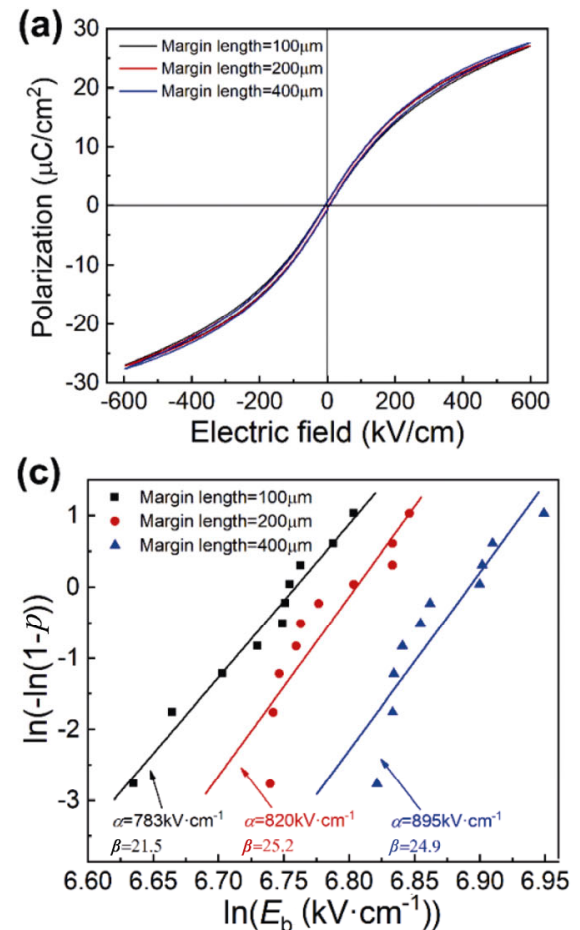

energy efficiency of MLCCs with various margin lengths as a function of the applied electric field is plotted in Fig. 25(d). The recoverable energy density and efficiency of various MLCCs are almost the same below an applied electric field of $64 \mathrm{MV} \cdot \mathrm{m}^{-1}$. The observation that the MLCCs fabricated in our lab display a stable and reliable performance is quite positive. A large $W_{\text {rec }}$ of $7.8 \mathrm{~J} \cdot \mathrm{cm}^{-3}$ can be achieved under an applied electric field of $79 \mathrm{MV} \cdot \mathrm{m}^{-1}$ in the MLCC with a margin length of $400 \mu \mathrm{m}$, which is $30 \%$ higher than that for a margin length of $100 \mu \mathrm{m}$ because of the enhanced breakdown strength. The experimental results clearly demonstrate the importance of the internal electrode structure to realize high-performance energy-storage MLCCs.

\section{3 State-of-the-art energy-storage MLCCs}

Over the last decade, energy-storage MLCCs that can realize higher energy densities because of their thin dielectric ceramic layers have received significant attention. Current reports on lead-free energy-storage MLCCs are all prototype devices and mainly divided into three systems, including $\mathrm{BaTiO}_{3}$-based, $\mathrm{BiFeO}_{3}$ based, and $\mathrm{Bi}_{0.5} \mathrm{Na}_{0.5} \mathrm{TiO}_{3}$-based MLCCs.

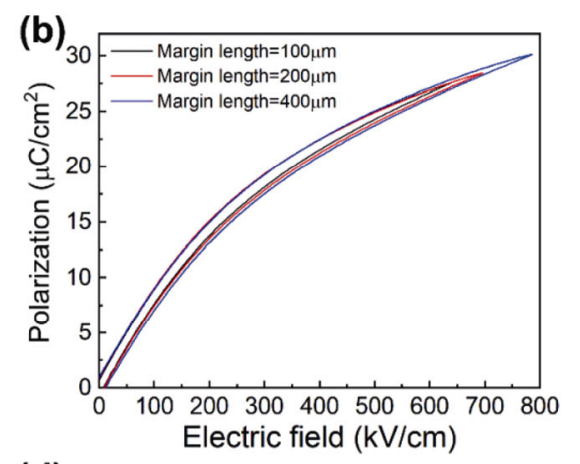

(d)

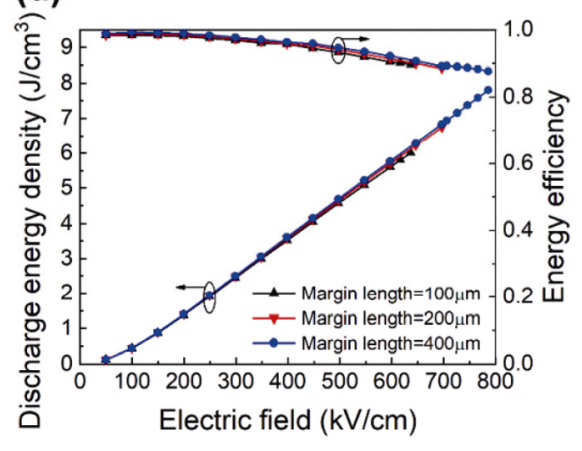

Fig. 25 (a) Hysteresis loops of MLCCs with various margin lengths measured under an applied electric field of $60 \mathrm{MV} \cdot \mathrm{m}^{-1}$ at $1 \mathrm{~Hz}$. (b) Unipolar hysteresis loops of the MLCCs with various margin lengths under their own AC breakdown strength at $1 \mathrm{~Hz}$. (c) Weibull plots of the DC dielectric breakdown strength for MLCCs with various margin lengths. (d) Calculated recoverable energy density and energy efficiency of MLCCs with various margin lengths as a function of the applied electric field, measured at $1 \mathrm{~Hz}$. Reproduced with permission from Ref. [121], (C) Author(s) 2019. 
Ogihara et al. [25] first studied the weakly-coupled relaxor ferroelectric $0.7 \mathrm{BaTiO}_{3}-0.3 \mathrm{BiScO}_{3}$ (BT-BS) for single-layer ceramic capacitors. The BT-BS capacitors used Pt as the internal electrodes and the thickness of the dielectric ceramic layer was $15 \mu \mathrm{m}$, which had a $W_{\text {rec }}$ of $6.1 \mathrm{~J} \cdot \mathrm{cm}^{-3}$ at an $E_{\mathrm{b}}$ of $73 \mathrm{MV} \cdot \mathrm{m}^{-1}$ (Fig. 26). It provided a good theoretical and experimental basis for the development of weakly coupled relaxor ferroelectric BT-BMO systems and energy-storage MLCCs. Then, Shay et al. [128] reported linear dielectric $0.8 \mathrm{CaTiO}_{3}-$ $0.2 \mathrm{CaHfO}_{3}(\mathrm{CT}-\mathrm{CH})$ single-layer ceramic capacitors, which had $\mathrm{Pt}$ internal electrodes and a dielectric ceramic layer of $9 \mu \mathrm{m}$. The linear dielectric usually has a high dielectric breakdown strength and energy efficiency, and this enabled CT-CH capacitors with a $W_{\text {rec }}$ of $9 \mathrm{~J} \cdot \mathrm{cm}^{-3}$ and a $\eta$ of $93 \%$ at an $E_{\mathrm{b}}$ of $120 \mathrm{MV} \cdot \mathrm{m}^{-1}$. The addition of $\mathrm{MnO}_{2}$ could effectively decrease the dielectric loss, which led to an enhanced $W_{\text {rec }}$ of $9.6 \mathrm{~J} \cdot \mathrm{cm}^{-3}$ with a $\eta$ of $96 \%$ at an $E_{\mathrm{b}}$ of $130 \mathrm{MV} \cdot \mathrm{m}^{-1}$ using the $0.5 \mathrm{~mol} \%$ Mn-doped $0.8 \mathrm{CaTiO}_{3}-0.2 \mathrm{CaHfO}_{3}$ (CT-CH-Mn) single-layer ceramic capacitor.

Kumar et al. [129] studied the $\mathrm{BaTiO}_{3}-\mathrm{Bi}\left(\mathrm{Zn}_{0.5} \mathrm{Ti}_{0.5}\right) \mathrm{O}_{3}$ (BT-BZT) MLCCs with 30 29- $\mu$ m-thick dielectric ceramic layers. The BT-BZN MLCCs with internal electrodes composed of the $40 \mathrm{Pt} / 40 \mathrm{Au} / 20 \mathrm{Pd}$ alloy had a $W_{\text {rec }}$ of $2.8 \mathrm{~J} \cdot \mathrm{cm}^{-3}$ at an $E_{\mathrm{b}}$ of $33 \mathrm{MV} \cdot \mathrm{m}^{-1}$ (Fig. $27(\mathrm{a})$ ). When the MLCCs used the $70 \mathrm{Ag} / 30 \mathrm{Pd}$ alloy for the internal electrodes, the $W_{\text {rec }}$ was still greater than $2 \mathrm{~J} \cdot \mathrm{cm}^{-3}$ (Fig. 27(c)). The cross-section SEM image of the MLCCs demonstrated that there were no obvious reactions between the $\mathrm{Ag} / \mathrm{Pd}$ electrodes and the ceramic layers (Fig. 27(b)), proving the feasibility of the $\mathrm{Ag} / \mathrm{Pd}$ alloy as internal electrodes for energystorage MLCC applications.

$\mathrm{BaTiO}_{3}-\mathrm{Bi}\left(\mathrm{Li}_{0.5} \mathrm{Ta}_{0.5}\right) \mathrm{O}_{3}$ (BT-BLT) and $\mathrm{BaTiO}_{3}-$ $\mathrm{Bi}\left(\mathrm{Li}_{0.5} \mathrm{Nb}_{0.5}\right) \mathrm{O}_{3}$ (BT-BLN) MLCCs with Pt internal electrodes and 13 30- $\mu$ m-thick dielectric ceramic layers were reported $[46,130]$, and they had similar energystorage performance. A $W_{\text {rec }}$ of $4.05 \mathrm{~J} \cdot \mathrm{cm}^{-3}$ with a $\eta$ of $95.5 \%$ at an $E_{\mathrm{b}}$ of $45 \mathrm{MV} \cdot \mathrm{m}^{-1}$ and a $W_{\text {rec }}$ of $4.5 \mathrm{~J} \cdot \mathrm{cm}^{-3}$ with a $\eta$ of $91.5 \%$ at an $E_{\mathrm{b}}$ of $46.6 \mathrm{MV} \cdot \mathrm{m}^{-1}$ were obtained, respectively, and the maximum operating temperature was $160{ }^{\circ} \mathrm{C}$. Similarly, 0.94 $\mathrm{BaTiO}_{3}-$ $0.06 \mathrm{Bi}\left(\mathrm{Mg}_{1 / 3} \mathrm{Nb}_{2 / 3}\right) \mathrm{O}_{3}$ (BT-BMN) MLCC with $\mathrm{Pt}$ internal electrodes and nine 9- $\mu$ m-thick dielectric ceramic layers was reported [131], which had a $W_{\text {rec }}$
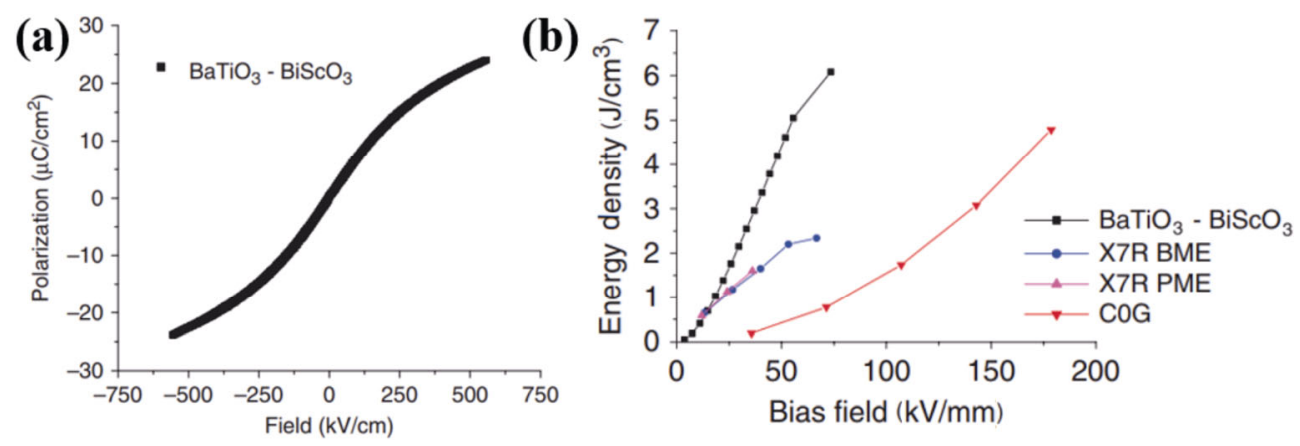

Fig. 26 (a) $P-E$ loop and (b) energy density of BT-BS capacitors. Reproduced with permission from Ref. [25], CC The American Ceramic Society 2009.
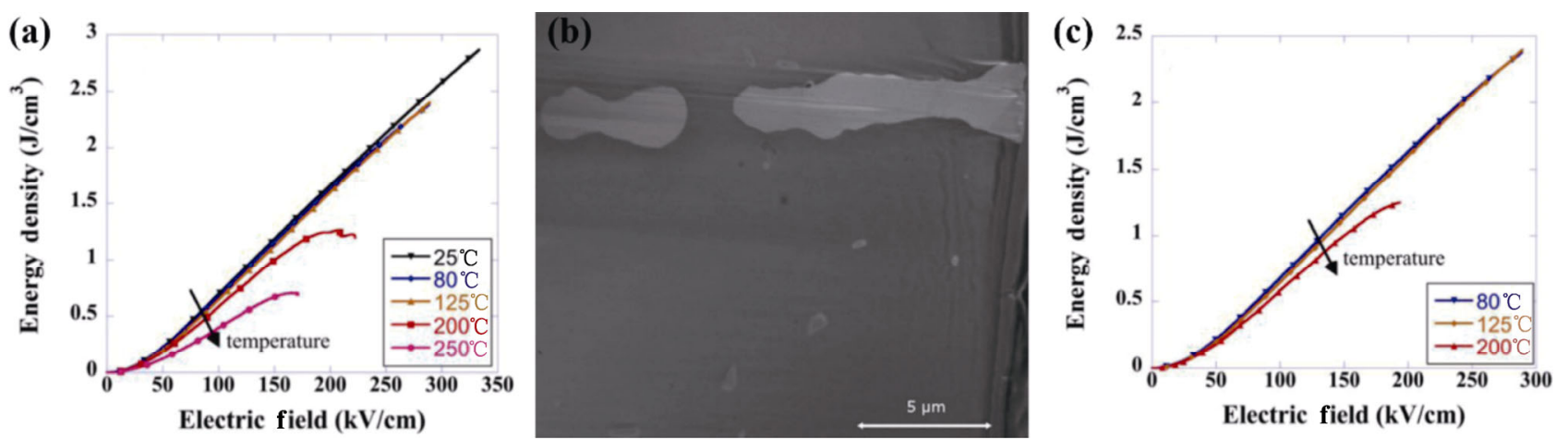

Fig. 27 Energy density of the BT-BZT MLCCs with (a) Pt alloy and (c) Ag/Pd alloy as the internal electrodes at various temperatures. (b) Cross-section SEM image of the MLCCs with Ag/Pd alloy as internal electrodes. Reproduced with permission from Ref. [129], (C) AIP Publishing LLC 2015. 
of $6.88 \mathrm{~J} \cdot \mathrm{cm}^{-3}$ with a $\eta$ of $90 \%$ at an $E_{\mathrm{b}}$ of $82 \mathrm{MV} \cdot \mathrm{m}^{-1}$. As part of work carried out in our $\mathrm{Lab}$, Chen et al. [132] studied multifunctional $0.9 \mathrm{BaTiO}_{3}-$ $0.1 \mathrm{Bi}_{0.5} \mathrm{Na}_{0.5} \mathrm{TiO}_{3}-\mathrm{Nb}-\mathrm{Mn}$ (BT-BNT) MLCCs, which satisfied the EIA X9R specification (temperature coefficient of capacitance $< \pm 15 \%$ within a temperature range from -55 to $200{ }^{\circ} \mathrm{C}$, Fig. 28(a)). The BT-BNT MLCCs formed using $10 \quad 30-\mu \mathrm{m}$-thick dielectric ceramic layers and internal electrodes composed of $60 \mathrm{Ag} / 40 \mathrm{Pd}$ had excellent energy-storage performance at high temperature, with a $W_{\text {rec }}$ of $3.33 \mathrm{~J} \cdot \mathrm{cm}^{-3}$ and $\eta$ of $81.6 \%$ at an $E_{\mathrm{b}}$ of $48 \mathrm{MV} \cdot \mathrm{m}^{-1}$ below $175{ }^{\circ} \mathrm{C}$ (Fig. 28(b)).

We also prepared and investigated weakly-coupled relaxor ferroelectric $\quad 0.87 \mathrm{BaTiO}_{3}-0.13 \mathrm{Bi}$ $\left(\mathrm{Zn}_{2 / 3}\left(\mathrm{Nb}_{0.85} \mathrm{Ta}_{0.15}\right)_{1 / 3}\right) \mathrm{O}_{3} \quad$ (BTBZNT) energy-storage MLCCs using 60Ag/40Pd for internal electrodes [37]. The MLCCs with two dielectric ceramic layers of $5 \mu \mathrm{m}$ each exhibited an excellent energy-storage performance with a $W_{\text {rec }}$ of $10.12 \mathrm{~J} \cdot \mathrm{cm}^{-3}$ and $\eta$ of $89.4 \%$ at an $E_{\mathrm{b}}$ of $104.7 \mathrm{MV} \cdot \mathrm{m}^{-1}$, as well as a high temperature stability. Based on this work, we proposed a multiscale optimization strategy (including atomic scale, grain scale, and device scale designs) to increase the breakdown field strength and decrease the leakage current of the MLCCs [133]. On the atomic scale, the addition of $\mathrm{Bi}\left(\mathrm{Zn}_{2 / 3}\left(\mathrm{Nb}_{0.85} \mathrm{Ta}_{0.15}\right)_{1 / 3}\right) \mathrm{O}_{3}$ to the $\mathrm{BaTiO}_{3}$ system breaks the long-range polar ordering of the typical ferroelectric and generated local polar nanoregions (PNRs) of the relaxor ferroelectric (Fig. 29(c)); it exhibited high electric-field-induced polarization, low $P_{\mathrm{r}}$, high $E_{\mathrm{b}}$, and high $\eta$ [27]. On the grain scale, introducing a $\mathrm{SiO}_{2}$ coating layer on the BTBZNT particles to form perfect grain core-shell structures after sintering would cause the breakdown path to dissipate more energy across the insulating $\mathrm{SiO}_{2}$ layer with a high breakdown energy, leading to a higher $E_{\mathrm{b}}$ [134]. Through theoretical simulations via a phasefield breakdown model, it was found that the nominal breakdown strength of BTBZNT@ $\mathrm{SiO}_{2}$ would be enhanced by $100 \%$ compared with the BTBZNT ceramics. On the device scale, the $\mathrm{SiO}_{2}$ barrier layers were introduced at the interfaces between the electrodes and dielectrics (Fig. 29(b)), which would raise the Schottky barrier height for electron injection and decrease the leakage current and electric field concentration; hence, a marked improvement in the $E_{\mathrm{b}}, \eta$, and temperature stability could be achieved. From theoretical simulations using a charge transport model related to the Schottky barrier for electron injection, the results show that the distortion of electric field and space charge density were much lower in the BTBZNT@, $\mathrm{SiO}_{2}$ MLCC than in the BTBZNT MLCC (Figs. 29(f) and 29(g)). Furthermore, the energy-storage MLCCs would benefit from a thin dielectric layer that has a lower porosity, finer grain size, and a large capacity $[16,37,135]$. Based on the above multiscale optimization strategy, the relaxor ferroelectric BTBZNT@ $\mathrm{SiO}_{2}$ MLCCs exhibited superior energy-storage performance with a large $W_{\text {rec }}$ of $18.24 \mathrm{~J} \cdot \mathrm{cm}^{-3}$ and an ultra-high $\eta$ of $94.5 \%$ under a high $E_{\mathrm{b}}$ of $175.5 \mathrm{MV} \cdot \mathrm{m}^{-1}$, along with excellent temperature stability (variation of $W_{\text {rec }}$ was $<10 \%$ in the temperature range from 25 to $190{ }^{\circ} \mathrm{C}$ under $50 \mathrm{MV} \cdot \mathrm{m}^{-1}$ ) and good cycling stability. Compared with the BTBZNT MLCCs without the $\mathrm{SiO}_{2}$ coating, the $W_{\text {rec }}$ was enhanced by $80 \%$ (Fig. 29(h)). The multiscale optimization strategy should provide a universal approach to comprehensively improve the energy-storage performance of dielectric ceramic multilayer capacitors.
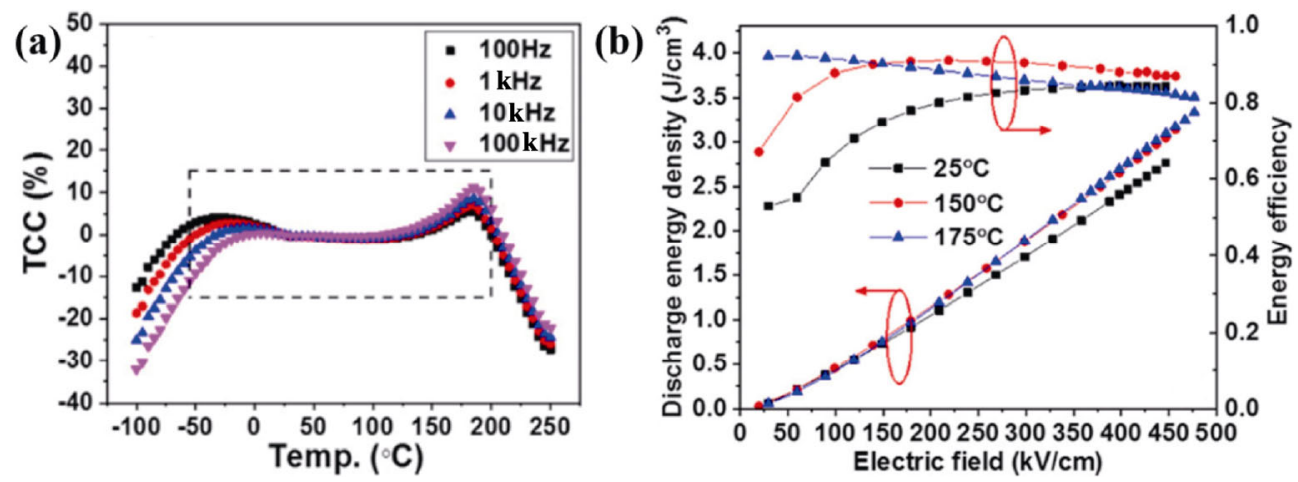

Fig. 28 (a) Temperature coefficient of capacitance (TCC) and (b) $W_{\text {rec }}$ of the BT-BNT MLCCs. Reproduced with permission from Ref. [132], (C) The American Ceramic Society 2018. 

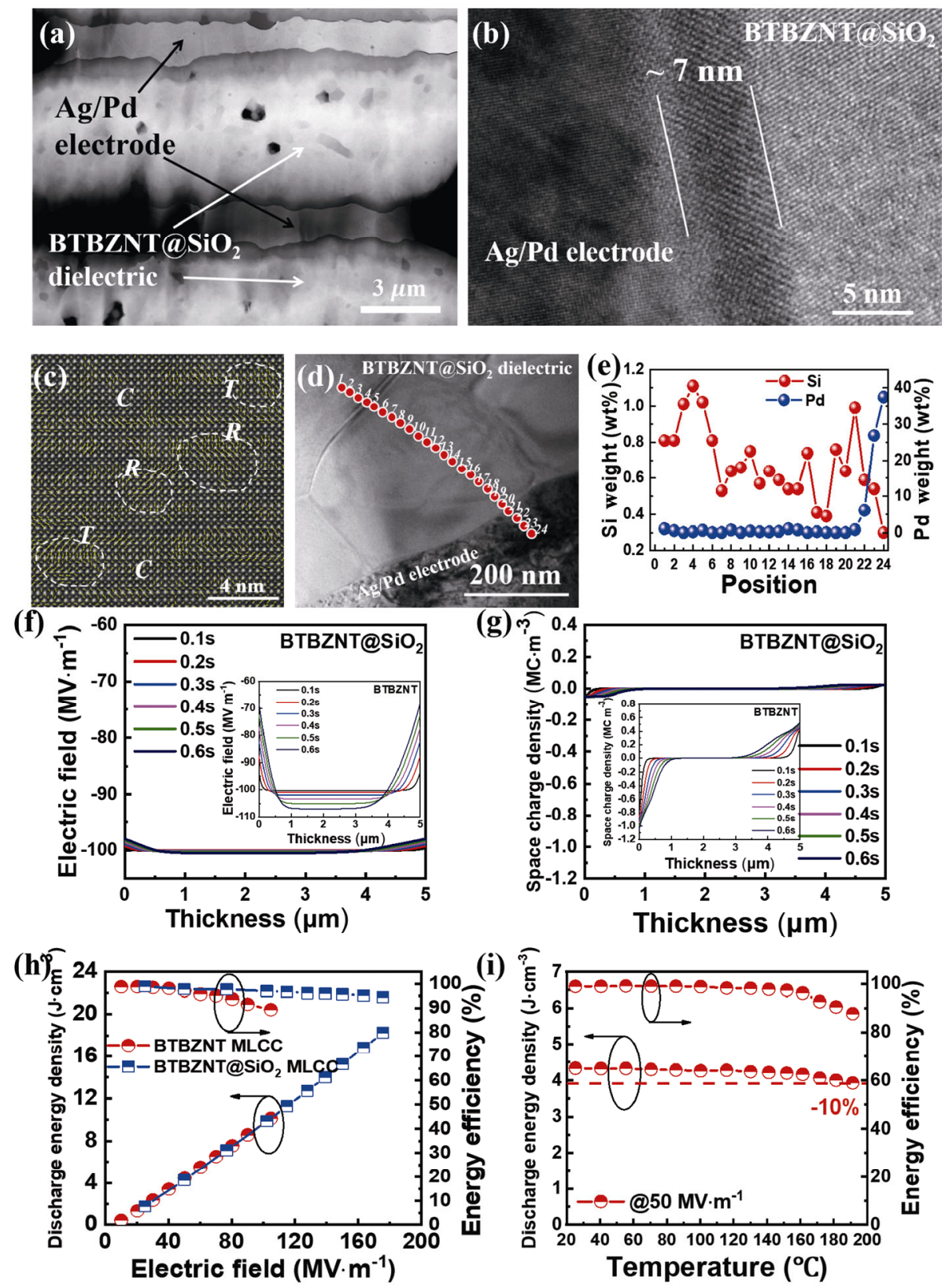

Fig. 29 (a) Low-magnification TEM dark-field image of BTBZNT@ $\mathrm{SiO}_{2}$ MLCCs. (b) High-resolution TEM bright-field image of the interface between the electrode and dielectric for BTBZNT@ $\mathrm{SiO}_{2} \mathrm{MLCCs}$ (c) Domain structure for BTBZNT@SiO $\mathrm{SiO}_{2}$ ceramics. (d, e) EDS analysis results of the Si and Pd distribution along the points from 1 to 24 in (d). The change in electric field concentration (f) and space charge density simulations (g) of the BTBZNT@SiO ${ }_{2}$ and BTBZNT MLCC from 0.1 to $0.6 \mathrm{~s}$ after applying an electric field of $100 \mathrm{MV} \cdot \mathrm{m}^{-1}$. (h) Energy-storage performance of the BTBZNT and BTBZNT@SiO $\mathrm{SiC}_{2}$ MLCs at room temperature. (i) Temperature-dependent energy storage properties of BTBZNT@SiO $\mathrm{MLCCs}_{2}$ under $50 \mathrm{MV} \cdot \mathrm{m}^{-1}$. Reproduced with permission from Ref. [37], C WILEY-VCH Verlag GmbH \& Co. KGaA, Weinheim 2019; Ref. [133], (C) The Royal Society of Chemistry 2020.

Zhao et al. [136] prepared $\mathrm{Ag}\left(\mathrm{Nb}_{0.85} \mathrm{Ta}_{0.15}\right) \mathrm{O}_{3}-$ $0.25 \mathrm{wt} \% \mathrm{MnO}_{2}$ (ANT-Mn) MLCCs. The Mn doping effectively reduced the leakage current and improved the $E_{\mathrm{b}}$ and $\eta$ of the MLCCs. Moreover, the role of strain engineering in enhancing the $P_{\mathrm{s}}$ and $P_{\mathrm{s}}-P_{\mathrm{r}}$ values was demonstrated by the MLCCs with different thickness of active and inactive layers (Figs. 30(a) and 30(b)). The optimal ANT-Mn MLCCs with Pt internal electrodes and $15-\mu \mathrm{m}$-thick dielectric ceramic layers had a $W_{\text {rec }}$ of $7.9 \mathrm{~J} \cdot \mathrm{cm}^{-3}$ with a $\eta$ of $71 \%$ at an $E_{\mathrm{b}}$ of $102 \mathrm{MV} \cdot \mathrm{m}^{-1}$ (Fig. 30(c)).

Lu et al. [137] and Wang et al. [138-141] studied 
(a) Terminal electrode

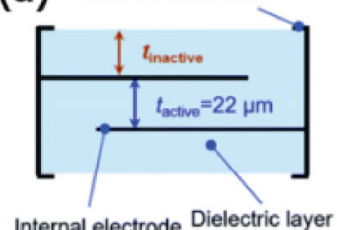

Internal electrode Dielectric layer
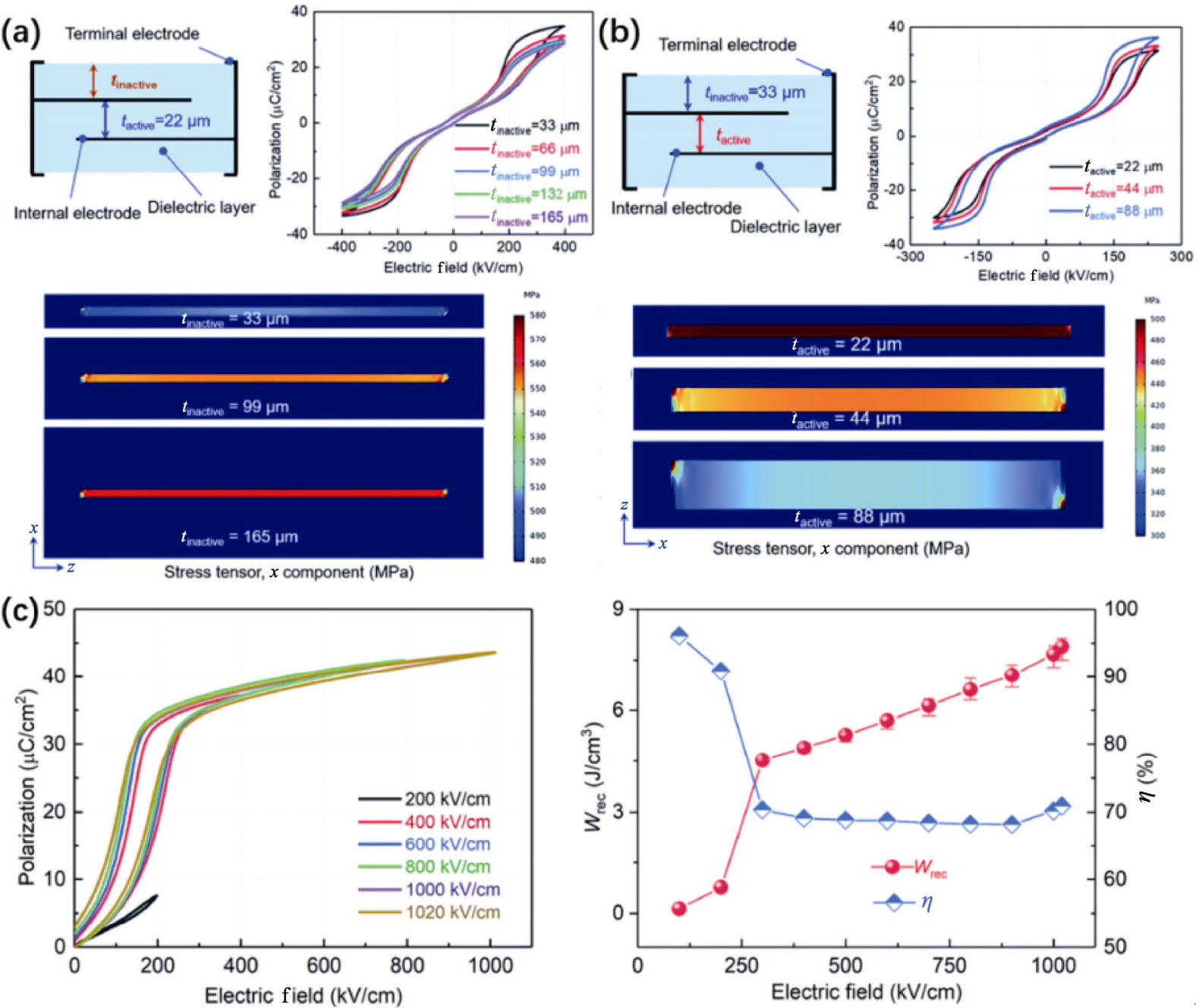

Fig. 30 (a) Effect of the thickness of inactive layer $\left(t_{\text {inactive }}\right)$ on the $P-E$ loops and the finite-element simulations of the stress of the active layers with different $t_{\text {inactive }}$. (b) Effect of the thickness of active layer $\left(t_{\text {inactive }}\right)$ on the $P-E$ loops and the finite-element simulations of the stress of the active layers with different $t_{\text {inactive }}$. (c) $P-E$ loops and energy-storage performance of ANT-Mn MLCCs at various temperatures. Reproduced with permission from Ref. [136], (C) The Royal Society of Chemistry 2021.

the energy-storage performance of a series of $\mathrm{BiFeO}_{3}$ based MLCCs. Among them, the $\mathrm{BiFeO}_{3}-\mathrm{SrTiO}_{3}-$ $0.03 \mathrm{Nb}-0.1 \mathrm{Bi}\left(\mathrm{Mg}_{1 / 3} \mathrm{Nb}_{2 / 3}\right) \mathrm{O}_{3}$

(BF-ST-Nb-BMN) single-layer ceramic capacitor had the largest $W_{\text {rec }}$ [137]. Nb doping could eliminate hole conduction and promote electrical uniformity, thereby enhancing the insulating properties of the dielectric materials. BMN-doping could reduce long range polar coupling in dielectric materials without decreasing the average ionic polarizability and enhance the relaxation properties. The capacitors used $\mathrm{Pt}$ as the internal electrode, and the thickness of the dielectric layer was $\sim 8 \mu \mathrm{m}$, and it had a large $W_{\text {rec }}$ of $15.8 \mathrm{~J} \cdot \mathrm{cm}^{-3}$ with a $\eta$ of $75.2 \%$ at an $E_{\mathrm{b}}$ of $100 \mathrm{MV} \cdot \mathrm{m}^{-1}$ (Figs. 31(a) and 31(b)). The $(0.7-x) \mathrm{BiFeO}_{3}-0.3 \mathrm{BaTiO}_{3}-x \mathrm{Nd}\left(\mathrm{Zn}_{0.5} \mathrm{Zr}_{0.5}\right) \mathrm{O}_{3}$
BT-NZZ) MLCC had the best thermal stability [139]. The BF-BT-NZZ MLCC with Pt internal electrodes and $716-\mu \mathrm{m}$-thick dielectric ceramic layers had a $W_{\text {rec }}$ of $10.5 \mathrm{~J} \cdot \mathrm{cm}^{-3}$ with a $\eta$ of $87 \%$ at an $E_{\mathrm{b}}$ of $70 \mathrm{MV} \cdot \mathrm{m}^{-1}$. The maximum stable working temperature of the BF-BT-NZZ MLCCs could reach $150{ }^{\circ} \mathrm{C}$ (Figs. 31(e) and 31(f)).

Li et al. $[135,142]$ introduced a relaxor end-member into the antiferroelectrics and developed a new relaxor antiferroelectric $\mathrm{Na}_{0.5} \mathrm{Bi}_{0.5} \mathrm{TiO}_{3}-x \mathrm{Sr}_{0.7} \mathrm{Bi}_{0.2} \mathrm{TiO}_{3}$ (NBTSBT) MLCC (Fig. 32), which demonstrated excellent characteristics including a high $E_{\mathrm{b}}$, high polarization strength, high $W_{\text {rec }}$, and high $\eta$. The NBT-0.45SBT MLCCs with Pt internal electrodes and $1020-\mu \mathrm{m}$-thick dielectric ceramic layers had a $W_{\text {rec }}$ of $9.5 \mathrm{~J} \cdot \mathrm{cm}^{-3}$ with 

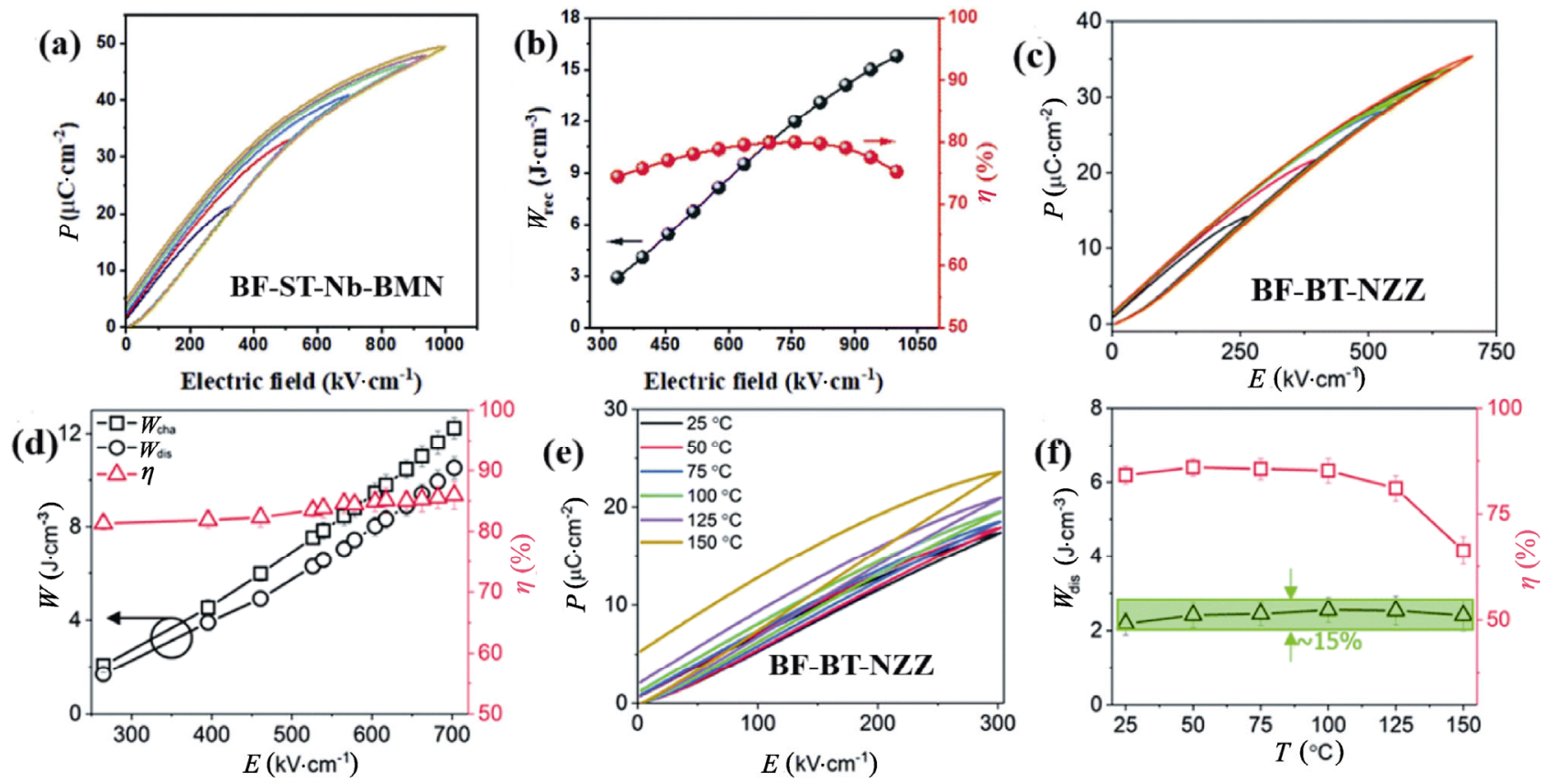

Fig. 31 (a) $P-E$ loops and (b) energy-storage performance of the BF-ST-Nb-BMN MLCCs at room temperature. (c) $P-E$ loops and (d) energy-storage performance of the BF-BT-NZZ MLCCs at room temperature. (e) $P-E$ loops and (f) energy-storage performance of BF-BT-NZZ MLCCs at various temperatures. Reproduced with permission from Ref. [137], (C) The Royal Society of Chemistry 2020; Ref. [139], (C) The Royal Society of Chemistry 2019.

a $\eta$ of $92 \%$ at an $E_{\mathrm{b}}$ of $72 \mathrm{MV} \cdot \mathrm{m}^{-1}$. The NBT$0.45 \mathrm{SBT}$ MLCCs could operate stably in the temperature range from -60 to $120{ }^{\circ} \mathrm{C}$, and the $W_{\text {rec }}$ was found to remain stable after $10^{6}$ cycles at $100{ }^{\circ} \mathrm{C}$. Subsequently, Li et al. used $<111>$-oriented $\mathrm{SrTiO}_{3}$ as templates to prepare <111>-textured NBT-0.35SBT MLCCs. Compared with nontextured samples, the $<111>$-textured samples could greatly reduce the strain of dielectric ceramics and MLCCs, thereby reducing the probability of electromechanical breakdown and enabling a higher $E_{\mathrm{b}}$. The $<111>$-textured NBT-0.35SBT MLCCs with $\mathrm{Pt}$ internal electrodes and $1020-\mu \mathrm{m}$-thick dielectric ceramic layers possessed the record-high $W_{\text {rec }}$ of $21.5 \mathrm{~J} \cdot \mathrm{cm}^{-3}$ with a $\eta$ of $80 \%$ at an $E_{\mathrm{b}}$ of $100 \mathrm{MV} \cdot \mathrm{m}^{-1}$. After $10^{6}$ cycles at $150{ }^{\circ} \mathrm{C}$, the energy-storage performance remained stable, demonstrating the excellent thermal and cycling stability. However, the preparation of the texture would result in a more complex fabrication process and greatly increase the cost of the energy-storage MLCCs. Recently, Ji et al. [143] introduced $\mathrm{Bi}\left(\mathrm{Mg}_{1 / 3} \mathrm{Nb}_{2 / 3}\right) \mathrm{O}_{3}$ into NBT-SBT and obtained the $0.62 \mathrm{Na}_{0.5} \mathrm{Bi}_{0.5} \mathrm{TiO}_{3}-0.3 \mathrm{Sr}_{0.7} \mathrm{Bi}_{0.2} \mathrm{TiO}_{3}-$ $0.08 \mathrm{BiMg}_{2 / 3} \mathrm{Nb}_{1 / 3} \mathrm{O}_{3}$ (NBT-SBT-0.08BMN) ceramic. The $W_{\text {rec }}$ of the NBT-SBT- $0.08 \mathrm{BMN}$ ceramic reached up to $7.5 \mathrm{~J} \cdot \mathrm{cm}^{-3}$ with a $\eta$ of $92 \%$. Based on the NBT-SBT-0.08BMN ceramic, single-layer ceramic capacitors were prepared with Pt internal electrodes and a dielectric ceramic layer of $7 \mu \mathrm{m}$ (average grain size of $3 \mu \mathrm{m})$, which had a $W_{\text {rec }}$ of $18 \mathrm{~J} \cdot \mathrm{cm}^{-3}$ with a $\eta$ of $93 \%$ at an $E_{\mathrm{b}}$ of $101.3 \mathrm{MV} \cdot \mathrm{m}^{-1}$ (Fig. 33) Additionally, excellent energy-storage performance was also achieved with good thermal stability (up to $160{ }^{\circ} \mathrm{C}$ ), frequency stability, and cycling stability.

The energy-storage performance of various reported MLCCs is shown in Fig. 34 and Table 8. Most of these MLCCs possess more excellent energy-storage properties than the commercial MLCCs, such as PLZT-based (B58031I5105 M002) and BT-based (C1812C334K CRACTU) in Table 1 . The $\mathrm{BiFeO}_{3}$-based energy-storage MLCCs usually have high maximum energy densities and low energy efficiencies, while the $\mathrm{BaTiO}_{3}-\mathrm{BiMeO}_{3}$ system and $\mathrm{Bi}_{0.5} \mathrm{Na}_{0.5} \mathrm{TiO}_{3}$-based energy-storage MLCCs can realize both high energy densities and high energy efficiencies. However, the Bi element can easily diffuse during sintering due to its low melting point, leading to large grains in the micrometer scale $[38,135,142]$. Hence, the thickness of the dielectric ceramic layers of the Birich MLCCs has some limits, which is not conducive for realizing miniaturized capacitors with a high capacity. Additionally, the Bi element would easily react with the $\mathrm{Ag} / \mathrm{Pd}$ alloy internal electrode during the hightemperature sintering process [144] and $\mathrm{Bi}^{3+}$ would be 

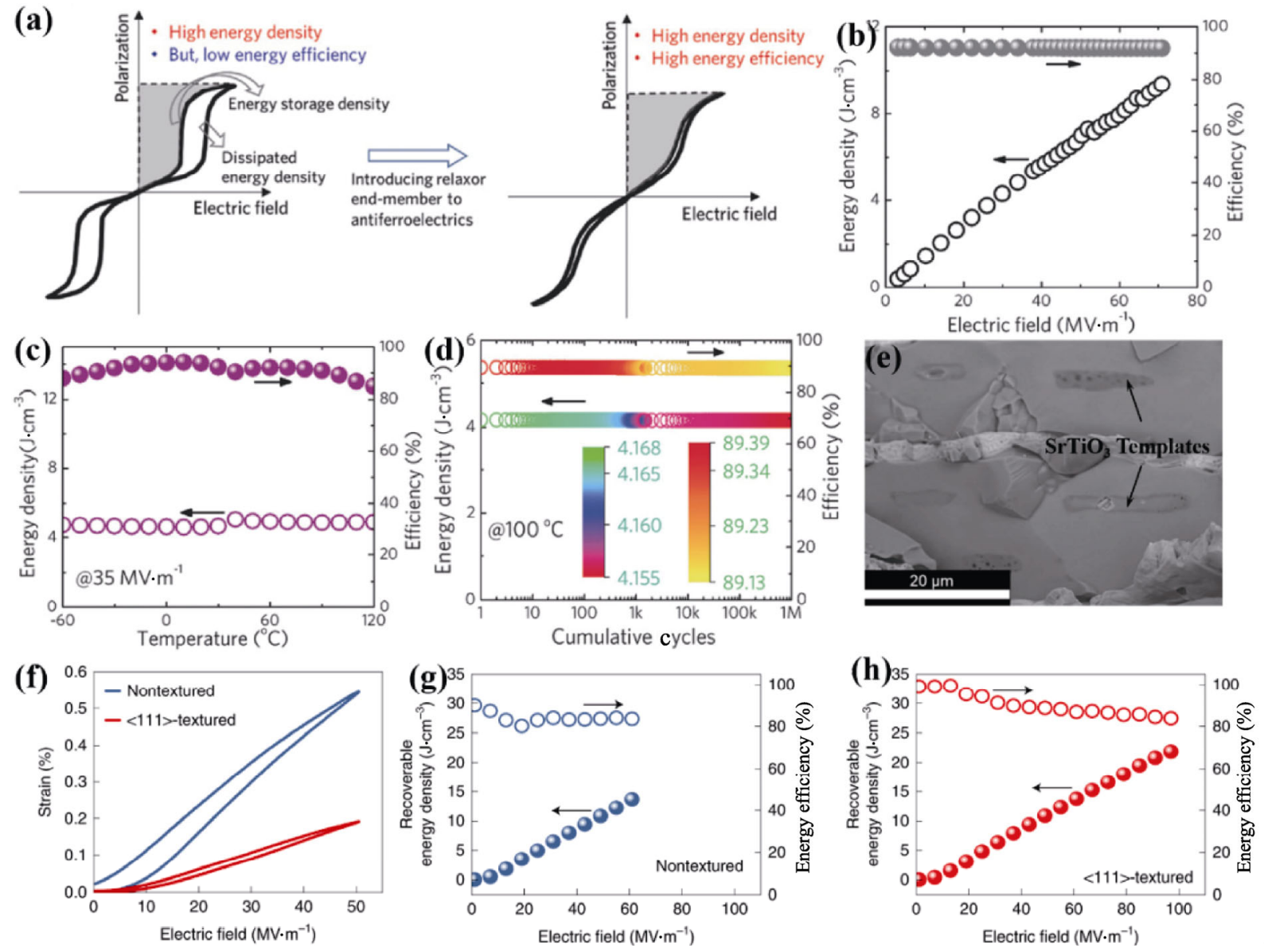

Fig. 32 (a) Schematic diagram for the preparation of relaxor antiferroelectrics. The energy-storage performance as a function of (b) the electric field, (c) the temperature, and (d) the cycles for NBT-0.45SBT MLCCs. (e-g) Cross-section SEM images, strain-electric field curves, and energy-storage performance of nontextured and $<111>$-textured NBT-0.35SBT MLCCs at room temperature. Reproduced with permission from Ref. [135], (C) WILEY-VCH Verlag GmbH \& Co. KGaA, Weinheim 2018; Ref. [142], (C) The Author(s), under exclusive licence to Springer Nature Limited 2020.
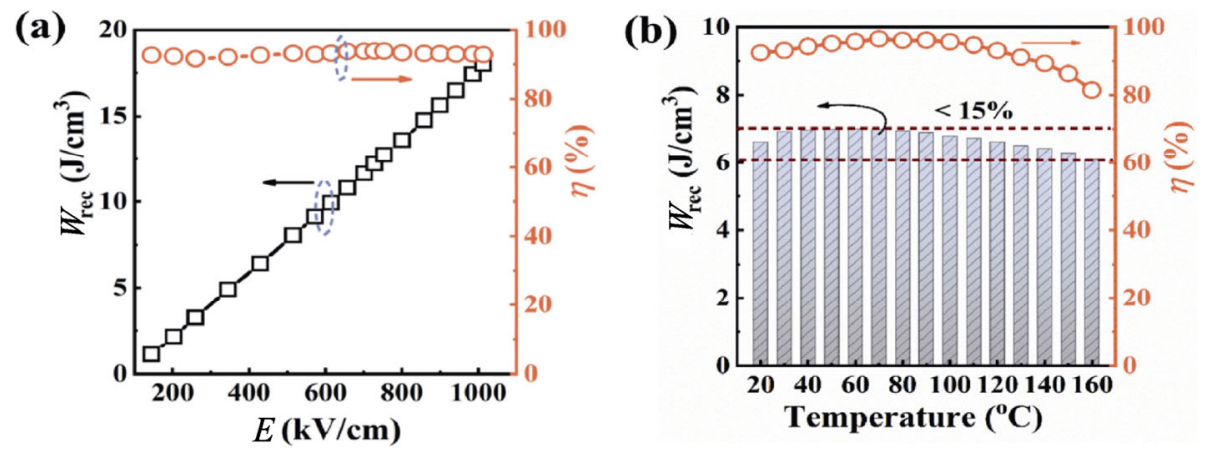

Fig. 33 Energy-storage performance of NBT-SBT-0.08BMN capacitors at (a) room temperature and (b) various temperatures. Reproduced with permission from Ref. [143], C Published by Elsevier B.V. 2021.

easily reduced in a reducing atmosphere [145]; therefore, most reported MLCCs use pure Pt for the internal electrodes. However, the expensive Pt significantly increases the cost of the MLCCs, which is not suitable for commercialization and practical application. There is an urgent demand to develop energy-storage ceramic dielectric materials with anti-reduction properties and can be co-fired with the base metal electrode. In summary, current research work and the development of energy-storage MLCCs are still at the laboratory stage 
and not yet ready for large-scale industrial application. Characterization and mechanism analysis related to insulator resistance degradation, fatigue characteristics, and the reliability of the MLCCs needs to be further investigated.

\section{Emerging applications}

The energy-storage MLCCs storage electric energy via the accumulation of charge, with functions including filtering, smoothing, coupling, decoupling, and snubbing in circuits [150]. The main applications that urgently require the miniaturization of energy-storage MLCCs are pulsed power sources and power converters. Before addressing these specific areas, we first look at how MLCCs behave in real circuits. The equivalent circuit model for MLCCs that is usually employed is described in Fig. 35(a). The capacitor is equivalently connected in series with a resistor and an inductor, with the values termed as the equivalent series resistance (ESR) and equivalent series inductance (ESL), respectively. For ideal cases, the capacitors exhibit only capacitance with no losses; nevertheless, under practical conditions, parasitic effects linked with the resistance and inductance

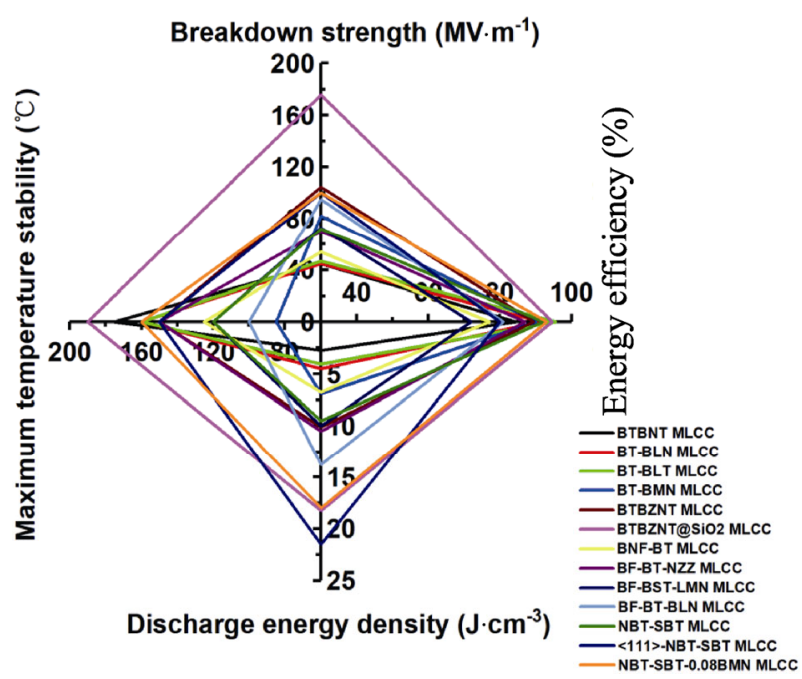

Fig. 34 Comprehensive energy-storage performance of various reported MLCCs [37,46,130-133,135,137-142].

Table 8 Energy-storage performance of various MLCCs

\begin{tabular}{|c|c|c|c|c|c|c|c|}
\hline Dielectric ceramic & Internal electrode & $N$ & $t(\mu \mathrm{m})$ & $W_{\text {rec }}\left(\mathrm{J} \cdot \mathrm{cm}^{-3}\right)$ & $E_{\mathrm{b}}\left(\mathrm{MV} \cdot \mathrm{m}^{-1}\right)$ & $\eta(\%)$ & Maximum operating temperature $\left({ }^{\circ} \mathrm{C}\right)$ \\
\hline BT-BS [25] & $\mathrm{Pt}$ & 1 & 15 & 6.1 & 73 & - & - \\
\hline BT-BZT [129] & $\mathrm{Pt} / \mathrm{Au} / \mathrm{Pd}$ & 30 & 29 & 2.8 & 33 & - & - \\
\hline BT-BNT [132] & $\mathrm{Ag} / \mathrm{Pd}$ & 10 & 30 & 2.76 & 45 & 84.3 & 175 \\
\hline BT-BZNT [37] & $\mathrm{Ag} / \mathrm{Pd}$ & 2 & 5 & 10.12 & 104.7 & 89.4 & 150 \\
\hline BT-BZNT [146] & $\mathrm{Pt}$ & 2 & 5 & 14.08 & 150 & 69.7 & 150 \\
\hline BT-BZNT [147] & $\mathrm{Ag} / \mathrm{Pd}$ & 10 & 11 & 8.13 & 75 & 95 & 170 \\
\hline BTBZNT@ $\mathrm{SiO}_{2}$ [133] & $\mathrm{Ag} / \mathrm{Pd}$ & 2 & 5 & 18.24 & 175.5 & 94.5 & 190 \\
\hline BTAS5 [15] & $\mathrm{Ag} / \mathrm{Pd}$ & 2 & 19 & 4.00 & 65.1 & 73.6 & 150 \\
\hline BT-BLT [45] & $\mathrm{Pt}$ & 13 & 30 & 4.05 & 46.6 & 95.5 & 160 \\
\hline BT-BLN [130] & $\mathrm{Pt}$ & 13 & 30 & 4.5 & 45 & 91.5 & 160 \\
\hline BT-BMN [131] & $\mathrm{Pt}$ & 9 & 9 & 6.88 & 82 & 90 & 85 \\
\hline $\mathrm{CT}-\mathrm{CH}[128]$ & $\mathrm{Pt}$ & 1 & 9 & 9 & 120 & 93 & - \\
\hline $\mathrm{CT}-\mathrm{CH}-\mathrm{Mn}$ [128] & $\mathrm{Pt}$ & 1 & 9 & 9.6 & 130 & 96 & - \\
\hline ANT-Mn [136] & $\mathrm{Pt}$ & - & 15 & 7.9 & 102 & 71 & 100 \\
\hline $\mathrm{NN}-\mathrm{CZ}-\mathrm{BNT}$ [148] & $\mathrm{Pt}$ & - & 19 & 3.7 & 42 & 82.1 & 120 \\
\hline BNF-BT [138] & $\mathrm{Pt}$ & 9 & 32 & 6.74 & 54 & 77 & 125 \\
\hline $0.4 \mathrm{BF}-0.6 \mathrm{ST}$ [149] & $\mathrm{Pd} / \mathrm{Ag}$ & - & 11 & 6 & 42 & - & - \\
\hline $0.2 \mathrm{BF}-0.8 \mathrm{ST}[149]$ & $\mathrm{Pd} / \mathrm{Ag}$ & - & 11 & 2.7 & 32 & - & 200 \\
\hline BF-BST-LMN [140] & $\mathrm{Pt}$ & 1 & 7 & 10 & 73 & 72 & 120 \\
\hline BF-BT-BLN [141] & $\mathrm{Pt}$ & 1 & 8 & 13.8 & 95 & 81 & 100 \\
\hline BF-BT-NZZ [139] & $\mathrm{Pt}$ & 7 & 16 & 10.5 & 70 & 87 & 150 \\
\hline $\mathrm{BF}-\mathrm{ST}-\mathrm{Nb}-\mathrm{BMN}$ [137] & $\mathrm{Pt}$ & 1 & 8 & 15.8 & 100 & 75.2 & - \\
\hline NBT-SBT-BMN [143] & $\mathrm{Pt}$ & 1 & 7 & 18 & 100 & 93 & 160 \\
\hline NBT-0.35SBT [142] & $\mathrm{Pt}$ & 10 & 20 & 21.5 & 100 & 80 & 150 \\
\hline NBT-0.45SBT [135] & $\mathrm{Pt}$ & 10 & 20 & 9.5 & 72 & 92 & 120 \\
\hline
\end{tabular}

Note: $N$-number of active dielectric layers; $t$ - thickness of dielectric layer. 
of MLCCs are also of concern because the ESR dissipates energy and the ESL may cause detrimental resonance, and these should be as small as possible. The ESR of MLCCs primarily originates from the loss of the dielectrics and the resistance of the inner electrodes and the outer terminals, while the ESL is closely related to the inner electrodes and the outer terminals. Because the ESR and ESL are in series form, an increased number of active layers and a smaller case size would lead to lower ESR and ESL, and hence, multi-layer and miniaturized MLCCs should be promoted. Additionally, the ESR and ESL are functions of the electric field, frequency, and temperature, and these conditions should be carefully considered for high-performance and high-reliability applications.

Pulsed power refers to devices that can provide high peak power by accumulating energy over a period of time and releasing it very quickly. Energy-storage MLCCs, which store electric charge at the electrodes, have an intrinsic ability to generate high power. MLCCs used in pulsed power sources can be roughly simplified according to the schematic shown in Fig. 35(a). The MLCCs can be charged under voltage-constant or current-constant modes with the switch open. Without controlling the discharge, MLCCs deliver energy to the load $\mathrm{R}$ via the inductor $\mathrm{L}+\mathrm{ESL}$. The discharge waveform can be underdamped, damped, or overdamped depending on the values of C, ESR, ESL, L, and R. For very highpower applications under near short discharge, the $L$ is minimized under a very tiny load R, so the ESR causes energy dissipation and the ESL increases the impedance, which have the effect of limiting the peak power to the load. The ESR and ESL are electric field and frequency dependent, and the RCL charging-discharging circuit currently applied in the research community can somewhat mimic the behavior of the MLCC under real pulse conditions. The energy-storage MLCCs in pulsed power applications are widely used in missile detonators (military service), defibrillators (medical application), and camera flashers (consumer use). The Knowles Capacitors company developed a type of high-energydensity MLCC-Novacap [151] for pulsed power based on lead lanthanum zirconate titanate (PLZT) antiferroelectric materials (Fig. 35(b)). However, the lead-free high-energy-density MLCCs need to be pursued to alleviate the healthy and environmental issues associated with lead-containing materials.

Power converters deal with the voltage and current
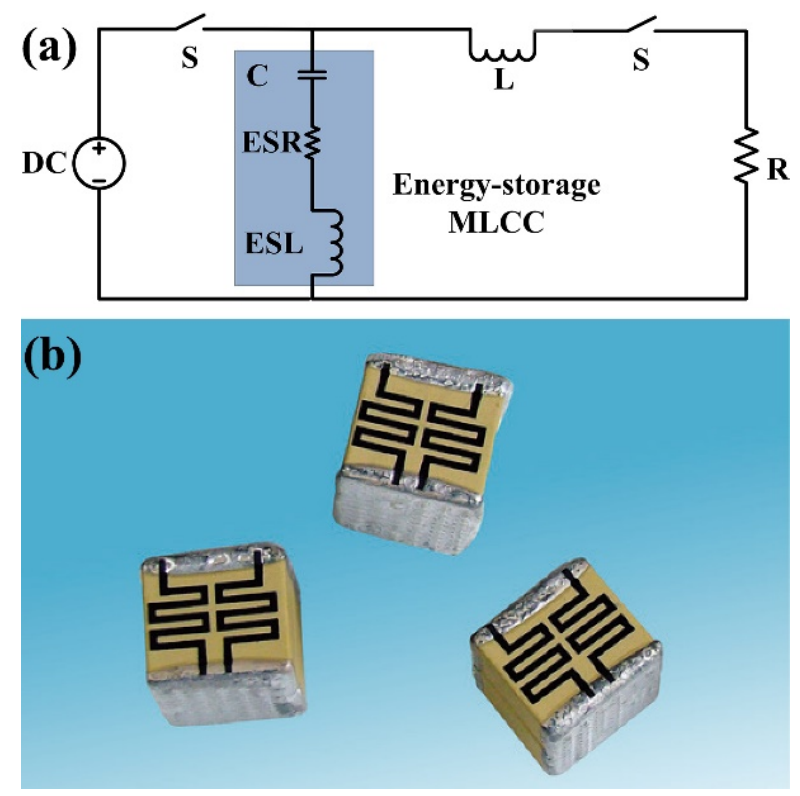

Fig. 35 (a) Simplified schematic of a pulsed power circuit using MLCC as the energy-storage element. (b) Highenergy-density Novacap MLCCs for pulsed power based on PLZT antiferroelectric materials developed by the Knowles Capacitors company. Reproduced with permission from Ref. [151], C) Knowles Precision Devices 2018.

conversions, such as alternating current to direct current (AC-DC), direct current to direct current (DC-DC), and direct current to alternating current $(\mathrm{DC}-\mathrm{AC})$ by means of power diodes and transistors. Capacitors in power converters can be found in electric vehicles, $5 \mathrm{G}$ base stations, clean energy generation, and smart grids; here, the most distinctive role played by the capacitor is the DC-Link, as shown in Fig. 36(a). A typical demonstration of DC-Link capacitors in three-phase motor inverters is shown in Fig. 36(b). Crucially, the DC-Link capacitors absorb the ripple current, maintain the power imbalance, and restrict over-voltage between the DC battery and the AC motor [152,153], which ensures smooth operation of the motor, decreases energy loss, and extends the life of the battery and inverter [154]. In practical designs, the minimum capacitance is generally determined by the maximum ripple current that the capacitors can handle rather than simply the circuit topology, and this value is related to heat generation stemming from the ESR and thermal dissipation of the capacitors. Therefore, a low ESR and thermal resistance are often required. A large ESL for the capacitors leads to over voltage stress on the semiconductors under a high $\mathrm{d} i / \mathrm{d} t$ on- and off-switching process, which should be minimized via inductance cancellation design. It should be pointed out that the 
DC-Link capacitors work at a large DC-biased voltage with small to medium AC superpositions (inset in Fig. 36(b)), and the capacitive response and energy-storage behavior around the DC-biased working point is more important than the overall energy-storage behavior evaluated based on the area enclosed by the $P-E$ loops. Energy-storage performance evaluation should be extended to a large DC-bias with AC superposition fields for frequencies up to the order of megahertz; here, the capacitive response and the energy-storage behavior should be examined at points with higher fields with higher frequencies. This differs from the current measurements reported in literature for both the zero-to-maximum field reversals in $P-E$ loops at low frequencies (typically $\leqslant 100 \mathrm{~Hz}$ ) and the RCL charging-discharging method.

As shown in Fig. 37(a), the DC-Link capacitor occupies almost $50 \%$ of the volume of the traction inverter in the 1st Gen Toyota Prius [155] and Tesla Model 3 [156] electric vehicles. The capacitors have conventionally been electrolytic and film based owing to the huge capacitance needed for semiconductors operating at lower frequencies $(16,500 \mu \mathrm{F}$ for an electrolytic capacitor or $420 \mu \mathrm{F}$ for a film capacitor is required for a $80 \mathrm{~kW}$ motor inverter operating at $20 \mathrm{kHz}$ [157]), where the utilization of MLCCs would appear to be technologically and economically inappropriate. The state-of-the-art DC-Link capacitors fall far short of the growing demands for compact, lightweight, and energyefficient capacitors for power conversion applications, in which high-capacitance-density, high-temperature, and high-ripple-current solutions are desirable. This is particularly true for high-temperature fast-switching wide-bandgap third-generation semiconductors. With increasing switching frequency, the total capacitance needed rapidly decreases without sacrificing performance, as illustrated in Fig. 37(b). Here, MLCCs are in a desirable position because of their extremely low ESR and ESL, high-capacitance-density, high-temperature, and high-ripple-current characteristics compared with their electrolytic and film counterparts [158].

Based on a partial view of the latest industrial offerings, two leading companies have recently announced their MLCC solutions for the third-generation semiconductors, i.e., the KC-LINK series by KEMET [159] and the Ceralink series by TDK [160], as shown in Figs. 38(a) and 38(b). The KC-LINK MLCCs are COG type with lead-free $\mathrm{CaZrO}_{3}$-based linear dielectric materials that
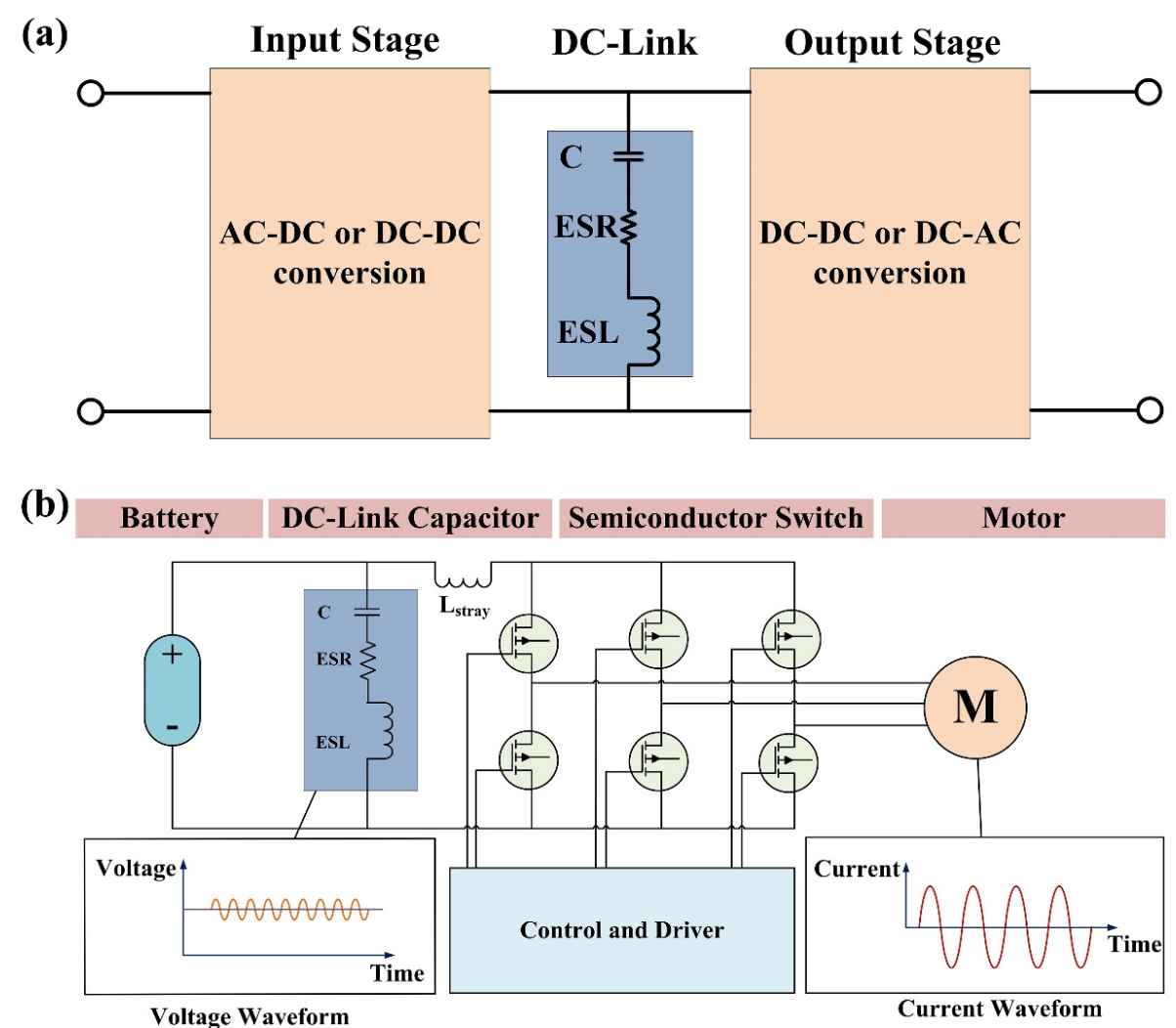

Fig. 36 (a) Role of DC-Link capacitor in the AC-DC, DC-DC, and DC-AC converters. (b) DC-Link capacitor in a three-phase motor inverter. The insets show the voltage and current waveforms of the capacitor and motor, respectively. 


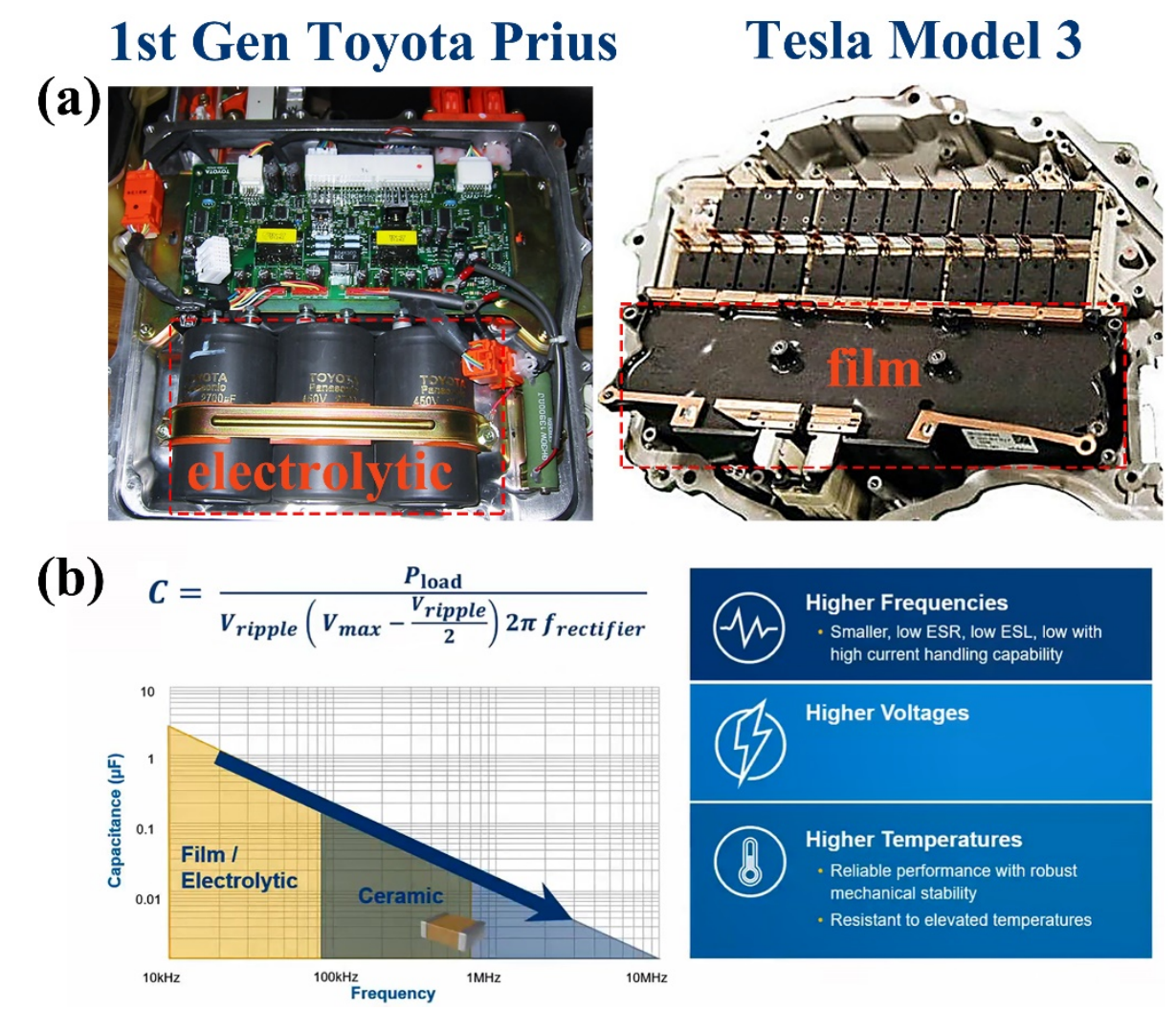

Fig. 37 (a) DC-Link capacitors in the traction inverters of the 1st Gen Toyota Prius and Tesla Model 3 [155,156]. (b) Trends and future requirements for DC-Link capacitors [158].

(a)

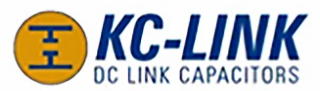

(b)
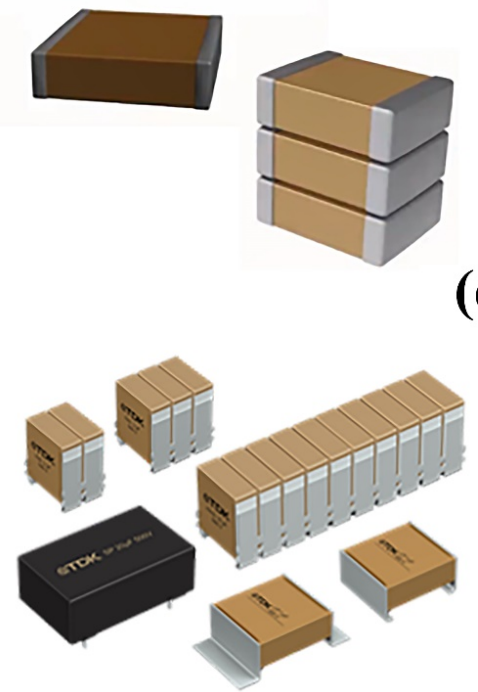

(c)

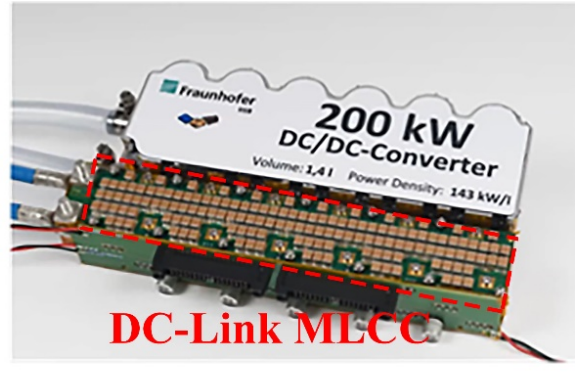

(d)

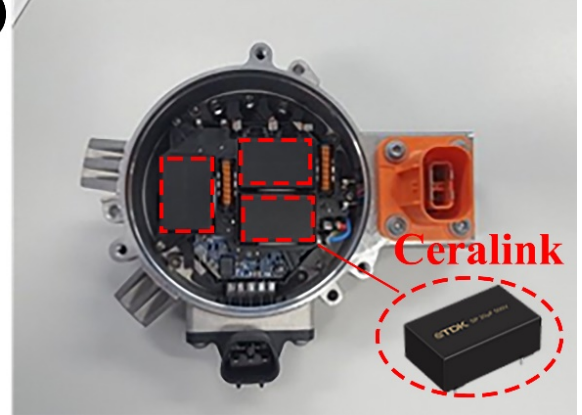

Fig. 38 (a) KEMET KC-LINK series DC-Link MLCCs [159]; (b) TDK Ceralink series DC-Link MLCCs [160]; (c) a highpower-density $200 \mathrm{~kW}$ DC-DC converter by Fraunhofer based on full DC-Link MLCCs and third-generation SiC MOSFETs [161]; and (d) a compact cooling pump power converter by AB Mikroelektronik GmbH for electric vehicles based on Ceralink MLCCs [162].

can function up to $200{ }^{\circ} \mathrm{C}$, while the Ceralink MLCCs are based on PLZT antiferroelectrics that can work properly under temperatures briefly up to $150{ }^{\circ} \mathrm{C}$. Compared with the KC-LINK, the Ceralink has a higher energy density. 
Nevertheless, the KC-LINK is lead-free and more temperature stable. Both the MLCCs are manufactured using cost-effective base-metal electrodes, i.e., nickel for the KC-LINK and copper for the Ceralink. Industrialization of lead-free MLCCs with a high energy density and good temperature stability is still ongoing. For the representative utilization of MLCCs for DC-Link applications, Fraunhofer demonstrated a high-powerdensity $200 \mathrm{~kW}$ DC-DC converter based on full DC-Link MLCCs and third-generation SiC MOSFETs (Fig. 38(c)) [161], which to the best of our knowledge is one of the most high-power-density DC-DC converters. AB Mikroelektronik $\mathrm{GmbH}$ developed a compact cooling pump power converter for electric vehicles based on the Ceralink MLCCs to replace the former electrolytic ones (Fig. 38(d)) [162].

\section{Challenges and future prospects}

Lead-free high-energy-density MLCCs that meet the practical requirements of current applications are of urgent demand to resolve the lead-free but low-energydensity problems or the high-energy-density but leadcontaining issues. Despite the breakthroughs achieved over the past decade, lab-scale lead-free high-energydensity MLCCs still face challenges, which include:

(1) Scale-up capability. it has to be determined whether the costly gradients and fine-tuning method used for small-scale energy-storage MLCCs can be scaled up for industrialization, and fundamental studies need to be performed to determine how the material and device fabrication conditions can be effectively controlled when scaled up.

(2) Compatibility with the base metal electrode. Stateof-the-art lead-free high-energy-density MLCCs utilize precious metals as internal electrode, which need to be replaced by base metals to significantly lower the cost. The compatibility of the base metal electrode requires the dielectric materials to be anti-reducible or low-fired. In addition, other issues related to maintaining a high energy-storage performance under extreme conditions, such high electric field, high frequency, and high temperature will need to be addressed.

(3) High reliability. High reliability determines longterm service capability towards high-quality industrial applications. The performance degradation and failure under the influence of electric-thermal-mechanicalhumid multiphysics should be unraveled. This requires effective theories, models, methods, experimental platforms, and simulation techniques of accelerated degradation.

(4) Application-oriented measurement and evaluation. Present measurement and evaluation of the energystorage performance deviate from real-world conditions for the specific applications previously mentioned. Hence, the developed materials and devices cannot be directly applied to practical applications. Proper standards should be set up based on the cooperation between researchers and manufacturers.

Despite these obstacles and challenges, industrialized lead-free high-energy-density MLCCs are anticipated in the future based on intensive research and development. With industrialization, a new era of pulsed power and power converter solutions may arrive, which can enable a more energy-efficient and eco-friendly world.

\section{Acknowledgements}

This work was supported by National Key R\&D Program of China (No. 2017YFB0406302), Key-Area Research and Development Program of Guangdong Province (No. 2019B090912003), the National Natural Science Foundation of China (No. 52002253), Sichuan Science and Technology Program (No. 2021YFH0181), Shuimu Tsinghua Scholar Program, and State Key Laboratory of New Ceramic and Fine Processing Tsinghua University (No. KFZD202002).

\section{References}

[1] Winter M, Brodd RJ. What are batteries, fuel cells, and supercapacitors? Chem Rev 2004, 104: 4245-4270.

[2] Collins J, Gourdin G, Foster M, et al. Carbon surface functionalities and SEI formation during Li intercalation. Carbon 2015, 92: 193-244.

[3] Yao ZH, Song Z, Hao H, et al. Homogeneous/inhomogeneousstructured dielectrics and their energy-storage performances. Adv Mater 2017, 29: 1601727.

[4] Li F, Zhai JW, Shen B, et al. Recent progress of ecofriendly perovskite-type dielectric ceramics for energy storage applications. J Adv Dielect 2018, 8: 1830005.

[5] Hao XH. A review on the dielectric materials for high energy-storage application. $J$ Adv Dielect 2013, 3: 1330001.

[6] Zou KL, Dan Y, Xu HJ, et al. Recent advances in lead-free dielectric materials for energy storage. Mater Res Bull 2019, 113: 190-201.

[7] Xu R, Feng YJ, Wei XY, et al. Analysis on nonlinearity of antiferroelectric multilayer ceramic capacitor (MLCC) for energy storage. IEEE Trans Dielectr Electr Insul 2019, 26: 2005-2011.

[8] Love GR. Energy storage in ceramic dielectrics. $J \mathrm{Am}$ 
Ceram Soc 1990, 73: 323-328.

[9] Li Q, Chen L, Gadinski MR, et al. Flexible high-temperature dielectric materials from polymer nanocomposites. Nature 2015, 523: 576-579.

[10] Pan H, Li F, Liu Y, et al. Ultrahigh-energy density lead-free dielectric films via polymorphic nanodomain design. Science 2019, 365: 578-582.

[11] Wang J-J, Su Y-J, Wang B, et al. Strain engineering of dischargeable energy density of ferroelectric thin-film capacitors. Nano Energy 2020, 72: 104665.

[12] Yang LT, Kong X, Li F, et al. Perovskite lead-free dielectrics for energy storage applications. Prog Mater Sci 2019, 102: $72-108$.

[13] Maurya D, Pramanick A, Viehland D. Ferroelectric Materials for Energy Harvesting and Storage. UK: Woodhead Publishing, 2020.

[14] Milliken AD, Bell AJ, Scott JF. Dependence of breakdown field on dielectric (interelectrode) thickness in base-metal electroded multilayer capacitors. Appl Phys Lett 2007, 90: 112910 .

[15] Wang HX, Liu BB, Wang XH. Effects of dielectric thickness on energy storage properties of surface modified $\mathrm{BaTiO}_{3}$ multilayer ceramic capacitors. J Alloys Compd 2020, 817: 152804.

[16] Wang HX, Zhao PY, Chen LL, et al. Effects of dielectric thickness on energy storage properties of $0.87 \mathrm{BaTiO}_{3}-$ $0.13 \mathrm{Bi}\left(\mathrm{Zn}_{2 / 3}\left(\mathrm{Nb}_{0.85} \mathrm{Ta}_{0.15}\right)_{1 / 3}\right) \mathrm{O}_{3}$ multilayer ceramic capacitors. J Eur Ceram Soc 2020, 40: 1902-1908.

[17] Cai ZM, Wang XH, Li LT. Phase-field modeling of electromechanical breakdown in multilayer ceramic capacitors. Adv Theory Simul 2019, 2: 1800179.

[18] Wang HS, Liu YC, Yang TQ, et al. Ultrahigh energy-storage density in antiferroelectric ceramics with field-induced multiphase transitions. Adv Funct Mater 2019, 29: 1807321.

[19] Liu XH, Li Y, Hao XH. Ultra-high energy-storage density and fast discharge speed of $\left(\mathrm{Pb}_{0.98-x} \mathrm{La}_{0.02} \mathrm{Sr}_{x}\right)\left(\mathrm{Zr}_{0.9} \mathrm{Sn}_{0.1}\right)_{0.995} \mathrm{O}_{3}$ antiferroelectric ceramics prepared via the tape-casting method. J Mater Chem A 2019, 7: 11858-11866.

[20] Chao S, Dogan F. $\mathrm{BaTiO}_{3}-\mathrm{SrTiO}_{3}$ layered dielectrics for energy storage. Mater Lett 2011, 65: 978-981.

[21] Puli VS, Pradhan DK, Chrisey DB, et al. Structure, dielectric, ferroelectric, and energy density properties of $(1-x)$ BZT $-x$ BCT ceramic capacitors for energy storage applications. J Mater Sci 2013, 48: 2151-2157.

[22] Puli VS, Pradhan DK, Riggs BC, et al. Synthesis and characterization of lead-free ternary component BST-BCT-BZT ceramic capacitors. J Adv Dielect 2014, 4: 1450014.

[23] Puli VS, Pradhan DK, Riggs BC, et al. Structure, ferroelectric, dielectric and energy storage studies of $\mathrm{Ba}_{0.70} \mathrm{Ca}_{0.30} \mathrm{TiO}_{3}$, $\mathrm{Ba}\left(\mathrm{Zr}_{0.20} \mathrm{Ti}_{0.80}\right) \mathrm{O}_{3}$ ceramic capacitors. Integr Ferroelectr 2014, 157: 139-146.

[24] Puli VS, Pradhan DK, Adireddy S, et al. Effect of lead borosilicate glass addition on the crystallization, ferroelectric and dielectric energy storage properties of $\mathrm{Ba}_{0.9995} \mathrm{La}_{0.0005} \mathrm{TiO}_{3}$ ceramics. J Alloys Compd 2016, 688: 721-728.

[25] Ogihara H, Randall CA, Trolier-Mckinstry S. High-energy density capacitors utilizing $0.7 \mathrm{BaTiO}_{3}-0.3 \mathrm{BiScO}_{3}$ ceramics. J Am Ceram Soc 2009, 92: 1719-1724.

[26] Ogihara H, Randall CA, Trolier-Mckinstry S. Weakly coupled relaxor behavior of $\mathrm{BaTiO}_{3}-\mathrm{BiScO}_{3}$ ceramics. $J$ Am Ceram Soc 2009, 92: 110-118.

[27] Shen $\mathrm{ZB}$, Wang $\mathrm{XH}$, Luo $\mathrm{BC}$, et al. $\mathrm{BaTiO}_{3}-\mathrm{BiYbO}_{3}$ perovskite materials for energy storage applications. $J$ Mater Chem A 2015, 3: 18146-18153.

[28] Wu LW, Wang XH, Li LT. Lead-free $\mathrm{BaTiO}_{3}-\mathrm{Bi}\left(\mathrm{Zn}_{2 / 3} \mathrm{Nb}_{1 / 3}\right) \mathrm{O}_{3}$ weakly coupled relaxor ferroelectric materials for energy storage. $R S C A d v$ 2016, 6: 14273-14282.

[29] Wu LW, Wang XH, Shen ZB, et al. Ferroelectric to relaxor transition in $\mathrm{BaTiO}_{3}-\mathrm{Bi}\left(\mathrm{Zn}_{2 / 3} \mathrm{Nb}_{1 / 3}\right) \mathrm{O}_{3}$ ceramics. $\mathrm{J} \mathrm{Am}$ Ceram $S o c$ 2017, 100: 265-275.

[30] Wu LW, Wang XH, Shen ZB, et al. Re-entrant relaxor behavior in $\mathrm{BaTiO}_{3}-\mathrm{Bi}\left(\mathrm{Zn}_{2 / 3} \mathrm{Nb}_{1 / 3}\right) \mathrm{O}_{3}$ ceramics. J Am Ceram Soc 2017, 100: 511-514.

[31] Yuan QB, Yao FZ, Wang YF, et al. Relaxor ferroelectric $0.9 \mathrm{BaTiO}_{3}-0.1 \mathrm{Bi}\left(\mathrm{Zn}_{0.5} \mathrm{Zr}_{0.5}\right) \mathrm{O}_{3}$ ceramic capacitors with high energy density and temperature stable energy storage properties. J Mater Chem C 2017, 5: 9552-9558.

[32] Yuan QB, Li G, Yao FZ, et al. Simultaneously achieved temperature-insensitive high energy density and efficiency in domain engineered $\mathrm{BaTiO}_{3}-\mathrm{Bi}\left(\mathrm{Mg}_{0.5} \mathrm{Zr}_{0.5}\right) \mathrm{O}_{3}$ lead-free relaxor ferroelectrics. Nano Energy 2018, 52: 203-210.

[33] Yuan QB, Yao FZ, Cheng SD, et al. Bioinspired hierarchically structured all-inorganic nanocomposites with significantly improved capacitive performance. Adv Funct Mater 2020, 30: 2000191.

[34] Chen XL, Chen J, Ma DD, et al. Thermally stable $\mathrm{BaTiO}_{3}-\mathrm{Bi}\left(\mathrm{Mg}_{2 / 3} \mathrm{Nb}_{1 / 3}\right) \mathrm{O}_{3}$ solid solution with high relative permittivity in a broad temperature usage range. $J \mathrm{Am}$ Ceram Soc 2015, 98: 804-810.

[35] Wang T, Jin L, Li CC, et al. Relaxor ferroelectric $\mathrm{BaTiO}_{3}-\mathrm{Bi}\left(\mathrm{Mg}_{2 / 3} \mathrm{Nb}_{1 / 3}\right) \mathrm{O}_{3}$ ceramics for energy storage application. J Am Ceram Soc 2015, 98: 559-566.

[36] Zhou MX, Liang RH, Zhou ZY, et al. Novel $\mathrm{BaTiO}_{3}$-based lead-free ceramic capacitors featuring high energy storage density, high power density, and excellent stability. J Mater Chem C 2018, 6: 8528-8537.

[37] Zhao PY, Wang HX, Wu LW, et al. High-performance relaxor ferroelectric materials for energy storage applications. $A d v$ Energy Mater 2019, 9: 1803048.

[38] Hu QY, Tian Y, Zhu QS, et al. Achieve ultrahigh energy storage performance in $\mathrm{BaTiO}_{3}-\mathrm{Bi}\left(\mathrm{Mg}_{1 / 2} \mathrm{Ti}_{1 / 2}\right) \mathrm{O}_{3}$ relaxor ferroelectric ceramics via nano-scale polarization mismatch and reconstruction. Nano Energy 2020, 67: 104264.

[39] Hu QY, Jin L, Wang T, et al. Dielectric and temperature stable energy storage properties of $0.88 \mathrm{BaTiO}$ $0.12 \mathrm{Bi}\left(\mathrm{Mg}_{1 / 2} \mathrm{Ti}_{1 / 2}\right) \mathrm{O}_{3}$ bulk ceramics. J Alloys Compd 2015, 640: 416-420.

[40] Zhao QC, Wang XH, Gong HL, et al. The properties of $\mathrm{Al}_{2} \mathrm{O}_{3}$ coated fine-grain temperature stable $\mathrm{BaTiO}_{3}$-based ceramics sintered in reducing atmosphere. J Am Ceram Soc 2018, 101: 1245-1254.

[41] Zhou MX, Liang RH, Zhou ZY, et al. Combining high energy efficiency and fast charge-discharge capability in novel $\mathrm{BaTiO}_{3}$-based relaxor ferroelectric ceramic for 
energy-storage. Ceram Int 2019, 45: 3582-3590.

[42] Li WB, Zhou D, Pang LX. Enhanced energy storage density by inducing defect dipoles in lead free relaxor ferroelectric $\mathrm{BaTiO}_{3}$-based ceramics. Appl Phys Lett 2017, 110: 132902.

[43] Wei M, Zhang JH, Wu KT, et al. Effect of $\mathrm{BiMO}_{3}(\mathrm{M}=\mathrm{Al}$, $\mathrm{In}, \mathrm{Y}, \mathrm{Sm}, \mathrm{Nd}$, and $\mathrm{La}$ ) doping on the dielectric properties of $\mathrm{BaTiO}_{3}$ ceramics. Ceram Int 2017, 43: 9593-9599.

[44] Li WB, Zhou D, Pang LX, et al. Novel barium titanate based capacitors with high energy density and fast discharge performance. J Mater Chem A 2017, 5: 19607-19612.

[45] Li WB, Zhou D, Xu R, et al. $\mathrm{BaTiO}_{3}-\mathrm{Bi}\left(\mathrm{Li}_{0.5} \mathrm{Ta}_{0.5}\right) \mathrm{O}_{3}$, leadfree ceramics, and multilayers with high energy storage density and efficiency. ACS Appl Energy Mater 2018, 1: 5016-5023.

[46] Zhao XB, Zhou ZY, Liang RH, et al. High-energy storage performance in lead-free $(1-x) \mathrm{BaTiO}_{3}-x \mathrm{Bi}\left(\mathrm{Zn}_{0.5} \mathrm{Ti}_{0.5}\right) \mathrm{O}_{3}$ relaxor ceramics for temperature stability applications. Ceram Int 2017, 43: 9060-9066.

[47] Li JF, Wang K, Zhu FY, et al. (K,Na) $\mathrm{NbO}_{3}$-based lead-free piezoceramics: Fundamental aspects, processing technologies, and remaining challenges. J Am Ceram Soc 2013, 96: 3677-3696.

[48] Yang ZT, Gao F, Du HL, et al. Grain size engineered lead-free ceramics with both large energy storage density and ultrahigh mechanical properties. Nano Energy 2019, 58: 768-777.

[49] Qu BY, Du HL, Yang ZT. Lead-free relaxor ferroelectric ceramics with high optical transparency and energy storage ability. J Mater Chem C 2016, 4: 1795-1803.

[50] Qu BY, Du HL, Yang ZT, et al. Large recoverable energy storage density and low sintering temperature in potassium-sodium niobate-based ceramics for multilayer pulsed power capacitors. J Am Ceram Soc 2017, 100: 1517-1526.

[51] Shao TQ, Du HL, Ma H, et al. Potassium-sodium niobate based lead-free ceramics: Novel electrical energy storage materials. J Mater Chem A 2017, 5: 554-563.

[52] Chai QZ, Yang D, Zhao XM, et al. Lead-free (K,Na) $\mathrm{NbO}_{3}$ based ceramics with high optical transparency and large energy storage ability. J Am Ceram Soc 2018, 101: 23212329.

[53] Wang XZ, Huan Y, Zhao PY, et al. Optimizing the grain size and grain boundary morphology of $(\mathrm{K}, \mathrm{Na}) \mathrm{NbO}_{3}$-based ceramics: Paving the way for ultrahigh energy storage capacitors. J Materiomics 2021, 7: 780-789.

[54] Qu BY, Du HL, Yang ZT, et al. Enhanced dielectric breakdown strength and energy storage density in lead-free relaxor ferroelectric ceramics prepared using transition liquid phase sintering. $R S C A d v$ 2016, 6: 34381-34389.

[55] Yang ZT, Du HL, Qu SB, et al. Significantly enhanced recoverable energy storage density in potassium-sodium niobate-based lead free ceramics. J Mater Chem A 2016, 4: 13778-13785.

[56] Chen IW, Wang XH. Sintering dense nanocrystalline ceramics without final-stage grain growth. Nature 2000, 404: 168-171.

[57] Qi H, Xie AW, Tian A, et al. Superior energy-storage capacitors with simultaneously giant energy density and efficiency using nanodomain engineered $\mathrm{BiFeO}_{3}-\mathrm{BaTiO}_{3}-$ $\mathrm{NaNbO}_{3}$ lead-free bulk ferroelectrics. Adv Energy Mater 2020, 10: 1903338.

[58] Yan F, Shi YJ, Zhou XF, et al. Optimization of polarization and electric field of bismuth ferrite-based ceramics for capacitor applications. Chem Eng J 2021, 417: 127945.

[59] Ji SS, Li QJ, Wang DD, et al. Enhanced energy storage performance and thermal stability in relaxor ferroelectric $(1-x) \mathrm{BiFeO}_{3}-x\left(0.85 \mathrm{BaTiO}_{3}-0.15 \mathrm{Bi}\left(\mathrm{Sn}_{0.5} \mathrm{Zn}_{0.5}\right) \mathrm{O}_{3}\right)$ ceramics. $J$ Am Ceram Soc 2021, 104: 2646-2654.

[60] Sun HN, Wang XJ, Sun QZ, et al. Large energy storage density in $\mathrm{BiFeO}_{3}-\mathrm{BaTiO}_{3}-\mathrm{AgNbO}_{3}$ lead-free relaxor ceramics. J Eur Ceram Soc 2020, 40: 2929-2935.

[61] Liu G, Tang MY, Hou X, et al. Energy storage properties of bismuth ferrite based ternary relaxor ferroelectric ceramics through a viscous polymer process. Chem Eng J 2021, 412: 127555.

[62] Zhu LF, Lei XW, Zhao L, et al. Phase structure and energy storage performance for $\mathrm{BiFeO}_{3}-\mathrm{BaTiO}_{3}$ based lead-free ferroelectric ceramics. Ceram Int 2019, 45: 20266-20275.

[63] Wang DW, Fan ZM, Zhou D, et al. Bismuth ferrite-based lead-free ceramics and multilayers with high recoverable energy density. J Mater Chem A 2018, 6: 4133-4144.

[64] Liu NT, Liang RH, Zhou ZY, et al. Designing lead-free bismuth ferrite-based ceramics learning from relaxor ferroelectric behavior for simultaneous high energy density and efficiency under low electric field. J Mater Chem C 2018, 6: 10211-10217.

[65] Liu NT, Liang RH, Zhao XB, et al. Novel bismuth ferritebased lead-free ceramics with high energy and power density. J Am Ceram Soc 2018, 101: 3259-3265.

[66] Li F, Zhai JW, Shen B, et al. Multifunctionality of lead-free $\mathrm{BiFeO}_{3}$-based ergodic relaxor ferroelectric ceramics: High energy storage performance and electrocaloric effect. $J$ Alloys Compd 2019, 803: 185-192.

[67] Yang HG, Qi H, Zuo RZ. Enhanced breakdown strength and energy storage density in a new $\mathrm{BiFeO}_{3}$-based ternary lead-free relaxor ferroelectric ceramic. J Eur Ceram Soc 2019, 39: 2673-2679.

[68] Qiao XS, Zhang FD, Wu D, et al. Superior comprehensive energy storage properties in $\mathrm{Bi}_{0.5} \mathrm{Na}_{0.5} \mathrm{TiO}_{3}$-based relaxor ferroelectric ceramics. Chem Eng J 2020, 388: 124158.

[69] Qi H, Zuo RZ. Linear-like lead-free relaxor antiferroelectric $\left(\mathrm{Bi}_{0.5} \mathrm{Na}_{0.5}\right) \mathrm{TiO}_{3}-\mathrm{NaNbO}_{3}$ with giant energy-storage density/efficiency and super stability against temperature and frequency. J Mater Chem A 2019, 7: 3971-3978.

[70] Yan F, Huang KW, Jiang T, et al. Significantly enhanced energy storage density and efficiency of BNT-based perovskite ceramics via A-site defect engineering. Energy Storage Mater 2020, 30: 392-400.

[71] Zhou X, Qi H, Yan Z, et al. Superior thermal stability of high energy density and power density in domain-engineered $\mathrm{Bi}_{0.5} \mathrm{Na}_{0.5} \mathrm{TiO}_{3}-\mathrm{NaTaO}_{3}$ relaxor ferroelectrics. ACS Appl Mater Interfaces 2019, 11: 43107-43115.

[72] Zhu CQ, Cai ZM, Luo BC, et al. High temperature leadfree BNT-based ceramics with stable energy storage and dielectric properties. J Mater Chem A 2020, 8: 683-692.

[73] Zhang L, Pu YP, Chen M, et al. Novel $\mathrm{Na}_{0.5} \mathrm{Bi}_{0.5} \mathrm{TiO}_{3}$ based, 
lead-free energy storage ceramics with high power and energy density and excellent high-temperature stability. Chem Eng J 2020, 383: 123154.

[74] Zhang L, Pu YP, Chen M, et al. High energy-storage density under low electric fields and improved optical transparency in novel sodium bismuth titanate-based lead-free ceramics. J Eur Ceram Soc 2020, 40: 71-77.

[75] Zhou XF, Qi H, Yan ZN, et al. Large energy density with excellent stability in fine-grained $\left(\mathrm{Bi}_{0.5} \mathrm{Na}_{0.5}\right) \mathrm{TiO}_{3}$-based lead-free ceramics. J Eur Ceram Soc 2019, 39: 4053-4059.

[76] Qiao XS, Sheng AH, Wu D, et al. A novel multifunctional ceramic with photoluminescence and outstanding energy storage properties. Chem Eng J 2021, 408: 127368.

[77] Hu D, Pan ZB, Zhang X, et al. Greatly enhanced discharge energy density and efficiency of novel relaxation ferroelectric BNT-BKT-based ceramics. J Mater Chem C 2020, 8: 591-601.

[78] Wu YC, Fan YZ, Liu NT, et al. Enhanced energy storage properties in sodium bismuth titanate-based ceramics for dielectric capacitor applications. J Mater Chem C 2019, 7: 6222-6230.

[79] Pan ZB, Hu D, Zhang Y, et al. Achieving high discharge energy density and efficiency with NBT-based ceramics for application in capacitors. J Mater Chem C 2019, 7: 40724078.

[80] Kang RR, Wang ZP, Lou XJ, et al. Energy storage performance of $\mathrm{Bi}_{0.5} \mathrm{Na}_{0.5} \mathrm{TiO}_{3}$-based relaxor ferroelectric ceramics with superior temperature stability under low electric fields. Chem Eng J 2021, 410: 128376.

[81] Zhang FD, Qiao XS, Shi QQ, et al. High energy storage density realized in $\mathrm{Bi}_{0.5} \mathrm{Na}_{0.5} \mathrm{TiO}_{3}$-based relaxor ferroelectric ceramics at ultralow sintering temperature. $J$ Eur Ceram Soc 2021, 41: 368-375.

[82] Zhang JT, Lin Y, Wang L, et al. Significantly enhanced energy storage density in sodium bismuth titanate-based ferroelectrics under low electric fields. J Eur Ceram Soc 2020, 40: 5458-5465.

[83] Zhao L, Liu Q, Gao J, et al. Lead-free antiferroelectric silver niobate tantalate with high energy storage performance. Adv Mater 2017, 29: 1701824.

[84] Gao J, Zhang YC, Zhao L, et al. Enhanced antiferroelectric phase stability in La-doped $\mathrm{AgNbO}_{3}$ : Perspectives from the microstructure to energy storage properties. J Mater Chem A 2019, 7: 2225-2232.

[85] Luo NN, Han K, Zhuo FP, et al. Aliovalent A-site engineered $\mathrm{AgNbO}_{3}$ lead-free antiferroelectric ceramics toward superior energy storage density. J Mater Chem A 2019, 7: 1411814128.

[86] Zhao L, Gao J, Liu Q, et al. Silver niobate lead-free antiferroelectric ceramics: Enhancing energy storage density by B-site doping. ACS Appl Mater Interfaces 2018, 10: 819-826.

[87] Tian Y, Jin L, Zhang HF, et al. Phase transitions in bismuthmodified silver niobate ceramics for high power energy storage. J Mater Chem A 2017, 5: 17525-17531.

[88] Li S, Nie HC, Wang GS, et al. Significantly enhanced energy storage performance of rare-earth-modified silver niobate lead-free antiferroelectric ceramics via local chemical pressure tailoring. J Mater Chem C 2019, 7: 1551-1560.

[89] Zhou MX, Liang RH, Zhou ZY, et al. Superior energy storage properties and excellent stability of novel $\mathrm{NaNbO}_{3}$ based lead-free ceramics with A-site vacancy obtained via a $\mathrm{Bi}_{2} \mathrm{O}_{3}$ substitution strategy. $J$ Mater Chem A 2018, 6: 17896-17904.

[90] Qi H, Zuo RZ, Xie AW, et al. Ultrahigh energy-storage density in $\mathrm{NaNbO}_{3}$-based lead-free relaxor antiferroelectric ceramics with nanoscale domains. Adv Funct Mater 2019, 29: 1903877.

[91] Zhou MX, Liang RH, Zhou ZY, et al. Novel sodium niobate-based lead-free ceramics as new environmentfriendly energy storage materials with high energy density, high power density, and excellent stability. ACS Sustainable Chem Eng 2018, 6: 12755-12765.

[92] Shi JP, Chen XL, Li X, et al. Realizing ultrahigh recoverable energy density and superior charge-discharge performance in $\mathrm{NaNbO}_{3}$-based lead-free ceramics via a local random field strategy. J Mater Chem C 2020, 8: 3784-3794.

[93] Yang D, Gao J, Shu L, et al. Lead-free antiferroelectric niobates $\mathrm{AgNbO}_{3}$ and $\mathrm{NaNbO}_{3}$ for energy storage applications. J Mater Chem A 2020, 8: 23724-23737.

[94] Qi H, Zuo RZ, Xie AW, et al. Excellent energy-storage properties of $\mathrm{NaNbO}_{3}$-based lead-free antiferroelectric orthorhombic P-phase (Pbma) ceramics with repeatable double polarization-field loops. J Eur Ceram Soc 2019, 39: 3703-3709.

[95] Wei T, Liu K, Fan PY, et al. Novel $\mathrm{NaNbO}_{3}-\mathrm{Sr}_{0.7} \mathrm{Bi}_{0.2} \mathrm{TiO}_{3}$ lead-free dielectric ceramics with excellent energy storage properties. Ceram Int 2021, 47: 3713-3719.

[96] Fan YZ, Zhou ZY, Liang RH, et al. Designing novel leadfree $\mathrm{NaNbO}_{3}$-based ceramic with superior comprehensive energy storage and discharge properties for dielectric capacitor applications via relaxor strategy. $J$ Eur Ceram Soc 2019, 39: 4770-4777.

[97] Shi RK, Pu YP, Wang W, et al. A novel lead-free $\mathrm{NaNbO}_{3}-$ $\mathrm{Bi}\left(\mathrm{Zn}_{0.5} \mathrm{Ti}_{0.5}\right) \mathrm{O}_{3}$ ceramics system for energy storage application with excellent stability. J Alloys Compd 2020, 815: 152356.

[98] Qu N, Du HL, Hao XH. A new strategy to realize high comprehensive energy storage properties in lead-free bulk ceramics. J Mater Chem C 2019, 7: 7993-8002.

[99] Ye JM, Wang GS, Zhou MX, et al. Excellent comprehensive energy storage properties of novel lead-free $\mathrm{NaNbO}_{3}$-based ceramics for dielectric capacitor applications. J Mater Chem C 2019, 7: 5639-5645.

[100] Sun CC, Chen XL, Shi JP, et al. Simultaneously with large energy density and high efficiency achieved in $\mathrm{NaNbO}_{3}$ based relaxor ferroelectric ceramics. J Eur Ceram Soc 2021, 41: 1891-1903.

[101] Chen HY, Chen XL, Shi JP, et al. Achieving ultrahigh energy storage density in $\mathrm{NaNbO}_{3}-\mathrm{Bi}\left(\mathrm{Ni}_{0.5} \mathrm{Zr}_{0.5}\right) \mathrm{O}_{3}$ solid solution by enhancing the breakdown electric field. Ceram Int 2020, 46: 28407-28413.

[102] Pang FH, Chen XL, Sun CC, et al. Ultrahigh energy storage characteristics of sodium niobate-based ceramics by introducing a local random field. ACS Sustainable Chem Eng 2020, 8: 14985-14995. 
[103] Dong XY, Li X, Chen XL, et al. High energy storage and ultrafast discharge in $\mathrm{NaNbO}_{3}$-based lead-free dielectric capacitors via a relaxor strategy. Ceram Int 2021, 47: 3079-3088.

[104] Tunkasiri T, Rujijanagul G. Dielectric strength of fine grained barium titanate ceramics. J Mater Sci Lett 1996, 15: 1767-1769.

[105] Zhu CQ, Cai ZM, Guo LM, et al. Grain size engineered high-performance nanograined $\mathrm{BaTiO}_{3}$-based ceramics: Experimental and numerical prediction. J Am Ceram Soc 2021, 104: 273-283.

[106] Cai ZM, Wang XH, Hong W, et al. Grain-size-dependent dielectric properties in nanograin ferroelectrics. $J \mathrm{Am}$ Ceram Soc 2018, 101: 5487-5496.

[107] Ren XD, Jin L, Peng ZH, et al. Regulation of energy density and efficiency in transparent ceramics by grain refinement. Chem Eng J 2020, 390: 124566.

[108] Wu LW, Cai ZM, Zhu CQ, et al. Significantly enhanced dielectric breakdown strength of ferroelectric energy-storage ceramics via grain size uniformity control: Phase-field simulation and experimental realization. Appl Phys Lett 2020, 117: 212902.

[109] Zhang YC, Wang XH, Tian ZB, et al. Preparation of BME MLCC powders by aqueous chemical coating method. $J$ Am Ceram Soc 2011, 94: 3286-3290.

[110] Zhang YC, Wang XH, Kim JY, et al. High performance $\mathrm{BaTiO}_{3}$-based BME-MLCC nanopowder prepared by aqueous chemical coating method. J Am Ceram Soc 2012, 95: 1628-1633.

[111] Zhao QC, Gong HL, Wang XH, et al. Superior reliability via two-step sintering: Barium titanate ceramics. $\mathrm{J} \mathrm{Am}$ Ceram Soc 2016, 99: 191-197.

[112] Ma R, Cui B, Shangguan MQ, et al. A novel double-coating approach to prepare fine-grained $\mathrm{BaTiO}_{3} @ \mathrm{La}_{2} \mathrm{O}_{3} @ \mathrm{SiO}_{2}$ dielectric ceramics for energy storage application. J Alloys Compd 2017, 690: 438-445.

[113] Wang JW, Xu C, Shen B, et al. Enhancing energy storage density of $(\mathrm{Ba}, \mathrm{Sr}) \mathrm{TiO}_{3}$ ceramic particles by coating with $\mathrm{Al}_{2} \mathrm{O}_{3}$ and $\mathrm{SiO}_{2}$. J Mater Sci: Mater Electron 2013, 24: 3309-3314.

[114] Cai ZM, Zhu CQ, Wang HX, et al. Giant dielectric breakdown strength together with ultrahigh energy density in ferroelectric bulk ceramics via layer-by-layer engineering. J Mater Chem A 2019, 7: 17283-17291.

[115] Liu BB, Wang XH, Zhao QC, et al. Improved energy storage properties of fine-crystalline $\mathrm{BaTiO}_{3}$ ceramics by coating powders with $\mathrm{Al}_{2} \mathrm{O}_{3}$ and $\mathrm{SiO}_{2}$. J Am Ceram Soc 2015, 98: 2641-2646.

[116] Yan F, Bai HR, Zhou XF, et al. Realizing superior energy storage properties in lead-free ceramics via a macrostructure design strategy. J Mater Chem A 2020, 8: 1165611664.

[117] Hong K, Lee TH, Suh JM, et al. Perspectives and challenges in multilayer ceramic capacitors for next generation electronics. J Mater Chem C 2019, 7: 9782-9802.

[118] Wang YL, Li LT, Ma ZW, et al. The inner electrode structure and its optimization for high voltage chip capacitors. Journal of Functional Materials, 2003, 34: 414-417. (in
Chinese)

[119] Cai ZM, Wang XH, Luo BC, et al. Thermal-mechanicalelectrical coupled design of multilayer energy storage ceramic capacitors. Ceram Int 2017, 43: 12882-12887.

[120] Cai ZM, Wang XH, Li LT. Phase-field modeling of electromechanical breakdown in multilayer ceramic capacitors. Adv Theory Simul 2019, 2: 1800179.

[121] Cai ZM, Wang HX, Zhao PY, et al. Significantly enhanced dielectric breakdown strength and energy density of multilayer ceramic capacitors with high efficiency by electrodes structure design. Appl Phys Lett 2019, 115: 023901.

[122] Cai ZM, Wang XH, Luo BC, et al. Multiscale design of high-voltage multilayer energy-storage ceramic capacitors. $J$ Am Ceram Soc 2018, 101: 1607-1615.

[123] Jiang WG, Feng XQ, Nan CW. Influence of residual thermal stresses and geometric parameters on stress and electric fields in multilayer ceramic capacitors under electric bias. $J$ Phys D: Appl Phys 2008, 41: 135310.

[124] Park JW, Chae JH, Park IH, et al. Thermo-mechanical stresses and mechanical reliability of multilayer ceramic capacitors (MLCC). J Am Ceram Soc 2007, 90: 2151-2158.

[125] Chen KY, Huang $\mathrm{CW}, \mathrm{Wu} \mathrm{M}$, et al. Control of stress concentration in surface-mounted multilayer ceramic capacitor subjected to bending. J Am Ceram Soc 2014, 97: 1170-1176.

[126] Huang CW, Chen BT, Chen KY, et al. Finite element analysis and design of thermal-mechanical stresses in multilayer ceramic capacitors. Int J Appl Ceram Technol 2015, 12: 451-460.

[127] Franken K, Maier HR, Prume K, et al. Finite-element analysis of ceramic multilayer capacitors: Failure probability caused by wave soldering and bending loads. J Am Ceram Soc 2000, 83: 1433-1440.

[128] Shay DP, Podraza NJ, Donnelly NJ, et al. High energy density, high temperature capacitors utilizing Mn-doped $0.8 \mathrm{CaTiO}_{3}-0.2 \mathrm{CaHfO}_{3}$ ceramics. J Am Ceram Soc 2012, 95: $1348-1355$.

[129] Kumar N, Ionin A, Ansell T, et al. Multilayer ceramic capacitors based on relaxor $\mathrm{BaTiO}_{3}-\mathrm{Bi}\left(\mathrm{Zn}_{1 / 2} \mathrm{Ti}_{1 / 2}\right) \mathrm{O}_{3}$ for temperature stable and high energy density capacitor applications. Appl Phys Lett 2015, 106: 252901.

[130] Li WB, Zhou D, Xu R, et al. $\mathrm{BaTiO}_{3}$-based multilayers with outstanding energy storage performance for high temperature capacitor applications. ACS Appl Energy Mater 2019, 2: 5499-5506.

[131] Yang HJ, Bao WC, Lu ZL, et al. High-energy storage performance in $\mathrm{BaTiO}_{3}$-based lead-free multilayer ceramic capacitors. J Mater Res 2021, 36: 1285-1294.

[132] Chen LL, Wang HX, Zhao PY, et al. Multifunctional $\mathrm{BaTiO}_{3}-\left(\mathrm{Bi}_{0.5} \mathrm{Na}_{0.5}\right) \mathrm{TiO}_{3}$-based MLCC with high-energy storage properties and temperature stability. J Am Ceram Soc 2019, 102: 4178-4187.

[133] Zhao PY, Cai ZM, Chen LL, et al. Ultra-high energy storage performance in lead-free multilayer ceramic capacitors via a multiscale optimization strategy. Energy Environ Sci 2020, 13: 4882-4890.

[134] Wu LW, Wang XH, Li LT. Enhanced energy density in core-shell ferroelectric ceramics: Modeling and practical 
conclusions. J Am Ceram Soc 2016, 99: 930-937.

[135] Li JL, Li F, Xu Z, et al. Multilayer lead-free ceramic capacitors with ultrahigh energy density and efficiency. Adv Mater 2018, 30: 1802155.

[136] Zhu LF, Zhao L, Yan YK, et al. Composition and strain engineered $\mathrm{AgNbO}_{3}$-based multilayer capacitors for ultrahigh energy storage capacity. J Mater Chem A 2021, 9: 9655-9664.

[137] Lu ZL, Wang G, Bao WC, et al. Superior energy density through tailored dopant strategies in multilayer ceramic capacitors. Energy Environ Sci 2020, 13: 2938-2948.

[138] Wang DW, Fan ZM, Zhou D, et al. Bismuth ferrite-based lead-free ceramics and multilayers with high recoverable energy density. J Mater Chem A 2018, 6: 4133-4144.

[139] Wang G, Li JL, Zhang X, et al. Ultrahigh energy storage density lead-free multilayers by controlled electrical homogeneity. Energy Environ Sci 2019, 12: 582-588.

[140] Wang G, Lu ZL, Li JL, et al. Lead-free (Ba,Sr) $\mathrm{TiO}_{3}-$ $\mathrm{BiFeO}_{3}$ based multilayer ceramic capacitors with high energy density. J Eur Ceram Soc 2020, 40: 1779-1783.

[141] Wang G, Lu ZL, Yang HJ, et al. Fatigue resistant lead-free multilayer ceramic capacitors with ultrahigh energy density. J Mater Chem A 2020, 8: 11414-11423.

[142] Li JL, Shen ZH, Chen XH, et al. Grain-orientation-engineered multilayer ceramic capacitors for energy storage applications. Nat Mater 2020, 19: 999-1005.

[143] Ji HF, Wang DW, Bao WC, et al. Ultrahigh energy density in short-range tilted NBT-based lead-free multilayer ceramic capacitors by nanodomain percolation. Energy Storage Mater 2021, 38: 113-120.

[144] Yang HJ, Lu ZL, Li LH, et al. Novel $\mathrm{BaTiO}_{3}$-based, Ag/Pdcompatible lead-free relaxors with superior energy storage performance. ACS Appl Mater Interfaces 2020, 12: 4394243949.

[145] Cen ZY, Wang XH, Huan Y, et al. Temperature stability and electrical properties of $\mathrm{MnO}$-doped $\mathrm{KNN}$-based ceramics sintered in reducing atmosphere. J Am Ceram Soc 2018, 101: 2391-2407.

[146] Wang HX, Zhao PY, Chen LL, et al. Energy storage properties of $0.87 \mathrm{BaTiO}_{3}-0.13 \mathrm{Bi}\left(\mathrm{Zn}_{2 / 3}\left(\mathrm{Nb}_{0.85} \mathrm{Ta}_{0.15}\right)_{1 / 3}\right) \mathrm{O}_{3}$ multilayer ceramic capacitors with thin dielectric layers. $J$ Adv Ceram 2020, 9: 292-302.

[147] Cai ZM, Zhu CQ, Wang HX, et al. High-temperature leadfree multilayer ceramic capacitors with ultrahigh energy density and efficiency fabricated via two-step sintering. $J$ Mater Chem A 2019, 7: 14575-14582.

[148] Zhu LF, Yan YK, Leng HY, et al. Energy-storage performance of $\mathrm{NaNbO}_{3}$ based multilayered capacitors. $J$ Mater Chem C 2021, 9: 7950-7957.

[149] Correia T, Stewart M, Ellmore A, et al. Lead-free ceramics with high energy density and reduced losses for high temperature applications . Adv Eng Mater 2017, 19: 1700019.

[150] Pan MJ, Randall CA. A brief introduction to ceramic capacitors. IEEE Electr Insul Mag 2010, 26: 44-50.

[151] Knowles Capacitors. Detonator and pulse energy capacitors. Information on https://www.knowlescapacitors.com/
getattachment/b89f4aaf-ff9c-4a59-9a4a-0ec1017edac6/De tonation-pulse-Energy.

[152] Wang H, Blaabjerg F. Reliability of capacitors for DC-link applications - An overview. In: Proceedings of the IEEE Energy Conversion Congress and Exposition, 2013, 18661873.

[153] Falck J, Felgemacher C, Rojko A, et al. Reliability of power electronic systems: An industry perspective. IEEE Ind Electron Mag 2018, 12: 24-35.

[154] López I, Ibarra E, Matallana A, et al. Next generation electric drives for HEV/EV propulsion systems: Technology, trends and challenges. Renew Sustain Energy Rev 2019, 114: 109336.

[155] Hobbs, D. Are you ready to service hybrids that are outside of their warranty period? Information on https://www. vehicleservicepros.com/service-repair/battery-and-electric al/article/21199811/are-you-ready-to-service-hybrids-thatare-outside-of-their-warranty-period.

[156] Zhu, Y. The inverter of Model 3. Information on https:// www.eefocus.com/automobile-electronics/418864.

[157] Wen H, Xiao W, Wen XH. Comparative evaluation of DC-link capacitors for electric vehicle application. In: Proceedings of the IEEE International Symposium on Industrial Electronics, 2012, 1472-1477.

[158] KEMET. DC link solutions for SiC and GaN applications. Information on https://ec.kemet.com/event/dc-link-solutionsfor-sic-and-gan-applications.

[159] KEMET. KC-LINK for fast switching semicondutor applications. Information on https://ec.kemet.com/kc-link.

[160] TDK. Ceralink capacitors. Information on https://product. tdk.com/en/products/capacitor/ceramic/ceralink/index.html.

[161] Fraunhofer. $200 \mathrm{~kW}$ full-SiC DC/DC converter. Information on https://www.iisb.fraunhofer.de/de/research_areas/vehicle_ electronics/dcdc_converters/projects/200_kw_full_sic_dcd c_converter.html.

[162] TDK. TDK CeraLink high ripple current capacitors for power electronics. Information on https://passive-components. eu/tdk-ceralink-high-ripple-current-capacitors-for-power-e lectronics.

Open Access This article is licensed under a Creative Commons Attribution 4.0 International License, which permits use, sharing, adaptation, distribution and reproduction in any medium or format, as long as you give appropriate credit to the original author(s) and the source, provide a link to the Creative Commons licence, and indicate if changes were made.

The images or other third party material in this article are included in the article's Creative Commons licence, unless indicated otherwise in a credit line to the material. If material is not included in the article's Creative Commons licence and your intended use is not permitted by statutory regulation or exceeds the permitted use, you will need to obtain permission directly from the copyright holder.

To view a copy of this licence, visit http://creativecommons.org/ licenses/by/4.0/. 